\title{
II. Das NSKK: Organisation und Aufbau 1933-1945
}

Mit der Machtübernahme hatten die Nationalsozialisten ihr primäres politisches Ziel erreicht. Die veränderten Machtverhältnisse in Deutschland stellten das NSKK und die Motor-SA vor neue Anforderungen. Gelang es den Sonderformationen nach der „Machteroberung“, neue Aufgabenbereiche für sich zu erschließen, die ihr Fortbestehen rechtfertigten?

Für den zukünftigen Stellenwert des NSKK im Herrschaftssystem waren verschiedene Szenarien denkbar: eine rein formale Existenz als zentrales Sammelbecken für motorisierte bzw. motorisierungswillige Nationalsozialisten, eine Funktion als Hilfsdienstleistender für die Partei oder eine aktive Festigung der Position im Partei- und Staatsgefüge durch neue Zuständigkeiten. Im folgenden Kapitel werden die Organisationsentwicklung, die Strukturen, das Selbstverständnis und die Mitglieder näher charakterisiert, um die Fundamente des NSKK kenntlich zu machen.

\section{Der Aufstieg zur selbständigen Gliederung}

\section{Der Status des NSKK 1933}

Das NSKK blieb nach der Machtübernahme eine Gliederung der SA, die dem Chefstabsführer der SA unterstellt war und ihre Aufgaben in enger Verbindung mit der SA wahrnahm. Adolf Hitler würdigte die Aufbauleistung des stellvertretenden Korpsführers und Chef des Kraftfahrwesens der SA, Obergruppenführer Hühnlein, indem er ihn Ende April 1933 anstelle von Röhm zum Korpsführer des NSKK ernannte. ${ }^{1}$

Nach der NS-Machtübernahme wuchs die SA zu einem Millionenheer heran. Auch die motorisierten Verbände der SA mussten im Sommer 1933 den enormen Mitgliederzuwachs kanalisieren und Organisationsstrukturen finden, die das Profil der Motor-SA und des NSKK neu schärften. Nach einem Erlass des Chefs des Kraftfahrwesens der SA vom 29. Juni 1933 wurden die Mitglieder des NSKK, die nicht der Motor-SA oder -SS angehörten, zu besonderen Einheiten zusammengefasst. Vor 1933 noch hatte man Wert darauf gelegt, dass die Führerstellen des NSKK - Landesführungen, Bereichführungen, Bezirksführungen und Korpswartstellen - von Motor-SA-Führern besetzt waren. Im Laufe des Sommers 1933 wurde diese Personalunion jedoch aufgelöst. Bis zum Oktober des Jahres sollte dort, wo die nötigen Führer vorhanden waren, eine Trennung zwischen NSKK

1 Vgl. Oppermann: Unter den Sturmstandern, S. 93. 
und Motor-SA-Dienststellen stattfinden. ${ }^{2}$ In einer Besprechung mit den Gruppenstaffelführern im Dezember 1933 teilte der Chef des Kraftfahrwesens der SA mit, dass das NSKK künftig eine feste Zahl von 100000 Mitgliedern nicht überschreiten solle. Die im NSKK organisierten Motorradfahrer wurden aufgefordert, zur Motor-SA zu wechseln, und die Motor-SA-Männer über 35 sollten zum NSKK übertreten. ${ }^{3}$ Außerdem führte die SA eine Automobilquote von $20 \%$ in den Motor-SA-Stürmen ein. Der Rest der Fahrzeuge wurde den NSKK-Kraftwagenzügen zugeteilt. ${ }^{4}$

Die geplante Trennung der Einheiten nach dem Alter der Mitglieder und der Art der Fahrzeuge vereinfachte die Integration neuer Mitglieder. Während die SA allgemeine Regelungen für den Übertritt der Stahlhelm-Mitglieder in die SA traf, setzte sich Hühnlein erfolgreich für die Eingliederung der Kraftfahrstaffeln des Stahlhelms und der Wehrwolf-Kraftfahrstaffeln in die SA ein. ${ }^{5}$ In einem Abkommen zwischen dem Herzog von Sachsen-Coburg, in seiner Funktion als ReichsStaffelführer des Stahlhelms, und dem Korpsführer des NSKK wurde am 11. Juli 1933 vereinbart, dass die Kraftfahrstaffeln geschlossen in das NSKK übertreten. Die Kraftrad-Gliederungen des Stahlhelms, in denen sich häufig die jüngeren und aktiveren Mitglieder sammelten, gingen in der Motor-SA auf. ${ }^{6} \mathrm{Um}$ zu verhindern, dass sich bewährte und lang gediente Stahlhelm-Angehörige bei der Eingliederung benachteiligt fühlten, befahl die Korpsführung, dass Stahlhelm-Führer in Führungsstellen der Motor-SA und des NSKK übernommen werden; diese Absicht wurde durch die Ernennung des Herzogs von Sachsen-Coburg zum Ehrenführer des NSKK symbolisch bekräftigt. ${ }^{7}$ Die Integration der in den nationalen Wehrverbänden organisierten Kraftfahrer bedeutete im Hinblick auf die Mitgliederzahl und die potenziell verfügbaren Fahrzeugbestände eine erhebliche Stärkung der motorisierten NS-Verbände.

\section{Der „Röhm-Putsch“ und seine Folgen}

Den Planungen und Entscheidungen bezüglich der zukünftigen Struktur der motorisierten Formationen vom Sommer 1933 standen bereits im folgenden Jahr neue Realitäten gegenüber: Die auf 2,9 Millionen Mitglieder angewachsene paramilitärische Massenformation SA hatte sich im Frühsommer 1934 nicht nur zu einem Bürgerschreck entwickelt, sondern sie bedrohte auch das Machtgefüge im

2 Vgl. Anordnung des Führers der Gruppenstaffel Hessen an die Führer der Motorstandarten und Bereichführungen des NSKK vom 26.10. 1933, HStA Wiesbaden, Abt. 483 Nr. 7302.

3 Vgl. ebenda; Mitteilung des Bezirksführers des NSKK von Schlüchtern an die Korpswarte vom 18. 10. 1933, HStA Wiesbaden, Abt. 483 Nr. 7304.

4 Vgl. Rundschreiben des Führers der Kraftwagengruppe Hessen vom 19. 12. 1933, HStA Wiesbaden, Abt. 483 Nr. 7302.

5 Zu den Kraftfahrstaffeln der Wehrverbände Stahlhelm und Wehrwolf vor 1933 vgl. das Kapitel „Die Anfänge des Nationalsozialistischen Kraftfahrkorps". Zur Eingliederung des Stahlhelms in die SA vgl. Heinz: „... die Reihen fest geschlossen“, S. 98; Bessel: Political Violence, S. 119-122; Oppermann: Unter den Sturmstandern, S. 95.

6 Vgl. Deutsche Kraftfahrt vom 15. 7. 1933: „Eingliederung“.

7 Vgl. G. L. Wagener: Warum sollte ich verschweigen, S. 576, StadtA Hannover. 
Staat. Hitler, Himmler, Göring, Heß und die Reichswehr nahmen - aus unterschiedlichen Gründen - Anstoß an den Ambitionen der SA auf stärkere militärische Beteiligung. ${ }^{8}$ Die von Hitler befohlenen und von der SS und der Gestapo durchgeführten Mordaktionen an SA-Führern und missliebigen Oppositionellen am 30. Juni 1934 und danach hatten das Ziel, die SA zu schwächen.

In dieser Krisenzeit war es anfänglich ein Gebot des physischen, dann des politischen Überlebens, Gefolgstreue gegenüber dem „Führer" zu demonstrieren.9 Dies betraf auch den „politischen Kampfgenossen" 10 Ernst Röhms, SA-Obergruppenführer Adolf Hühnlein, der aufgrund seiner Freundschaft und Nähe zu Röhm Verdächtigungen ausgesetzt war. Obgleich er nicht an dem am 30. Juni 1934 in Bad Wiessee anberaumten Treffen aller Obergruppenführer, Gruppenführer und Inspekteure der SA teilnahm, schwebte Hühnlein kurze Zeit selbst in Gefahr. ${ }^{11}$ Nach Aussagen von Freunden, Mitarbeitern und der Ehefrau nach dem Krieg hielt er sich in diesen Tagen beim internationalen Automobilrennen (Grand Prix de France) in Paris auf. SS-Männer durchsuchten währenddessen Dienststellen des NSKK sowie das Privathaus des Korpsführers und stellten Unterlagen sicher. Nach seiner Rückkehr protestierte Hühnlein bei Himmler gegen dieses Vorgehen. ${ }^{12}$ Auch der technische Berater der Korpsführung Kraus warf dem SSOberabschnitt Süd vor, falsche Gerüchte lanciert zu haben, nach denen Hühnlein erschossen und er selbst verhaftet worden sei.13 Die Beziehungen zwischen

${ }^{8}$ Die Monographien über die SA enden normalerweise mit dem „Röhm-Putsch“ oder fahren mit der Beschreibung der SS fort. Tatsächlich wurde die Macht der SA beschnitten, dennoch blieb die SA eine feste Größe im Machtgefüge und die mitgliederstärkste nationalsozialistische Gliederung bis 1945. Vgl. zur SA nach dem „Röhm-Putsch“ den Aufsatz von Campbell: The SA after the Röhm Purge.

9 Vgl. Bessel: Political Violence, S. 137.

10 So bezeichnte Baldur von Schirach Hühnlein; vgl. Schirach: Die Pioniere des Dritten Reiches, S. 114.

11 Dies wurde in NSKK-Kreisen berichtet, so G. L. Wagener: Warum sollte ich verschweigen, S. 598, StadtA Hannover. Für die Annahme, dass Hühnleins persönliche und politische Zukunft Anfang 1934 höchst ungewiss war, spricht die Tatsache, dass er in dem Handbuch: Das deutsche Führerlexikon 1934/1935, nicht aufgeführt ist. Es gibt Seiten, die geschwärzt sind, weil SA-Führer nach dem „Röhm-Putsch“ getötet oder ausgeschlossen wurden. Es scheint also bei Drucklegung nicht festgestanden zu haben, ob SA-Obergruppenführer Hühnlein seine Führerkarriere fortsetzen konnte.

12 Vgl. Eidesstattliche Erklärungen von Paula Hühnlein, des Hausarztes Dr. K. vom 13. 5. 1940 und von Hans-Helmuth Krenzlin vom 25.5. 1949, Entnazifizierungsakte Adolf Hühnlein, Amtsgericht München; Protokoll der öffentlichen Sitzung vom 12.11. 1948, Befragung von Kraus, Entnazifizierungsakte Erwin Kraus, Amtsgericht München; Schreiben des Rechtsanwaltes an die Spruchkammer München vom 27.9. 1948, Entnazifizierungsakte Ritter von Denk, Amtsgericht München. Es existiert noch eine zweite, aber unwahrscheinlichere, Version über den Aufenthaltsort Hühnleins am 30.6. 1934: Der NSKK-Gruppenführer von Hannover Wagener will von Oppermann erfahren haben, dass sich Hühnlein in Berlin aufgehalten habe und die Reichswehr Posten vor der Dienststelle in Berlin aufziehen ließ, um Hühnlein vor der SS zu schützen; vgl. G. L. Wagener: Warum sollte ich verschweigen, S. 605, StadtA Hannover.

13 Vgl. Schreiben von Erwin Kraus an den SS-Oberabschnitt Süd vom 18. 7. 1934, BArch NS 24/250. 
NSKK und SS, insbesondere zwischen Hühnlein und Himmler, waren aufgrund dieser Vorfälle auch für die Zukunft belastet.

Hühnlein äußerte sich erleichtert und zufrieden darüber, dass sich kein Führer der Motor-SA in den „Röhm-Putsch" habe verwickeln lassen. ${ }^{14}$ In Motor-SAund NSKK-Kreisen schien man den vorgeschobenen Rechtfertigungsversuchen der Parteiführer Glauben zu schenken, die die moralische Verdorbenheit und die angeblichen Putschversuche der Röhm-Anhänger anprangerten. In einem privaten Schreiben versicherte Kraus am 6. Juli 1934, dass in der Dienststelle beim Chef des Kraftfahrwesens "keiner Ahnung hätte" von solchen "Schweinereien“ und "Verrätereien“. Stolz machte ihn, dass auf die Motor-SA und das Korps „kein Stäubchen Dreck" gefallen sei. ${ }^{15}$

Hitler hatte offenbar keinen Grund, an der Zuverlässigkeit seines alten Weggefährten Adolf Hühnlein zu zweifeln. Die persönliche Integrität des Korpsführers blieb gewahrt. Zum einen war Hühnlein weder für ein ausschweifendes Leben noch für andere Verstöße gegen den Moralkodex bekannt, zum anderen hatte er sich sofort nach der Machtübernahme konkreten Aufgaben im Motorsport und im Automobilvereinswesen zugewandt. Er erhob also im Gegensatz zu seinem Förderer Ernst Röhm keine weitergehenden politischen Machtansprüche und sozialen Forderungen. ${ }^{16}$

Im Zuge der Reorganisation der SA löste Hitler am 23. August die Motor-SA und das NSKK aus dem Verband und der Befehlsgewalt der SA heraus. Beide Formationen wurden zu einer Gliederung, dem „Nationalsozialistischen Kraftfahrkorps“, zusammengefasst und der Befehlsgewalt des Chefs des Kraftfahrwesens, SA-Obergruppenführer Adolf Hühnlein, übergeben. ${ }^{17}$ Im Dezember 1934 ernannte Hitler den bisherigen Führer des NSKK und Chef der Motor-SA, SAObergruppenführer Hühnlein, offiziell zum Korpsführer des gesamten NSKK. Die neue, von der SA völlig getrennte selbständige Einheit wurde Hitler direkt unterstellt. ${ }^{18}$ Die SS-Motorstaffeln, die Hühnlein als Inspekteur der Motorstürme der SA und SS zuvor ebenfalls befehligt hatte, wurden in die SS eingegliedert. Die SS war bereits am 20. Juli 1934 in eine selbständige Gliederung verwandelt worden.

Hühnlein selbst wollte die Erhebung zur Gliederung als Zeichen der Anerkennung für die erfolgreiche Arbeit des Korps verstanden wissen. ${ }^{19}$ Doch ausschlaggebend waren andere Faktoren. Obwohl der Aufstieg des NSKK zur selbständigen Gliederung im August, also ganze zwei Monate nach dem „Röhm-Putsch“,

14 Vgl. Archiv der Gegenwart, 3. Juli. 1934, S. 1508. Wagener gibt jedoch nach dem Krieg an, dass ein Gruppenstaffelführer der Motor-SA im Gruppenstab Heines von SS-Männern ermordet worden sei; vgl. G. L. Wagener: Warum sollte ich verschweigen, S. 605, StadtA Hannover.

15 Schreiben von Kraus an Otto Sommer vom 6. 7. 1934, BArch NS 24/250.

16 Zu den militärischen Machtambitionen der SA vgl. Jamin: Das Ende der „Machtergreifung", S. 208.

17 Vgl. Volz: Daten zur Geschichte der NSDAP, S. 57.

18 Vgl. DDAC-Wochenschrift vom 7.9. 1934: „Motor-SA und NSKK jetzt selbständige Einheit".

19 Vgl. DDAC-Wochenschrift vom 7. 9. 1934: "Tagesbefehl an Motor-SA und NSKK“. 
erfolgte, muss dieser Vorgang eindeutig im Kontext des 30. Juni 1934 gesehen werden. Die mündlichen Ausführungen des Reichswehrministers vor den $\mathrm{Be}-$ fehlshabern der Armee am 5. Juli 1934 zeigen dies deutlich. Der Reichswehrminister berichtete wenige Tage nach den Ereignissen in Bad Wiessee über geplante Strukturveränderungen innerhalb der SA, insbesondere über die Verringerung der Mitgliederzahl und den organisatorischen Rückbau der SA. In diesem Zusammenhang kündigte er an: „N.S.K.K. und die SA-Schulen werden dem Führer persönlich unterstellt [...].“20

Vermutlich wäre der Aufstieg des NSKK zu einer selbständigen Gliederung ohne die Mordaktion in Bad Wiessee und die nachfolgende Machtbeschränkung der SA niemals erfolgt. Das Ziel der machtpolitischen Schwächung der SA erklärt jedoch nicht, warum gerade das NSKK und nicht, wie theoretisch denkbar, das NS-Marinekorps profitierte.

Folgende Gründe legten eine Separierung von der SA nahe: Bereits vor 1933 wurde das NSKK als eigenständige Gruppe wahrgenommen.21 Die Motor-SA ihrerseits nahm innerhalb der SA einen Sonderstatus ein, weil sie die mitgliederstärkste Sonderformation unter dem Dach der SA war. Rein thematisch bot sich eine Zusammenlegung der Motorformationen an, da sie einem gemeinsamen Führer unterstanden. Motor-SA und Flieger-SA, die politisch relevante Aufgaben erhielten, wurden beide nach der Machtübernahme ausgegliedert, wohingegen die Marine-SA, die Reiter-SA und die Nachrichten-SA bis 1945 weiterhin Sondereinheiten der SA blieben. ${ }^{22}$

Auch der Rückhalt des NSKK in der Reichswehr mag für die Entscheidung zur Herauslösung der motorisierten Parteiformationen maßgebend gewesen sein, arbeiteten doch Einheiten der Reichswehr und der Chef des Kraftfahrwesens seit 1933 auf dem Gebiet der vormilitärischen Kraftfahrerausbildung zusammen. Die Reichswehrführung begrüßte nach dem „Röhm-Putsch“ die Ausgliederung des Ausbildungswesens und des Kraftfahrwesens aus der SA, bot sich ihr damit doch die Möglichkeit, die Zusammenarbeit mit diesen Einrichtungen im vormilitärischen Bereich unmittelbar fortzusetzen. ${ }^{23}$ Auch auf nachgeordneten Hierarchieebenen galten die Beziehungen zwischen NSKK und Kraftfahrabteilung als her-

$20 \mathrm{Vgl}$. die mündlichen Ausführungen des Reichswehrministers vor den Befehlshabern am 5. 7. 1934: Handschriftliche Aufzeichnungen des General der Infanterie Curt Liebmann, IfZ ED 1.

21 Hitler hatte bereits 1932 in seinem Neujahrsbefehl das NSKK unabhängig von der SA angesprochen; vgl. Domarus: Hitler, Bd. 1.1, S. $62 \mathrm{f}$.

22 Vgl. Organisationsbuch der NSDAP, 1943, S. $364 \mathrm{ff}$.

23 Hitler hatte dem Reichenau-Plan (die Reichswehr als Elitearmee in Stärke von 450000 Mann plus Einbeziehung der SA als Miliz in die Landesverteidigung) zugestimmt und am 12. 7. 1933 die Einrichtung von SA-Geländesportschulen für die vormilitärische Ausbildung durch den neu ernannten Chef des Ausbildungswesens der SA befohlen. Der Chef AW hatte sieben Ausbildungsbereiche und ca. 250 Geländesportschulen, darunter auch Motorgeländeschulen, unter sich. Nach dem „Röhm-Putsch“" war der Chef des Ausbildungswesens Krüger bis zur Auflösung am 24. 1. 1935 Hitler direkt unterstellt; vgl. Absolon: Die Wehrmacht im Dritten Reich, Bd. I, S. 110f., 112 f.; Kern: Die innere Funktion der Wehrmacht 1933-1939, S. 80; G. L. Wagener: Warum sollte ich verschweigen, S. 578, StadtA Hannover. 
vorragend. Artillerieführer bescheinigten dem NSKK in einer Meldung an das Wehrkreiskommando Bayern vom April 1934 den Willen zur Mitarbeit, wohingegen einem Teil der SA diese Bereitschaft abzusprechen sei. Die SA-Führer würden durch ihr persönliches Geltungsbedürfnis und die Überschätzung ihres militärischen Wertes unangenehm auffallen. ${ }^{24}$

Mit der Erhebung zur Gliederung wurde das NSKK Hitler direkt unterstellt. Rein formal gesehen bedeutete die Erhebung zur Gliederung eine engere Anbindung an die NSDAP. Gemäß dem „Zweiten Gesetz zur Sicherung der Einheit von Staat und Partei“ vom 29. März 1935 besaßen Gliederungen keine eigene Rechtspersönlichkeit und kein eigenes Vermögen. Dies unterschied sie rein formal von den „angeschlossenen Verbänden“ der NSDAP. Unter die Gliederungen der Partei fielen: SA, SS, NSKK, HJ, NS-Deutscher Studentenbund, Nationalsozialistischer Dozentenbund und NS-Frauenschaft. ${ }^{25} \mathrm{Als}$ wichtige Stütze im Staat wurden die drei „Kampfgliederungen“ SA, SS und NSKK betrachtet:

"Sie sind der Garant, der eiserne Arm der Bewegung, die Fahnenträger der NSDAP und des nationalsozialistischen Staates. Ihre Aufgaben sind Schutz und Mitwirkung bei der Propagandatätigkeit, Pflege des Frontsoldatengeistes und Erziehung zur Kämpfernatur und Selbstzucht." 26

Das NSKK hatte also einen Prestigegewinn zu verzeichnen, der es auf eine Stufe mit SA und SS stellte. ${ }^{27}$

\section{Der Zusammenschluss mit der Motor-SA}

Was auf dem Papier zusammengefügt wurde, musste sich nun in der Praxis als zusammengehörig erweisen bzw. musste miteinander verbunden werden. Die Fusion der Motor-SA mit dem NSKK zog für die Motor-SA den Verlust des Namens und die Trennung von der SA nach sich. Dies war ein Bruch mit dem Selbstverständnis der Motor-SA-Männer, denen Hühnlein im Mai 1933 noch zugerufen hatte: „Motor-SA-Mann zu sein ist die höchste Auszeichnung." 28 Korpsführer Hühnlein versuchte, Gefühle der Demütigung nicht aufkommen zu lassen. Er bekräftigte in seinem Tagesbefehl vom 2. September 1934, dass das neu entstandene NSK K in treuester Kameradschaft zur SA stehe. ${ }^{29}$ Hühnlein bekundete Verständnis für die von vielen Motor-SA-Mitgliedern empfundene schmerzliche Trennung

24 Vgl. Nachricht des Artillerie-Führers (Bayern) VII an das Wehrkreiskommando (Bayern) VII vom 26. 4. 1934, BArch-MA RH 26-7/744. Vgl. auch die Einladung zum kameradschaftlichen Treffen des Artillerie-Führers (Bayern) VII vom 11.11. 1933 an den Obergruppenführer Hühnlein, BArch NS 24/273.

25 Vgl. Broszat: Der Staat Hitlers, S. 263.

26 Blankenburg u.a.: Nationalsozialistischer Wirtschaftsaufbau und seine Grundlagen, S. 227.

27 Das NSKK betonte den Status als dritte „selbständige Kampfgliederung“ im Kontakt mit Dienststellen der Partei; vgl. Schreiben des Führers der Motorobergruppe Süd an die Verbindungsstelle der Dienststelle des Reichsleiters Rosenberg vom 13.11. 1940, BArch NS 24/830.

28 Deutsche Kraftfahrt vom 15. 6. 1933: „Der Siegeszug des NSKK“.

29 Vgl. Oppermann: Unter den Sturmstandern, S. $125 \mathrm{f}$. 
von der SA. ${ }^{30}$ In ersten Reaktionen äußerten sich Motor-SA-Männer durchaus positiv darüber, dass sie nun nicht mehr als „Transportmädchen für alles“31 gebraucht wurden. Wenig erfreut waren sie jedoch darüber, mit den NSKK-Männern, denen der Ruf der Vereinsmeierei anhängig war, in einen Topf geworfen zu werden. Nach Aussagen des ehemaligen NSKK-Gruppenführers Georg Wagener empfanden viele die Bezeichnung "NSKK-Mann“ als Degradierung. Doch der wehmütige Blick zu den Kampfgenossen von der SA verlor sich mit der Zeit. Die Führung der SA war aufgrund des Putsch-Vorwurfes geschwächt und der politische Enthusiasmus der Mitglieder gedämpft. ${ }^{32}$ Regelmäßige Dienste sowie der Erwerb des SA-Sportabzeichens und der Reichswettkampf entwickelten sich seit 1934 zu Bestandteilen einer SA-spezifischen Beschäftigungstherapie. Das Sinnvakuum der SA stand in Gegensatz zu dem neuen Elan, den das NSKK im Hinblick auf neue Aufgaben und Ziele entfalten konnte. Es bot denjenigen SA-Anhängern eine Alternative, die gewillt waren, sich in den Bereichen Motorsport, Wehrsport und Verkehr zu engagieren.

Ein Vorteil für übertrittswillige SA-Männer und -Führer war das Umgehen von Säuberungsmaßnahmen im SA-Führerkorps. Die zum NSKK übergetretenen Motor-SA-Führer durften nicht vom Sondergericht OSAF, das sich ab März 1935 Disziplinargericht der OSAF nannte, belangt werden. Bis 1939 wurden rund 1750 SA-Führer, in der Mehrzahl „alte Kämpfer“, disziplinarisch bestraft und zumeist aus der SA ausgeschlossen. ${ }^{33}$ SA-Untersuchungsausschüsse gaben Verfahren an das NSKK ab. ${ }^{34}$ In den von den Wehrkreiskommandos erstellten Listen, in denen SA-Führer aufgeführt waren, die auf Wunsch der Wehrmacht aus ihrem Dienstbereich entfernt werden sollten, waren auch NSKK-Führer genannt. Dieser Personenkreis blieb aber aufgrund seiner Zugehörigkeit zum NSKK von einem Ausschluss verschont. ${ }^{35}$

Korpsführer Hühnlein hatte sich in der turbulenten Zeit nach dem 30. Juni 1934 politisch äußerst klug verhalten. Er stellte NSKK und Motor-SA als die politisch zuverlässigeren Gruppierungen dar, ohne sich gleichzeitig von der kämpferischen Tradition der SA zu distanzieren. Das NSKK, das in der „Kampfzeit“ noch als Reserveorganisation der Motor-SA gedient hatte, war aus dem Schatten dieser Formation herausgetreten. ${ }^{36}$ Auch die aus der Motor-SA stammenden Mitglieder akzeptierten ihre Mitgliedschaft im NSKK nach einiger Zeit, da das NSKK unbelasteter und flexibler agieren konnte als die zur Kulisse erstarrte SA. ${ }^{37}$

$30 \mathrm{Vgl}$. ebenda.

31 G. L. Wagener: Warum sollte ich verschweigen, S. 607.

32 Die Stettiner Gestapo beschrieb die Stimmung unter den SA-Männern 1935 als apathisch. Sie zweifelten am Sinn der SA; Bessel: Political Violence, S. 148.

${ }^{33}$ Vgl. Jamin: Zwischen den Klassen, S. 8.

34 Vgl. Verfügung der OSAF vom 7. 10. 1934, betr. Zuständigkeit SA-Sondergericht, BArch Research O. 254.

35 Die Liste wurde auf Verfügung des Reichswehrministeriums vom 14.7. 1934 erstellt; BArch-MA RH 26-7/744.

36 Hühnlein: NSKK als Wegbereiter der deutschen Kraftfahrt, S. 20.

37 Vgl. G. L. Wagener: Warum sollte ich verschweigen, S. 607, StadtA Hannover. 


\section{Der Aufbau}

\section{Äußere Strukturen: Gliederung und Einbeiten}

Neugliederung: $\mathrm{M}$ - und K-Einheiten

Nach dem Zusammenschluss und der Erhebung zur selbständigen Gliederung waren neue Organisationsstrukturen vonnöten. Die bereits vor 1933 eingeleitete Trennung in Motorradfahrer und Autofahrer wurde weiter verfolgt. Während die Einheiten der bisherigen Motor-SA zu Kraftradeinheiten zusammengefasst wurden, übernahmen die Einheiten des bisherigen NSKK die Aufgaben des Nachschubs und Transports. Die Motorbrigaden als oberste Einheiten des NSKK gliederten sich zwischen 1934 und 1935 demnach in Motorrad-Einheiten (bisher Motor-SA) und Kraftwagen-Einheiten (bisher NSKK). Die M-Einheiten setzten sich vorwiegend aus Fahrern von Krafträdern zusammen und die K-Einheiten aus Besitzern von Pkw, Lkw, Omnibussen und Zugmaschinen. Gegenseitige Überstellungen von Mitgliedern waren erforderlich, um die Trennung zu erreichen: Waren Motor-SA-Männer bereits älter, übergewichtig oder wiesen ein körperliches Gebrechen auf, wurden sie als ungeeignet für den Sturmdienst eingestuft und an die Kraftwagenabteilungen überwiesen. ${ }^{38}$

Die M-Einheiten waren in Motorstandarten, -staffeln und -stürme aufgeteilt; die K-Einheiten gliederten sich in Kraftwagen-Abteilungen, -Staffeln und -Stürme (bisher -Züge). Das Gebiet der Motorstandarte deckte sich mit der dazugehörigen Kraftwagenabteilung. ${ }^{39}$ Neben der Motorstandarte M 54 bestand in Freiburg eine entsprechende Kraftwagenabteilung K 54.40 Die Trennung zwischen Motor-SA und NSKK bestand somit innerhalb der gemeinsamen Gliederung vorerst weiter.

Die Einteilung des NSKK in M-Einheiten und K-Einheiten galt bis 1935. Durch Verfügung der Korpsführung des NSKK vom 20. März 1935 wurde die Trennung aufgehoben und die beiden Teile in einer Organisationsform zusammengefasst. ${ }^{41}$ Die völlige Verschmelzung aller Einheiten sollte bis zum 1. Oktober 1935 abgeschlossen sein. Die NSKK-Motorbrigaden gliederten sich von diesem Zeitpunkt an ohne Ansehen der Person und des Fahrzeugbesitzes nur mehr in Motorstandarten, Motorstaffeln und Motorstürme. Führer der Motorbrigaden, der obersten Gliederungseinheiten des NSKK, wurden die ehemaligen Gruppenstaffelführer der Motor-SA. ${ }^{42}$

$38 \mathrm{Vgl}$. Befehl des Standartenführers der Standarte M 77 an den Sturm 1/M 77 Bayreuth vom 20. 2. 1935, BArch NS 24/8.

39 Vgl. Korpsbefehl Nr. 2 vom 22. 9. 1934, BArch NSD 42/9; Staffelbefehl der II/M77 vom 20. 9. 1934, BArch NS 24/3.

40 Vgl. Schreiben NSKK-Kraftwagenabteilung 54 vom 12.1. 1935, StadtA Freiburg CV/ XIII/31/8.

41 Vgl. Anordnung der NSKK-Motorstandarte 54 an alle Dienststellen vom 1.4. 1935, ebenda; Volz: Daten zur Geschichte der NSDAP, S. 58.

42 Vgl. G. L. Wagener: Warum sollte ich verschweigen, S. 607, StadtA Hannover; Korpsbefehl Nr. 1 vom 17. 9. 1934, BArch NSD 42/9. 
Geographische und hierarchische Gliederung

Motor-SA und NSKK waren nach ihrem Zusammenschluss in 21 Motorbrigaden zusammengefasst worden. Korpsführer Hühnlein legte großen Wert darauf, dass sich die Bereiche der Motorbrigaden mit denen der SA-Gruppen deckten. ${ }^{43}$ Dies war nicht selbstverständlich, da sich die Gliederungen und Verbände der NSDAP hinsichtlich ihrer geographischen Einteilung sowohl dem Namen nach als auch nach der Gebietseinteilung unterschieden. Die HJ gliederte sich 1935 in $25 \mathrm{HJ}$ Gebiete, die SS in 10 Oberabschnitte, die SA in 21 SA-Gruppen und das NSKK, wie erwähnt, in 21 Motorbrigaden. ${ }^{44}$ Die angeschlossenen Verbände wie die Deutsche Arbeitsfront folgten der NSDAP-Gliederung und waren nach Gauen aufgeteilt.

Während sich 1935 die NSKK-Motorbrigaden aus traditioneller Verbundenheit mit der SA mit den SA-Gruppen deckten, setzten sich im Laufe der Zeit andere Loyalitäten durch. Die Grenzen des Korps wurden an die Grenzen der Wehrkreise, Ersatzbezirke und Bezirke angeglichen. ${ }^{45}$ Der große Aufwand, der für die Neugliederung der Motorbrigaden 1937 erforderlich war, zeigte den entschlossenen Willen zur intensiven Zusammenarbeit mit den Wehrkreiskommandos. ${ }^{46}$

Um eine straffere hierarchische Gliederung zu erreichen, wurden den Motorbrigaden im April 1935 vier Kraftfahrinspektionen (Süd, Ost, West, Nord) vorangestellt. ${ }^{47}$ Die Inspektionen fungierten als Dienstaufsichtsorgane. Die Kraftfahrinspektion Süd (München) umfasste Anfang 1935 die Motorbrigaden Bayerische Ostmark, Franken, Hochland, Kurpfalz und Südwest; der Kraftfahrinspektion Ost (Berlin) waren die Motorbrigaden Berlin, Leipzig, Mitte, Ostmark, Sachsen und Thüringen unterstellt; die Kraftfahrinspektion West (Köln) vereinte die Motorbrigaden Hessen, Niederrhein, Niedersachsen, Westfalen, Westmark; die Kraftfahrinspektion Nord (Hamburg) hatte die Motorbrigaden Hansa, Nordmark, Nordsee und Pommern unter sich. 48

Nachdem 1935 die Grundlagen für eine einheitliche Gliederung gelegt worden waren, baute man in den kommenden Jahren die Strukturen weiter aus. So wurden im Frühjahr 1936 aus den Kraftfahrinspektionen Motorobergruppen. ${ }^{99}$ Die Breitengliederung war nunmehr unterteilt in vier Motorobergruppen, drei selbständige Motorgruppen (Hessen, Ostland, Schlesien), die keiner Motorobergruppe unterstanden, und 21 Motorbrigaden. 50

43 Vgl. G. L. Wagener: Warum sollte ich verschweigen, S. 608, StadtA Hannover.

44 Vgl. Volz: Daten zur Geschichte der NSDAP, S. 63; Blankenburg u. a.: Nationalsozialistischer Wirtschaftsaufbau, S. 226.

45 Vgl. Korpsbefehl Nr. 25 vom 15. 11. 1937, BArch NSD 42/9; Geheime Neugliederung vom 1. 11. 1937, BArch NS 24/320.

46 Im Juni 1944 wurden die Motorgruppen und -brigaden des NSKK an die Grenzen der Parteigaue angepasst. Mit Ausnahme der NSKK-Motorgruppe Adolf Hühnlein und der Motorgruppe Niederrhein erhielten alle übrigen NSKK-Motorgruppen und -brigaden den Namen des jeweiligen Gaues. Im Juli geschah dassselbe mit den SA-Gruppenbereichen; vgl. Bekanntgabe des Leiters der Parteikanzlei vom 21. 6. 1944, NS 6/347, Bl. 76, 81.

47 Vgl. Aufstellung des Reichskassenverwalters vom 17.4. 1936, BArch NS 24/1; Korpsbefehl Nr. 23 vom 11. 11. 1936, BArch NSD 42/9.

48 Vgl. NSK K-Korpsführung (Hrsg.): Gliederung des NSKK, 1935, S. 13.

49 Vgl. Korpsbefehl Nr. 23 vom 11. 11. 1936, BArch NSD $42 / 9$.

50 Vgl. Organisationsbuch der NSDAP, Berlin 1936, S. 394, 400. 
Nach zahlreichen Reorganisationsmaßnahmen in der Breitengliederung gestaltete sich die Struktur 1938 gemäß folgendem Organigramm ${ }^{51}$ :

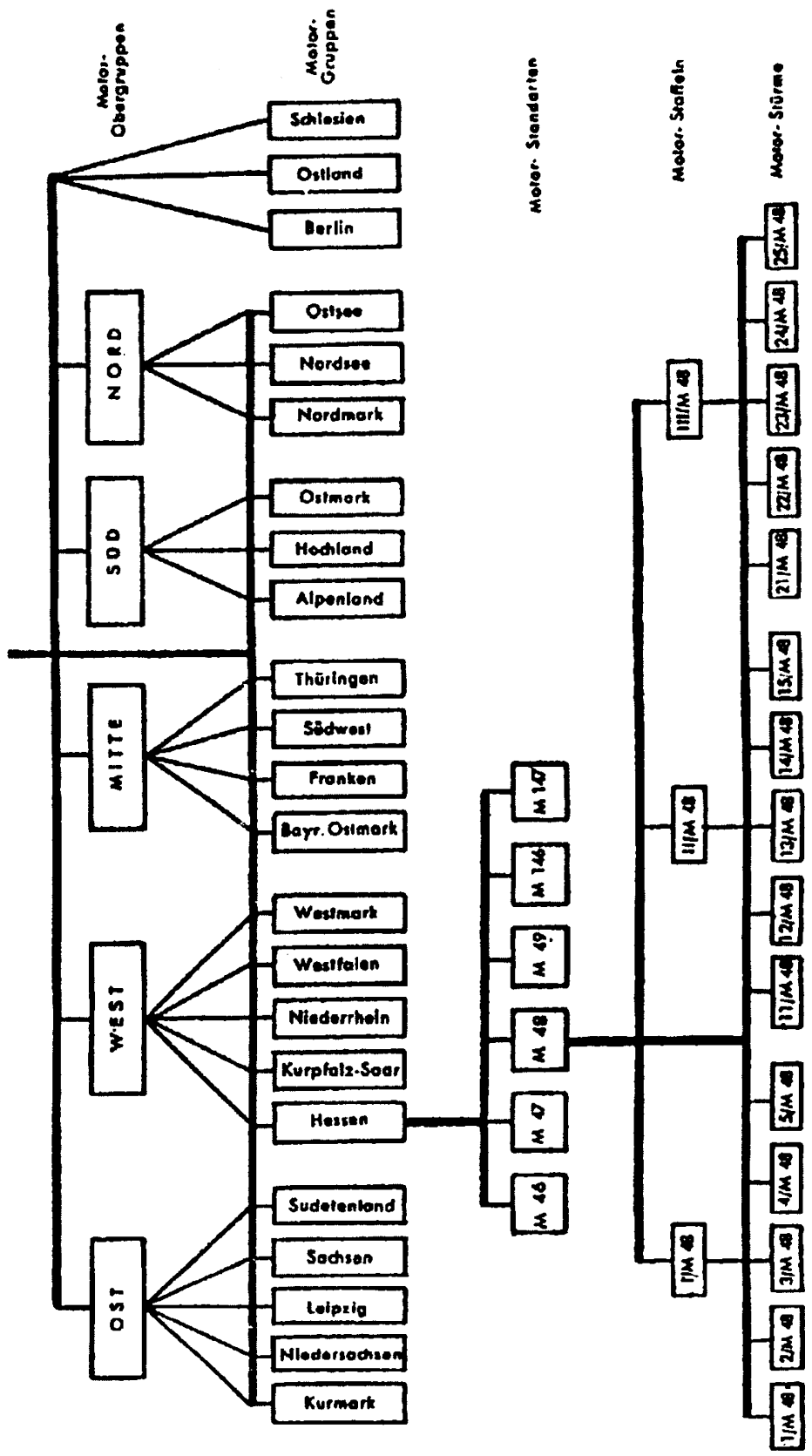

51 Das Organigramm zeigt die Gliederung nach dem Stand vom 1.12. 1938; abgedr. in: Krenzlin: Das NSKK, S. 27. 
Die fünf Motorobergruppen Nord, Ost, Mitte, Süd und West gliederten sich in 20 Motorgruppen, die aus den ehemaligen Motorbrigaden hervorgingen. Selbständige Motorgruppen, die keiner Motorobergruppe unterstanden, waren die Motorgruppe Ostland mit Sitz in Königsberg, die Motorgruppe Schlesien mit Sitz in Breslau und die Motorgruppe Berlin. Jede Motorgruppe teilte sich in sieben Motorstandarten, jede Motorstandarte in fünf bis sechs Motorstaffeln und jede Staffel in sechs Motorstürme. Die Motorstürme ihrerseits gliederten sich in Trupps und Scharen. ${ }^{52}$

Die Zahl der Einheiten stieg in den Jahren 1933 bis 1939 erheblich an. 1936 unterstanden den Motorbrigaden insgesamt 109 Motorstandarten und 1793 Motorstürme..$^{53}$ Ein Jahr später existierten 118 Motorstandarten und 1808 Motorstürme. ${ }^{54}$ Bis 1938 erhöhte sich die Zahl auf 1823 Stürme ${ }^{55}$ und erfuhr bis 1941 nochmals eine gewaltige Steigerung auf 3207 Motorstürme. ${ }^{56}$ Von dem Gründungsboom im Bereich der Motorstürme zeugte auch die Idee, das NSKK auf andere Länder auszudehnen. In Afrika und Schanghai beispielsweise existierten motorisierte Sondereinheiten, in denen deutschstämmige Kraftfahrer der Auslandsabteilung der NSDAP zusammengeschlossen waren. ${ }^{57}$

Seit den Anfängen des NS-Automobilkorps 1930 existierte auch eine Gruppe von nationalsozialistischen Kraftfahrern in Wien, die von Hühnlein betreut wurde ${ }^{58} \mathrm{Nach}$ dem Einmarsch in Österreich erfolgte die Ausweitung der Organisationsstrukturen. Es entstand die Motorgruppe Österreich, die von NSKKBrigadeführer Kurt von Barisani befehligt wurde. Die NSKK-Korpsführung stellte für die Einkleidung 5000 vollständige Ausrüstungen zur Verfügung. ${ }^{59}$ Der erste öffentliche Auftritt des NSKK war die Volksabstimmung am 10. April 1938, bei der der NSKK-Wahldienst für ein „Ja“" warb. 60 Die Motorgruppe Österreich wurde in die Motorgruppe Ostmark mit Sitz in Wien und die Motorgruppe Alpenland mit Sitz in Salzburg aufgeteilt. Als im Juni 1939 die Motorobergruppe Südost unter Führung von Obergruppenführer Seydel in Wien gebildet wurde, teilte man ihr die zwei österreichischen Motorgruppen zu. ${ }^{61}$

$52 \mathrm{Vgl}$. ebenda.

53 Vgl. Aufstellung des Reichskassenverwalters vom 17. 4. 1936, BArch NS 24/1.

54 Vgl. NSKK-Korpsführung (Hrsg.): Das NSKK, S. 3.

55 Vgl. Weisung des Korpsführers vom 28. 3. 1938, BArch NS 24/155. Siehe auch das Schema des Organisationsamtes vom 5. 1. 1939, BArch MA, RH 2/v.-988 K10.

56 Vgl. Bericht „Der Kriegseinsatz des NSKK“, 2. Folge, Stand: 1. 10.1941 (geheim), StadtA Leipzig, Kap. 3 Nr. 70.

57 Vgl. Schreiben des Korpsführers an den NSKK-Brigadeführer Nord vom 1. 7. 1938 (Abschrift), BArch NS 24/35; Mitteilung des Organisationsamtes an den Korpsführer vom 8. 7. 1940, betr. Koloniales NSKK, BArch NS 24/212.

58 Vgl. Der NSKK- Mann vom 9. 4. 1938: „Ihr besitzt eine stolze Tradition“.

59 Vgl. Der NSKK-Mann vom 26. 3. 1938.

60 Vgl. Der NSKK-Mann vom 2. 4. 1938: „Wahlhilfeaufruf an alle deutschen Kraftfahrer des Landes Österreich zum Erlaß des Gauleiters Bürckel über den Einsatz des NSKK-Wahlhilfsdienst".

61 Vgl. Verfügung des Chefstabsführers vom 1.6. 1939, betr. Bildung der Motorobergruppe Süd-Ost und Auflösung der Motorobergruppe West, BArch NS 24/282. 
Anfang des Jahres 1939 gliederten sich die fünf Motorobergruppen Nord, Ost, West, Süd und Mitte in drei bis fünf Motorgruppen. Insgesamt existierten $22 \mathrm{Mo-}$ torgruppen und eine Motorbrigade. Die Motorgruppen Ostland, Schlesien und Berlin waren keiner Motorobergruppe, sondern dem Korpsführer direkt unterstellt. Jede Motorgruppe umfasste jeweils 5 bis 12 Motorstandarten. Insgesamt gab es, verteilt über das ganze Reich, 144 Standarten. ${ }^{62}$

Auch im Krieg erfolgten zahlreiche Veränderungen und eine weitere Ausweitung der Organisationsstrukturen. Mit Wirkung vom 1. Mai 1941 wurde die Motorobergruppe Ost nach Breslau verlegt und die Motorobergruppe Nordost nach Berlin. ${ }^{63} \mathrm{Am}$ 1. September 1941 bestanden 6 Motorobergruppen und 28 Motorgruppen. ${ }^{64}$ Bis 1944 vergrößerte das NSKK die Zahl seiner Motorobergruppen auf 8 (Nordost, Ost, Südost, Süd, Südwest, West, Nord, Mitte) und die Zahl der Motorgruppen auf 33.65 Es wird aus der Entwicklung der äußeren Strukturen deutlich, dass das NSKK bis zuletzt eine enorme Aufbau-Dynamik besaß.

\section{Dienstrangordnung}

Das NSKK, mit dem Anspruch, gleichberechtigt neben SA und SS zu stehen, passte sich in seiner Dienstrangordnung den zwei anderen Kampfgliederungen an. Mit Ausnahme der Führertitel: Chef des Stabes, Reichsführer SS und Korpsführer war die Bezeichnung und die Reihenfolge der Dienstgrade vom SA-, SS- und NSKK-Obergruppenführer bis hinunter zum SA-, SS- und NSKK-Anwärter ab 1935 identisch. 66 Folgende Aufstellung von 1939 listet die Dienstränge auf. Von unten nach oben in der Befehlsstruktur waren zu unterscheiden:

- NSKK-Mannschaften: NSKK-Anwärter, Sturmmann (vor November 1939 NSKK-Mann, danach galten alle Diensttuenden des NSKK als NSKK-Männer), Obersturmmann, Rottenführer

- NSKK-Unterführer: Scharführer, Oberscharführer, Truppführer, Obertruppführer, Haupttruppführer

- NSKK-Führerkorps:

Unteres Führerkorps: Sturmführer, Obersturmführer, Hauptsturmführer.

62 Zur geographischen Gliederung des NSKK siehe auch RH 2/v.-998 K9, k 10 vom 5. 1. 1939. Eingezeichnet sind die Grenzen der Motorobergruppen, Motorgruppen, -brigaden und -standarten. Im Rahmen einer Strukturreform am 10.6. 1939 wurde die Motorobergruppe West aufgelöst, die darin enthaltenen Motorgruppen wurden selbständig. Als Motorobergruppen existierten nunmehr Nord (Hamburg), Ost (Berlin), Süd (München), Südost (Wien) und Mitte (Nürnberg). Vgl. das Schema: Breitengliederung des NSKK vom 19. 6. 1939 , BArch NS $1 / 2002$.

63 Vgl. Verfügung des Korpsführers vom 28. 4. 1941, BArch NS 24/28. Am 1. 8. 1942 umfasste die Motorobergruppe Ost unter Höfle die Motorgruppen: Oberschlesien, Niederschlesien, Sachsen-Leipzig; die Motorobergruppe Nordost die Motorgruppen Ostland, Danzig-Westpreußen und Wartheland, Sitz Danzig mit dem neuen Obergruppenführer Sauer, vgl. Gliederung 1942, BArch Research O. 254.

64 Vgl. Bericht „Der Kriegseinsatz des NSKK“, 2. Folge, Stand: 1. 10. 1941 (geheim), StadtA Leipzig, Kap. 3, Nr. 70.

65 Vgl. Anlage zum Befehl vom 25.4. 1944, BArch NS 24/10; Organisationsbuch der NSDAP, 1943, S. 399.

66 Vgl. Volz: Daten zur Geschichte der NSDAP, S. 63. 
Mittleres Führerkorps: Staffelführer (entsprechend Sturmbannführer NSFK, SA, SS), Oberstaffelführer (entsprechend Obersturmbannführer NSFK, SA, $\mathrm{SS}^{67}$ ) und Standartenführer.

Höheres NSKK-Führerkorps: Oberführer, Brigadeführer, Gruppenführer, Obergruppenführer und Korpsführer. ${ }^{68}$

Vergleichbare Dienstränge hatten den Vorteil, dass die Autoritätsstrukturen im Dienstverkehr mit den Gliederungen deutlich erkennbar waren. Die ähnlichen Hierarchien ermöglichten außerdem unter Beibehaltung des Dienstrangs einen problemlosen Wechsel von einer Gliederung zur anderen.

\section{Sondereinheiten}

Neben den allgemeinen Motorstürmen existierten Einheiten, die besondere Aufträge zu erfüllen hatten. ${ }^{69}$ Spezielle Nachrichtenstürme wurden im Grenzschutz und bei Straßenabsperrungen eingesetzt, Pionierstürme rüsteten sich für Katastrophen-, Waldbrand- und Hochwassereinsätze. ${ }^{70}$ Der Nachrichtenübermittlung widmete sich eine kuriose NSKK-Sondereinheit: der „Brieftauben-Trupp“ im Ruhrgebiet, dessen Stolz ein fahrbarer Taubenschlag war. ${ }^{11}$ Polizisten, die dem NSKK angehörten, hatten die Möglichkeit, sich Polizei-Motorabteilungen anzuschließen, die das NSKK-Emblem an der Uniform trugen. ${ }^{72}$

Neben diesen Splittergruppen unterhielt das NSKK wichtige Sondereinheiten, die Spezialaufgaben zu lösen hatten, darunter die Motor-HJ, der Verkehrserziehungsdienst und der Verkehrshilfsdienst des NSKK, die im Laufe dieser Arbeit noch ausführlich beschrieben werden. Daneben existierten zwei Formationen, die ebenfalls als Sondereinheiten bezeichnet werden können: die Kraftfahrtechnischen Arbeitsgemeinschaften an den Hochschulen und die Motorbooteinheiten des Korps.

Das NSKK versuchte, an den Universitäten um Nachwuchs zu werben. Gemäß einer Vereinbarung zwischen Hühnlein und dem Führer des Reichsstudentenbundes Derichsweiler wurden 1936 studentische Kameradschaften gebildet. Derichsweiler versprach, sich dafür einzusetzen, dass diejenigen Studenten, die „neben einer weltanschaulichen Schulung eine motortechnische oder motorsportliche Ausbildung erfahren wollen, um später in motorisierten Verbänden der Wehrmacht dienen zu können", sich in NSKK-Kameradschaften zusammenschlossen. ${ }^{73}$

67 Vgl. Kammer u. a.: Nationalsozialismus, S. $204 \mathrm{f}$.

68 Vgl. Verfügung vom 6. 11. 1939, BArch NS 24/28; Neugliederung des Stabes der Korpsführung vom 1.1. 1940, BArch NS 24/151; Verfügung des Korpsführers vom 6.11.1939, betr. Dienstgrade, BArch NS 24/158.

$69 \mathrm{Zu}$ den Sondereinheiten Motor-HJ und Verkehrserziehungsdienst vgl. die eigenständigen Kapitel: „Die Jugend strömt zum Motor“ und „Das Ideal: Verkehrssicherheit auf den Straßen des ,Dritten Reiches““.

70 Vgl. Verfügung des Korpsführers vom 5. 12. 1935, betr. Nachrichten- und Pionierstürme, BArch NS 24/162; Schreiben der Motorbrigade an die Kraftfahrinspektion Süd vom 14. 2. 1936, BArch NS 24/750.

71 Vgl. Deutsche Kraftfahrt vom 1. Januar 1937: „Meldetauben“.

72 Vgl. zu den Polizei-Motorabteilungen der Polizei die Hinweise in: BArch NS 24/422, 427.

73 Vgl. Ausschnitt aus der Partei-Korrespondenz vom 29. 4. 1936, BArch NS 22/918. 
Eine besondere Zielgruppe unter den Studenten war der technisch ausgebildete Nachwuchs an den Technischen Hochschulen und den Ingenieurschulen im Deutschen Reich. Dort wurden ab 1935 so genannte kraftfahrtechnische Arbeitsgemeinschaften gebildet, die dem NSKK angegliedert waren - ähnlich den akademischen Fliegergruppen, die mit dem NS-Fliegerkorps zusammenarbeiteten. Korpsführer Hühnlein beharrte darauf, dass die Studenten dem NSKK angehörten und das NSKK ihre Ausbildung übernehmen durfte. ${ }^{74}$ Im September 1941 existierten 21 akademische Arbeitsgemeinschaften, so genannte Hochschul-Motorstürme, an deutschen und österreichischen Hochschulen. ${ }^{75}$ Der Korpsführer setzte sich im Reichsverkehrsrat besonders für das Forschungsinstitut für Kraftfahrwesen und Fahrzeugmotoren an der Technischen Hochschule Stuttgart ein.76 Dort war eine der ersten „akademischen Kraftfahrgruppen“ entstanden, die Professor Wunibald Kamm leitete. Kamm bekleidete einen NSKK-Führerrang und stand zur „besonderen Verfügung“ des Korpsführers. ${ }^{77}$ Das Institut pflegte sehr gute Beziehungen zum Korps. Auf Empfehlung des Korpsführers bewilligte der Reichsverkehrsminister dem Stuttgarter Universitätsinstitut für 1937 über 200000 RM an Forschungsgeldern.78

Das NSKK erklärte sich nicht nur für den Straßenverkehr zuständig, sondern auch für die mit Kraftstoff betriebenen Wasserfahrzeuge. Am 31. Mai 1933 wurde im NSKK eine „Kraftbootabteilung" unter dem Befehl von Sturmführer Lange gegründet. Alle nationalsozialistischen Besitzer und Fahrer von motorisierten Wasserfahrzeugen wurden zum Eintritt in diese neue Abteilung aufgefordert. Parallel zu den Zielen des NSKK im Straßenverkehr lauteten die Aufgaben: Förderung des Wehrsportgedankens im Rahmen des Motorbootwesens, Erziehung

74 Im Reichsverkehrsrat hatte es im März 1938 Diskussionen darüber gegeben, ob die Mitglieder verschiedenen Organisationen angehören durften, zumal die Arbeitsgemeinschaften zu den Hochschuleinrichtungen zählten; Aktennotiz Hösl vom 1.4. 1938, BArch NS 24/340; Beschwerde Hühnleins an den Ministerialdirektor im Reichsverkehrsministerium Brandenburg vom 28.3. 1938 und Antwortschreiben vom 6. 4. 1938; ebenda.

75 Vgl. Bericht „Das NSKK im Kriegseinsatz“, 2. Folge, Stand: 1. 10. 1941 (geheim), StadtA Leipzig, Kap. 3 Nr. 70. Die Mitglieder wurden nach der Grundausbildung in Fahrzeugpflege und im Fahren einem Sachgebiet zugeteilt: Motorsport, Forschung, Schirrmeisterei oder Verkehrswesen. Einmal im Monat erfolgte ein weltanschaulicher Dienst; vgl. Anleitung des Inspekteurs Technik vom 16. 4. 1940 zum Aufbau der Kraftfahrtechnischen Arbeitsgemeinschaften an den Technischen Hoch- und Ingenieurschulen, „H“-Motorstürme des NSKK, BArch NS 24/96. Im Krieg wurde auf die Ausbildung von Medizinstudenten besonderes Augenmerk gelegt; vgl. Der NSKK-Mann vom 3. 5. 1940: „Student und Motorisierung " und "NSKK und NSD-Studentenbund vor gemeinsamen Aufgaben".

$76 \mathrm{Vgl}$. Schreiben des Inspekteurs für technische Ausbildung und Geräte an das RVM vom 7. 11. 1938, BArch NS 24/103.

$77 \mathrm{Vgl}$. Schreiben des Reichsverkehrsministers an den Reichsminister für Wissenschaft, Erziehung und Volksbildung vom 31.3. 1938, BArch NS 24/103; Liste der NSKK-Führer zur besonderen Verfügung der Korpsführung vom Inspekteur Technik an die Korpsführung vom 29.7.1938, BArch NS 24/85.

78 Das Institut bat das Korps um Fürsprache zur Bewilligung weiterer 270000 RM. Schreiben des Forschungsinstituts für Kraftfahrwesen an der TH Stuttgart vom 27.11. 1936, BArch NS 24/144. Wunibald Kamm (1893-1966) war Leiter des Instituts für Kraftfahrwesen und Fahrzeugmotoren an der Technischen Hochschule Stuttgart und beschäftigte sich vor allem mit der Aerodynamik von Kraftfahrzeugen. 
der Wasserverkehrsteilnehmer zu vorschriftsgemäßem Verhalten und Zusammenarbeit mit der Wasserschutzpolizei. ${ }^{79}$

Im August 1939 umfassten die Motorbooteinheiten des Korps drei Motorbootstandarten, zwei Staffeln und 31 Stürme. Darin taten 2774 Mitglieder und 54 Hitlerjungen mit 244 privaten und 32 korpseigenen Motorbooten ihren Dienst. Die größte Einheit war die Motorbootstandarte I Berlin, die im August 1939 über 109 Boote verfügte, von denen $21 \mathrm{im}$ Besitz des Korps waren. ${ }^{80}$ Anders als beim Kraftfahrwesen, das durch die Fusion zwischen Motor-SA und NSKK vereinheitlicht worden war, existierte die Marine-SA weiter. Obgleich sich das NSKK nur auf ein Segment des maritimen Verkehrs spezialisiert hatte - Boote mit Motorantrieb -, ist die Ausweitung des Einflusses von der Straße auf das Wasser als Erweiterung der Machtbasis anzusehen.

\section{Innere Strukturen: Ämter, Selbstdarstellung und Ausbildung}

Korpsführung und Ämter

Als Hitler Ende April 1933 den stellvertretenden Korpsführer und Chef des Kraftfahrwesens der SA, Obergruppenführer Hühnlein, zum Korpsführer des NSKK ernannte, begann der Ausbau der Korpsführung. ${ }^{81}$ Die Ämter Verkehr, Presse und Sport wurden von München nach Berlin verlegt. Dies brachte den Vorteil, dass die Korpsführung intensivere Kontakte zu Ministerien und internationalen Organisationen in der deutschen Hauptstadt pflegen konnte. Die Ämter für Organisation, Personal, Recht, Sanitätswesen und Verwaltung blieben hingegen in München.

Die Aufwertung des NSKK zu einer NSDAP-Gliederung, die Vergrößerung der Mitgliederzahl und die Erweiterung des Kompetenzbereichs verlangten nach einem Ausbau der Organisationsstruktur. ${ }^{82} 1938$ umfasste der Stab des Korpsführers mit den Dienststellen München und Berlin folgende Arbeitsgebiete: Chefstabsführer, Chefadjutant, Inspekteur für technische Ausbildung und Geräte, Inspekteur der Motorsportschulen, Reichskassenverwalter, Organisationsamt, Personalamt ${ }^{83}$, Sanitätsamt, Rechtsamt, Stabskommandant, Amt Kraftfahrsport, Amt Presse, Amt Verkehr und Inspekteur für Ausbildung (früher selbständige Abteilung Wehrsport). ${ }^{84}$ Der Korpsführung direkt unterstellt waren drei Schulen:

79 Vgl. Der NSKK-Mann vom 10. 9. 1938: „Blaue Jungs“ vom NSKK“.

80 Vgl. Deutsche Kraftfahrt vom August 1939: "Motorbootsport vor neuem Aufstieg“.

81 Vgl. Oppermann: Unter den Sturmstandern, S. 93.

82 Die Stabsbefehle des Korpsführers zwischen 1934 und 1936 weisen darauf hin, dass der Organisationsaufbau zügig verlief. Viele Ämter wurden neu geschaffen und mit Personal ausgestattet, darüber hinaus sprach der Korpsführer zahlreiche Beförderungen aus; vgl. BArch NSD 42/10.

83 Das Personalamt (Oberführer Klug) mit den Abteilungen: Personalien, Fürsorge, Aufnahmegenehmigung, Korpskartei, Führung der Personalakten; Krenzlin: Das NSKK, S. 31 .

84 Vgl. Korpsbefehl 9a vom 30.6. 1938, BArch NSD 42/9; Krenzlin: Das NSKK, S. 27-44. 
die Reichsführerschule, die Reichsmotorsportschule und die Technische Führerschule. ${ }^{85}$

$\mathrm{Zu}$ den wichtigsten Ressorts in der Korpsführung zählten die Ämter für Technik, Sport und Verkehr. Der Amtschef für Technik, ab 1935 Inspekteur für technische Ausbildung und Geräte, Obergruppenführer Erwin Kraus, war neben dem Korpsführer der wichtigste Entscheidungsträger im NSKK. Er war für die Technische Führerschule in München, die Erhaltung und Aufstockung des Fahrzeugparks der Motorsportschulen sowie deren technische Ausstattung zuständig. Bestellungen und Rechnungen, welche die Dienstfahrzeuge in der Breitengliederung betrafen, mussten ihm zur Prüfung vorgelegt werden. Im Kraftfahrsport übernahm der Stab des Inspekteurs für technische Ausbildung und Geräte die technische Vorbereitung und Durchführung der Veranstaltungen. ${ }^{86}$

Ein weiteres wichtiges Amt innerhalb der Korpsführung war das Amt Kraftfahrsport. Ihm oblag der gesamte kraftfahrsportliche Einsatz des NSKK. Zu den Aufgaben zählten Etatfragen, die Durchführung von Veranstaltungen, die Zusammenstellung von Mannschaften, die Bildung einer korpseigenen SportwagenMannschaft und im Rahmen der Obersten Nationalen Sportbehörde auch die Organisation des internationalen Sportverkehrs. ${ }^{87}$

Das Amt Verkehr bearbeitete Gesetze und Verordnungsentwürfe auf dem Gebiet des Straßenverkehrs und brachte Vorschläge und Anträge bei den zuständigen Stellen von Partei und Staat ein. Es regelte die Aufstellung des Verkehrserziehungsdienstes und des Verkehrshilfsdienstes und organisierte den Einsatz von freiwilligen Helfern des Korps für Verkehrseinsätze der Polizei. 88

Das Rechtsamt arbeitete Stellungnahmen des Korps zu eingereichten Gesetzentwürfen aus und prüfte die Gesetzgebung hinsichtlich der gesetzlichen Rahmenbedingungen, nach denen die Anschaffung und der Betrieb von Kraftfahrzeugen geregelt wurden. ${ }^{89}$ Die Tätigkeitsfelder des Rechtsamtes und des Amtes Verkehr zeigen deutlich, dass das NSKK gewillt war, im Politikfeld Verkehr auf ministerieller Ebene Einfluss zu gewinnen.

Besonders ausgebaut beim NS-Kraftfahrkorps war der Gesundheits- und Sanitätssektor. Dem Sanitätsamt unterstanden 3500 Sanitätsführer (Ärzte, Zahnärzte und Apotheker) und annähernd 13000 Sanitäter in der Breitengliederung. Neben der Untersuchung aller aktiven NSKK-Mitglieder und der Führung der Gesundheitsstammbücher waren Sanitäter aufgrund des erhöhten Unfallrisikos im NSKK von besonderer Wichtigkeit. Bei den motorsportlichen Veranstaltungen wurden sowohl NSKK-Sanitäter als auch Mitarbeiter vom Deutschen Roten Kreuz eingesetzt.

85 Vgl. Krenzlin: Das NSKK, S. 45.

86 Vgl. Schreiben des Inspekteurs für technische Ausbildung und Geräte an das Amt Presse vom 14. 1. 1939, BArch NS 24/220; NSKK-Korpsführung (Hrsg.): Das NSKK, S. 14, $19 \mathrm{f}$.

87 Vgl. Krenzlin: Das NSKK, S. 35. Mehr zu den Aktivitäten des Amtes Sport im Kapitel "Motorsport im ,Dritten Reich': Organisation und Funktion“.

88 Vgl. Krenzlin: Das NSKK, S. 32.

89 Vgl. ebenda, S. 34. 
Da das NSKK eine Gliederung der NSDAP war, verfügte sie über kein eigenes Vermögen. Finanzielle Angelegenheiten wurden vom Reichsschatzmeister der NSDAP mitverwaltet. An der Spitze der Verwaltung des NSKK stand als Sachbearbeiter des Korpsführers und als Bevollmächtigter des Reichsschatzmeisters der NSDAP der Reichskassenverwalter des NSKK. Er war für die Haushaltsführung des Korps verantwortlich, teilte dem Korps Personal- und Sachmittel zu, besoldete die hauptamtlichen NSKK-Führer und Sachbearbeiter, übernahm den Einzug der Beiträge und verwaltete Grundstücke und Gebäude des NSKK. 90

Nicht nur die Korpsführung entwickelte ein weit verzweigtes Ämtersystem. Auch die in der Hierarchie weiter unten angesiedelten Motorobergruppen, Motorgruppen und Motorstandarten hatten Referenten für die Sachgebiete Führung, Adjutantur, Technik, Verwaltung, Motor-HJ, Wehrsport, Kraftfahrsport, Verkehr, Presse und Sanitätswesen. ${ }^{91}$ Auf der Standarten-Ebene waren die meisten Referenten ehrenamtliche Mitarbeiter. ${ }^{92}$

An der Ämtervielfalt lässt sich erkennen, dass das Korps bestrebt war, seine Belange selbständig und eigenverantwortlich zu regeln. Wie die SA und die SS baute das NSKK einen kleinen Parallelstaat im Staate auf. Die Vielzahl an Ämtern und Führerstellen, die bis zur Ebene der Motorstürme reichten, ist nicht nur ein Beispiel für bürokratischen Regelungswahn, sondern war ein rational einsetzbares Instrument zur Kontrolle und Mobilisierung der Mitglieder.

Zum Aufbau einer eigenständigen Gliederung gehörte nicht nur das Ämterwesen. Um die innere Einheitlichkeit und die äußere Abgrenzung von anderen Gliederungen und Verbänden der NSDAP zu demonstrieren, erließ die Korpsführung eine „Anzugsordnung des NSKK“ sowie Vorschriften über „Ausrichtung und Ausbildung der Spielmanns- und Musikzüge des NSKK “ und brachte eine Schrift über „Dienstfahrzeuge im NSKK“ und eine eigene Dienst-, Straf- und Ehrenordnung heraus. Außerdem baute das NSKK ein eigenes Pressewesen auf.

\section{Presse}

Presseerzeugnisse einer Organisation dienen in erster Linie dazu, die Mitglieder einer Gruppe zu informieren und das Zusammengehörigkeitsgefühl zu fördern. Das Mitteilungsorgan für korpsinterne Fragen nannte sich „Der NSKK-Mann“ und erschien ab 1. April 1936 als vierseitige Wochenbeilage der Zeitung „Der SAMann“. Damit wurde die Verbundenheit zwischen den beiden Gliederungen betont. ${ }^{93}$ Ab 1938 erschien „Der NSKK-Mann. Kampfschrift des Nationalsozialistischen Kraftfahrkorps. Amtliches Organ der Korpsführung des NSKK" unab-

90 Vgl. ebenda; Verordnungsblatt der Korpsführung München vom 15.8. 1935, IfZ Db 30.01 .

91 Vgl. Stärkenachweis für den Stab einer Motorstandarte und Einteilung der Sachgebiete, Anlage 1, vom 30. 1. 1937, BArch NS 24/2.

$92 \mathrm{Vgl}$. ebenda.

93 „Spiegelt die Deutsche Kraftfahrt das Leben des Korps und seine vielgestaltigen Aufgaben als sein geschichtliches Tagebuch" wider, so sollte die Beilage "Der NSKK-Mann“ die SA an dem „Erleben des Schulter an Schulter mit ihr marschierenden NSKK teilnehmen lassen“; Verfügung des Korpsführers vom 7.11. 1936, betr. Werbeaktion für den NSKKMann, BArch NS 24/24. 
hängig von der SA als eigenständiges Heft. Dies zeugt von dem neu erworbenen Selbstbewusstsein des NSKK und dem Wunsch, sich von der SA endgültig abzunabeln. Der Hauptschriftleiter der Zeitung war NSKK-Brigadeführer Hans-Helmuth Krenzlin, der zugleich als Leiter des Presseamtes des Korps fungierte. „Der NSKK-Mann", dessen Auflage 1938 rund 40000 Exemplare betrug94, wurde im Zentralparteiverlag der NSDAP verlegt. Einen festen Platz in der Zeitung hatten die Sparten „Zeitspiegel zur internationalen Politik“, „Technische Beratung" und die Rubrik „Aus den Reihen des Korps“. Inhaltlich stark vertreten waren militärische Themen, z. B. der Fortsetzungsbericht „Zwanzig Jahre deutsche Kampfwagen “. ${ }^{95} \mathrm{Um}$ die Zeitschrift lesernah zu gestalten, wurden die Motorstürme regelmäßig aufgefordert, Berichte für den „NSKK-Mann“ zu verfassen. ${ }^{96}$ Obgleich offiziell als "Kampfschrift" bezeichnet, achtete man auf eine leserfreundliche Mischung, um den Leser durch Kurzgeschichten und abenteuerliche Reisereportagen bei Laune zu halten.

Das Leben im Korps und die Einsätze des NSKK spiegelte auch das zweite Sprachrohr des Korps wider: die in Hannover erscheinende Monatsschrift „Deutsche Kraftfahrt" ${ }^{97}$ Die reich bebilderte und technisch orientierte Zeitschrift des Oppermann-Verlags ging 1933 aus den Monatsblättern des NSKK hervor. ${ }^{98}$

Die „Deutsche Kraftfahrt“ wurde 1934 Eigentum des Korps und auf Anordnung des Korpsführers 1935 der Presseabteilung des NSKK angegliedert. Sie erschien von nun an zweimal monatlich und wurde mit je 100 Exemplaren an jeden Motorsturm abgegeben. Die NSKK-Männer waren verpflichtet, die Zeitschrift an Sturmkameraden und andere Interessierte zu verkaufen. ${ }^{99}$ Obgleich die Zeitschrift von den Mitgliedern gern gelesen wurde, klagten die Stürme über die Abnahmepflicht und die ihnen auferlegte Nebenbeschäftigung als Zeitungsverkäufer. ${ }^{100}$ Trotz auftretender Streitigkeiten zwischen Oppermann und Hühnlein, die sowohl die inhaltliche Gestaltung des Heftes als auch die Eigentumsverhältnisse betrafen, war die „Deutsche Kraftfahrt“ bis zum Kriegsende ein Sprachrohr des NSKK. 101 Im Krieg mussten infolge Papiermangels verschiedene Zeitungen mit der Deutschen Kraftfahrt zusammengelegt werden. ${ }^{102}$

94 Vgl. Der NSK K-Mann vom 5. 3. 1938.

95 Vgl. die militärischen Themen: Der NSKK-Mann vom 27.11. 1937: „Die Kraftfahrkampftruppe“; Der NSKK-Mann vom 1. 1. 1938: „Zwanzig Jahre deutsche Kampfwagen“" und „Voraus den Kameraden - im Kampfe ganz allein“; Der NSKK-Mann vom 5. 3. 1938: „Panzer-Kampfwagen, moderne Kriegselefanten“.

96 Vgl. Erfahrungsbericht über die Pressearbeit der fränkischen Motorstandarte M 77, später M 95; BArch NS 24/25.

97 Vgl. Krenzlin: Das NSKK, S. 38.

98 Vgl. Oppermann: Unter den Sturmstandern, S. 93.

99 Vgl. Ankündigung des Verlags Deutsche Kraftfahrt vom 18. 7. 1935, BArch NS 24/24. Die Gründe für die Angliederung der Deutschen Kraftfahrt an das NSKK sind nicht geklärt. Nach Angaben von Kraus in einem Schreiben an den Reichsrevisor Walther vom 8. 1.1936 wurde die Zeitschrift Eigentum des Korps, weil sich Oppermann die finanziellen Belastungen nicht mehr leisten konnte; vgl. BArch NS 24/513.

100 Vgl. Erfahrungsbericht über die Pressearbeit der fränkischen Motorstandarte M 77, später M 95; BArch NS 24/25.

101 Die „Deutsche Kraftfahrt“ befand sich zwischen Februar 1934 und Juni 1937 nicht im 
Weitere Presseerzeugnisse, in denen NSKK-Belange zur Sprache kamen, waren die bis 1934 erscheinende Zeitschrift „Deutscher Sport“, die auch als Organ des NS-Kraftfahr-Korps, des Wassersportverbandes und der Fliegerstaffel BerlinBrandenburg fungierte ${ }^{103}$, die „ONS-Mitteilungen“ (1935-1939), die über den Verlauf und die Ergebnisse motorsportlicher Veranstaltungen Auskunft gaben, und der vom Oppermann-Verlag herausgegebene „Kraftfahrt-Pressedienst“ (1934). Dies war ein Service des NSKK und des DDAC mit dem Ziel, die Motorisierung Deutschlands publizistisch zu fördern und der Lokalpresse in Deutschland Informationen und Presseartikel zu liefern. ${ }^{104}$ Als dem NSKK nahe stehend können die „DDAC-Wochenschrift“ (1933-1934), das Nachfolge-Blatt „Motorwelt" (1935-38) und die "Amtlichen Mitteilungen des DDAC“ bezeichnet werden, die der Einheitsclub nach der Fusion der Automobilclubs im Herbst 1933 herausbrachte.

Im Zweiten Weltkrieg schickten die lokalen Motorstürme an ihre NSKK-Mitglieder im Feld „Heimatbriefe“ und fassten "Soldatenbriefe“ an den Sturm zu Druckschriften zusammen. ${ }^{105}$ Ab 20. September 1939 erschien ein „Mitteilungsblatt des NSKK“.

Neben den genannten Zeitungen, die unter dem Einfluss des NSKK standen, gab es eine Vielzahl weiterer Motorzeitschriften aus der Zeit der Weimarer Republik, die weiterhin erschienen, so z.B. die „Neue Kraftfahrer-Zeitung“, „Motor und Sport“, „Das Kraftfahrzeug“, „Allgemeine Automobilzeitung“, „Motor-Kritik“ und „Das Motorrad“. 106 Diese Zeitungen wurden vom NSKK als Konkurrenz betrachtet und zumeist abgelehnt. Die bis in die Zeit des Zweiten Weltkriegs vorhandene Vielfalt auf dem Zeitungsmarkt verhinderte ein Meinungsmonopol des NSKK im Kraftfahrwesen. Die Herausforderung für das NSKK bestand darin, die politischen und wehrhaften Aspekte der Motorisierung innerhalb der NSKK-Presseerzeugnisse stärker zum Ausdruck zu bringen als die anderen Motorzeitschriften, und zwar möglichst ohne die Leser durch politische Belehrungen zu langweilen.

Eigentum des Oppermann-Verlags; vgl. den Brief von Oppermann vom 7.12.1939 an den Korpsführer, Entnazifizierungsakte Oppermann, HStA Hannover. Der Korpsführer warf der „Deutschen Kraftfahrt“ vor, in letzter Zeit wiederholt auf Juden bzw. Schwindler „hereingefallen“ und in technischen Fragen inkompetent zu sein; vgl. Schreiben des Inspekteurs Technik an das Presseamt der Korpsführung vom 24. 1. 1939, BArch NS 24/ 220.

102 1939-42 „Deutsche Kraftfahrt“ vereint mit „Motorwelt"; 1943-44 erschien das Gemeinschaftsblatt aus: „Deutsche Kraftfahrt“ - „Motor und Sport“ - „Allgemeine Automobilzeitung“ - „Das Kraftrad“ - „Motorwelt“.

103 Vgl. Bernett: Umbruch oder Kontinuität?, S. 8, Anmerkung 4.

104 Vgl. die erste Ausgabe des Kraftfahrt-Pressedienstes. Sprachrohr der Einheitsfront der deutschen Kraftfahrer vom 1.2.1934.

105 Vgl. dazu die zahlreichen Druckschriften, die sich in der Deutschen Bücherei in Leipzig befinden.

106 Vgl. das Schreiben des Inspekteurs Technik an die Reichsmotorsportschule vom 3. 2. 1939, BArch NS 24/94; IT an die ONS vom 3. 7. 1939 NS 24/80; IT an den Reichsverband der deutschen Zeitschriften-Verleger vom 25. 9. 1936, BArch NS 24/114. 
Die NSKK-Publizistik verfolgte neben dem Informationsauftrag zwei Ziele, die die inhaltliche Gestaltung des „NSKK-Mannes“ und der „Deutschen Kraftfahrt" in der gesamten Zeit ihres Erscheinens prägten: das Loblied auf die technische Errungenschaft Kraftfahrzeug mit dem Loblied auf den Nationalsozialismus zu verbinden und, anknüpfend an den Abenteuergeist und den Erlebnishunger der Mitglieder, soldatische Vorbilder zu entwerfen.

\section{Uniform}

Auch die Uniform der NSKK-Mitglieder übte eine Integrationsfunktion nach innen aus. Nach der Trennung von der SA wurde dem NSKK das Recht auf eine eigene Anzugsordnung zugestanden. Hitler erließ am 12. August 1935 eine Bekleidungsordnung für das NSKK. Danach blieb das Braunhemd der Große Dienstanzug. Auch entsprach die Farbe der Achselstücke der Farbe der SAGruppe, in deren Bereich die NSKK-Einheit lag. Dies geschah, wie die Korpsführung betonte, aus „Traditionsgründen und um der unlösbaren Verbundenheit mit der SA sichtbaren Ausdruck zu verleihen". 107

Die Uniformierung stellte das wesentliche Erkennungsmerkmal jeder Gliederung dar. Im Unterschied zur SA-Uniform waren sowohl die Kragenspiegel als auch die Hose, das Lederzeug und die Feldmütze bei der NSKK-Uniform schwarz. ${ }^{108}$ Am 1. Februar 1936 trug das gesamte Korps zum erstenmal die schwarzen Kragenspiegel. ${ }^{109}$ Das Dienstgradabzeichen war auf der linken und die Einheitsbezeichnung in weißen Metallbuchstaben und Ziffern auf der rechten Spiegelseite angebracht. Die Einheitsbezeichnung 22/M 29 stand z. B. für den Motorsturm 22 Berlin-Charlottenburg der Motorstandarte 29 Berlin. Auf Befehl Hühnleins wurden die Dolchhalter der Standard-SA-Dolche, die seit 1933 in Gebrauch waren, 1936 schwarz gefärbt. ${ }^{110}$ Die schwarzen Uniformstücke auf dem Braunhemd hatten eine von der SA abgesetzte Signalwirkung und gaben dem NSKK-Mann den Beinamen „braunschwarze Motorkämpfer“.111

Charakteristisch für das NSKK waren weiterhin das NSKK-Zeichen am Arm und an der Mütze und die Kraftfahrraute, die an den Uniformärmeln angebracht wurde. ${ }^{112}$ Sondereinheiten wie Musikzüge oder der Verkehrserziehungsdienst er-

107 NSKK-Korpsführung (Hrsg.): Anzugsordnung des NSKK. Neben den allgemeinen Abzeichen gab es Sonderabzeichen für Musik- und Spielmannszüge, für Ehrenführer und Adjutanten und zudem Armwinkel für Personen, die dem NSKK bereits vor dem 31. 12. 1932 angehört hatten. Vgl. zur Bekleidung und den Abzeichen auch: Organisationsbuch der NSDAP, 1936, S. 403-416.

108 Vgl. Oppermann: Unter den Sturmstandern, S. 130.

$109 \mathrm{Vgl}$. Verfügung des Korpsführers vom 25.11. 1935, betr. Anzugsänderung; BArch NS $24 / 2$.

$110 \mathrm{Vgl}$. Anweisung des NSKK-Organisationsamtes vom 1.4. 1936, betr. Schwarzfärbung von gebrauchten SA-Dolchscheiden; BArch NS 24/1.

111 Oppermann: Unter den Sturmstandern, S. 86. Vgl. auch das Lied „Ich bin des Dritten Reiches schwarz-brauner Stahlhusar"; Ostland-Treuefahrt (Druckschrift), S. 58.

112 Abzeichen und Raute wurden ab 1. 6. 1939 am rechten Oberarm getragen. Die Kraftfahrraute am linken Unterarm war nur für Männer, die einen Führerschein besaßen; Verordnungsblatt der Korpsführung vom 1.4. 1939: „NSKK-Armabzeichen und Kraftfahrraute“, BArch NSD 42/1. 
hielten besondere Zusatzabzeichen. Der Verkehrserziehungsdienst beispielsweise trug einen Ringkragen aus Weißblech. ${ }^{113}$

Die Anzugsordnung des NSKK erlaubte zwei spezielle Formen der Kopfbedeckung: zum einen das aus schwarzem Stoff gefertigte Schiffchen, das nach 1936 mit Dienstgradabzeichen versehen war, zum anderen einen schwarzen, ledernen Sturzhelm mit NSKK-Hoheitsabzeichen an der Stirnseite, der mit oder ohne Nackenschutz getragen wurde. ${ }^{114}$

\section{Öffentliche Auftritte}

Die schwarzen Sturzhelme mit Prallschutzstreifen erinnerten an die Kopfbedeckung der ersten Kradschützen der Reichswehr. ${ }^{115}$ Obgleich Fachleute die Zweckmäßigkeit des Helmes anzweifelten, wurde er von den Mitgliedern mit Stolz getragen. Es ging eine militärische Ausstrahlung von ihm aus, die einen nachhaltigeren Eindruck verbreitete als die einfachen SA-Mützen. ${ }^{116}$ Bilder von den Reichsparteitagen zeigen, dass der Vorbeizug von rund 12000 NSKK-Männern - zum Teil marschierend, zum Teil fahrend - zu den visuellen Höhepunkten der Massenkundgebung zählte. ${ }^{117}$ Versetzt man sich in einen Zuschauer dieser Zeit, für den motorisierte Kolonnen eine positive Faszination ausübten, dann erschien der Auftritt der Männer mit den schwarzen Helmen als eine Art modernes Gladiatorentum. Stand der Beobachter derartigen Aufzügen, z. B. bei sportlichen Veranstaltungen, ablehnend gegenüber, bewertete er die Aufmachung leicht als lächerliche Maskerade. „Wie ein zusammengewürfelter Haufen von Feuerwehrhelmen aus Leder" habe sich das NSKK nach Ansicht des Rennfahrers Manfred von Brauchitsch bei den Rennen präsentiert. ${ }^{118}$

Für den Aufbau einer eigenen Identität bemühte sich der Korpsführer, neben der Uniform zusätzliche Erkennungsmerkmale zu etablieren. Jede Motorgruppe des NSKK verfügte über einen eigenen Musik- und Spielmannszug, dessen Spezialität die Hörnermärsche waren. ${ }^{119}$ Korpsführer Hühnlein achtete penibel darauf, dass diese musikalische Tradition ihre Exklusivität behielt:

„So wie das Korps die traditionellen Gebräuche der anderen Gliederungen der Partei achtet, z. B. die dumpfen Trommeln der HJ, den Stechschritt der SS, die Trommelgriffe der Wachstandarte „Feldherrnhalle“ usw., beanspruche ich für das Korps, daß unsere Hörnermärsche von keiner anderen Gliederung nachgeahmt werden." 120

Korpsführer Hühnlein wusste, dass das öffentliche Auftreten zur Akzeptanz einer Gliederung beiträgt. Er mahnte anlässlich einer undisziplinierten Vorstellung

\footnotetext{
113 Vgl. Davis u. a.: Deutsche Uniformen im Dritten Reich 1933-1945, S. 113.

114 Vgl. ebenda.

115 Vgl. Erb: Kradschützen, S. 25.

116 Vgl. G. L. Wagener: Warum sollte ich verschweigen, S. $863 \mathrm{f}$., StadtA Hannover. Warum und zu welchem Zweck die Einziehung der Sturzhelme bis 8.6.1938 erfolgen sollte, ist unklar. Ablieferung nach Befehl vom 25. 4. 1938, BArch NS 24/60.

117 Vgl. G. L. Wagener: Warum sollte ich verschweigen, S. 651, StadtA Hannover.

118 Brauchitsch: Ohne Kampf, S. 59.

$119 \mathrm{Vgl}$. Schreiben des Chefadjutanten vom 21.8. 1937 und Anweisung des Korpsführers vom 2. 9. 1938, BArch NS 24/17.

120 Verfügung des Korpsführers vom 1. 12. 1937, BArch NS 24/279.
} 
bei der Heldengedenkfeier in Berlin am 12. März 1939, „nicht die Haltung“ zu verspielen, die man sich durch Leistungen in der Partei verdient habe. ${ }^{121} \mathrm{Um}$ nicht auf die Tagesform und den Übungswillen des durchschnittlichen Motorstürmers angewiesen zu sein, hielt das NSKK so genannte Lehrstürme bereit. Sie absolvierten Propagandafahrten und wurden als Fahrkommando für NS-Führer und für andere repräsentative Anlässe wie z. B. den Reichsparteitag eingesetzt. ${ }^{122}$ Die Lehrstürme der Motorgruppen Hochland, Franken, Ostmark und Hessen setzten sich aus rund 200 Männern zusammen, die speziell ausgewählt wurden und ein besonderes Übungsprogramm zu absolvieren hatten. Eine systematische Ausstattung dieser Vorzeigestürme mit Bekleidung und einem eigenen Fahrzeugpark erfolgte Anfang des Jahres 1938. ${ }^{123}$

\section{Ausstattung und Finanzierung}

Der Kraftfahrzeugpark, bestehend aus Dienstfahrzeugen der Breitengliederung und Inventar der Motorsportschulen des Korps, stellte einen erheblichen Teil des Korpsvermögens dar. Für seine Pflege und den Unterhalt wurden jährlich große Summen aufgewendet. ${ }^{124}$ In der Breitengliederung waren 1936 rund 1000 Dienstfahrzeuge, davon $70 \%$ Motorräder, im Einsatz. ${ }^{125}$ Die Fahrzeuge wurden entweder aus Mitteln der NSDAP und des NSKK angeschafft, von den Einheiten selbst erworben oder von Dritten gestiftet. ${ }^{126}$ Die Ausrüstung des Korps mit Fahrzeugen entwickelte sich langsamer als die schnell ansteigende Anzahl an Motorstürmen. Die Hälfte der 2200 Motorstürme blieb somit bis 1936 ohne ein einziges Dienstfahrzeug. Die Tatsache, dass andere Formationen der NSDAP im Vergleich zum NSKK ein Vielfaches an Dienstfahrzeugen in Betrieb hatten, war eine überaus peinliche Feststellung für die „motorisierte Gliederung der NSDAP“.127 Um das Defizit auszugleichen, setzte sich das NSKK für neue Ankäufe ein. Jeder Motorsturm sollte mindestens ein Solokrad zur Verfügung haben, so dass der Sturm-

121 Vgl. Schreiben des Korpsführers an die Stabsführung und die Höheren Führer vom 13. 3. 1939 (vertraulich), betr. Auftreten des NSKK bei der Helden-Gedenkfeier in Berlin am 12. 3. 1939 , BArch NS 24/156.

122 Anweisung des NSKK-Obergruppenführers Süd an den Führer der Motorbrigade Hochland vom 4. 8. 1936, BArch NS 24/428. Vgl. zu den Lehrstürmen auch die Akteneinheiten BArch NS 24/230 bis 234.

123 Vgl. ebenda.

124 Vgl. Schreiben des Chefstabsführers vom 26. 5. 1937, betr. Abstellung von korpseigenen Kraftfahrzeugen, BArch NS 24/2.

125 Vgl. NSKK-Korpsführung (Hrsg.): Das NSKK, S. 18. Diese Zahlen widersprechen der Erläuterung zum Beschaffungsplan an Dienstkraftfahrzeugen des NSKK vom 13.3. 1936. Danach hatte das Korps 1936922 Fahrzeuge im Einsatz, davon waren 544, also $59 \%$, Pkw; BArch NS 24/147.

126 Vgl. Erläuterung zum Beschaffungsplan an Dienstkraftfahrzeugen des NSKK vom 13. 3. 1936, BArch NS 24/147.

$127 \mathrm{Bis}$ zu sechsmal so viele Dienstfahrzeuge sollen andere Gliederungen besessen haben. Es geht aus der Klage der Korpsführung nicht hervor, welche anderen Gliederungen gemeint waren und ob dies in absoluten Zahlen oder in Relation zur Mitgliederzahl gerechnet wurde; vgl. ebenda. 
führer den Sturm beaufsichtigen konnte. ${ }^{128}$ Die Dienststellen der Staffeln und Stürme wurden mit Motorrädern versorgt, die Standarten, Brigaden und Ämter der Korpsführung erhielten zudem noch Autos. ${ }^{129}$ Für die Jahre 1936 bis 1938 wurden knapp 3,5 Millionen RM für die Beschaffung neuer Kraftfahrzeuge bereitgestellt. ${ }^{130}$ Die Anzahl der korpseigenen Fahrzeuge erhöhte sich bis August 1938 auf 2757 Fahrzeuge. Darunter waren 1981 Solo-Kräder, 326 Beiwagenmaschinen, 231 Autos, 67 Kübelsitzwagen, 49 Lkw und 103 Feldküchen. ${ }^{131}$ Dort, wo die Dienstfahrzeuge zum Üben verwandt wurden, hatte die Anschaffung den positiven Nebeneffekt, dass nach Erfahrung der Korpsführung auch die Dienstfreude in den Motorstürmen stieg. ${ }^{132} \mathrm{Obwohl}$ es viele Gründe gab, die dafür sprachen, den Fahrzeugbestand zu erhöhen, stand ein solches Ansinnen im Gegensatz zu der finanziellen Leistungsfähigkeit des Korps. Bereits im Juli 1936 teilte der Inspekteur für technische Ausbildung und Geräte mit, dass Unterhaltskosten für weitere Pkw nicht aufgebracht werden könnten. ${ }^{133}$ Es wurde den Stürmen deshalb verboten, Fahrzeugschenkungen entgegenzunehmen oder Privatfahrzeuge gegen Erstattung der Kosten einzusetzen, da die Unterhaltskosten den sachlichen Haushalt zu stark belasteten. Ab 15. April 1937 durften nur Fahrzeuge dienstlich verwendet werden, die eine Dienstfahrzeug-Bestätigung hatten. ${ }^{134}$

Auch wenn 1938 rund 2800 Dienstfahrzeuge zur Verfügung standen, waren es doch zu wenige, um den rund 200000 Mitgliedern, von denen viele über kein eigenes Fahrzeug verfügten, praktische Erfahrungen zu vermitteln oder geländesportliche Aktivitäten zu bieten. Hätte das NSKK für die fahrtechnische Ausbildung nicht auf die Fahrzeuge von Mitgliedern zurückgreifen können und für den Motorsport auf die Leihgaben der Automobil- und Motorradindustrie, wäre das NS-Kraftfahrkorps seinem Namen nicht im Geringsten gerecht geworden. Ohne die Leihgaben der Deutschen Reichsbahngesellschaft hätte das NSKK 1936 außerdem keine wirksame Unterstützung der Wahlpropaganda und ohne die Fahrzeuge der Reichspost keine Transportaufgaben im Rahmen der Reichsparteitage übernehmen können. ${ }^{135}$ Die Einnahmen des NSKK und die Zuschüsse aus

$128 \mathrm{Vgl}$. ebenda; Motorstandarte 95. Dienstfahrzeuge, Stand vom 25. 11. 1937, BArch NS 24/ 1.

129 Schreiben der Motorbrigade Franken an die Motorstandarte 77 vom 28. 2. 1936, BArch NS 24/7.

$130 \mathrm{Vgl}$. Beschaffungsplan an Dienstkraftfahrzeugen des NSKK 1936, 1937, 1938; BArch NS 24/147.

$131 \mathrm{Vgl}$. Zusammenstellung über die Anzahl der korpseigenen Fahrzeuge vom 1.1.1938 und 31. 8. 1938, BArch NS 24/99. Eine andere Zusammenstellung vom 1. 1.1938 beziffert die Zahl der korpseigenen Dienstfahrzeuge auf 3630. Die Finanzierung stammte zum überwiegenden Teil aus Mitteln der Korpsführung, zum kleinen Teil aus der Breitengliederung; Schreiben des Inspekteurs Technik an den Korpsführer vom 31. 8. 1938, betr. Auswertung der Halbjahresberichte 1. 4. 1938 - 30. 9. 1938, BArch NS 24/100.

132 Vgl. Zusammenstellung über die Anzahl der korpseigenen Fahrzeuge vom 1.1.1938 und 31. 8. 1938, BArch NS 24/99.

133 Vgl. Schreiben der Motorbrigade Franken an die Motorstandarten vom 1. 7. 1936, BArch NS 24/7.

134 Vgl. Verfügung des Korpsführers vom 8. 3. 1937, BArch NS 24/1.

$135 \mathrm{Vgl}$. Schreiben des Korpsführers an die Gauleiter der NSDAP vom 11. 3. 1936, betr. Ein- 
Reichsmitteln reichten für die Aufstellung und den Unterhalt eines wirklich gut bestückten Fuhrparks nicht aus. Die Definition des NSKK als "motorisierte Kraft der Partei" blieb in Bezug auf die Ausstattung mit Dienstfahrzeugen propagandistisches Wunschdenken.

Widersprüche innerhalb der nationalsozialistischen Motorisierungspolitik wurden auch bei der Verwendung der Dienstwagen der Partei deutlich. Der Vierjahresplan sah eine sparsame Verwendung von Treibstoff und Kautschuk vor. Um die Reifen zu schonen, sollten ab September 1936 die Dienstfahrzeuge des Korps nicht schneller als $80 \mathrm{~km} / \mathrm{h}$ fahren. ${ }^{136}$ Außerdem ordnete der Reichsschatzmeister im August 1937 an: „Im Stadt- und Überlandverkehr dürfen Dienstkraftwagen zu Dienstfahrten nur benutzt werden, wenn und insoweit öffentliche Verkehrsmittel zu diesem Zweck nicht zur Verfügung stehen. "137 Durch die für die Zeitgenossen unbegreifliche Direktive, die Führer des Kraftfahrkorps sollten sich mit öffentlichen Verkehrsmitteln fortbewegen, drohte der Vereinigungszweck des NSKK ad absurdum geführt zu werden. Was heute als Zeichen von Umweltbewusstsein gewertet würde, stellte dem Propagandisten der Motorisierung, der selbst unter Fahrzeugmangel und den Benutzungsbeschränkungen zu leiden hatte, ein Armutszeugnis aus.

Laut offizieller Darstellung schuf das NSKK „aus eigener Kraft" beträchtliche Vermögenswerte in Gestalt von Schulen, Dienststellen, Sturmheimen und Fahrzeugparks. 138 Über eigene Beiträge wäre jedoch keiner der genannten Vermögenswerte, vielleicht mit Ausnahme der Sturmheime, finanzierbar gewesen. Der Monatsbeitrag für Mitglieder mit Kraftfahrzeug betrug $1 \mathrm{RM}$, für Motorradbesitzer oder fahrzeuglose Mitglieder 50 Pfennig. Ab Oktober 1934 bezahlten Nichtparteigenossen einen Sonderbeitrag von 1 RM. Die Korpsbeiträge und Nichtparteigenossenbeiträge wurden an die Korpsführung abgeführt. Nichtparteigenossenbeiträge stellten bis 1937, als der größte Teil der Angehörigen des Korps nach Lockerung der Aufnahmesperre in die NSDAP aufgenommen wurde, einen wesentlichen Teil der Einnahmen dar. ${ }^{139}$

Der Reichskassenverwalter des NSKK überwies Personal- und Sachmittel an die Verwaltungsdienststellen der Motorobergruppe, der Motorgruppe und der Standarten. Die Motorgruppen bzw. -brigaden überwiesen einen festgelegten $\mathrm{Be}$ trag, unterteilt in sachlichen und persönlichen Haushalt, an die Motorstandarten, Staffeln und Stürme.140 1938 erhielt jeder Sturm von der Motorgruppe 120 RM sowie Benzinzuschüsse. 141

satz des NSKK für den Wahlkampf, BArch NS 24/275; Müller: Hitlers motorisierte Stoßarmee, S. 195.

136 Vgl. Mitteilung des Korpsführers vom 7. 9. 1936, BArch NS 24/92.

137 Der Reichskassenverwalter des NSKK gab mit Schreiben vom 26. 8. 1937 die Anordnung des Reichsschatzmeisters vom 16. 8. 1937 zur Kenntnis, BArch NS 24/1.

138 Vgl. Krenzlin: Das NSKK, S. $34 \mathrm{f}$.

139 Vgl. Schreiben der Kassenverwaltung vom 1.7. 1937, betr. Nichtparteigenossenbeiträge, BArch NS 24/1.

140 Vgl. Krenzlin: Das NSKK, S. 34 f. Die Standarte erhielt 3811 RM, die Staffeln je 360 RM und die Stürme 70 RM für den sachlichen und 40 für den persönlichen Haushalt; vgl. Schreiben der Motorbrigade Franken an die Verwaltungsdienststelle der Motorstandarte 
Zusatzeinnahmen konnte der Sturm durch die Beiträge seiner Korpsangehörigen verbuchen. Fördernde Mitglieder zahlten mindestens $1 \mathrm{RM}$, wenn sie der Partei, einer anderen Gliederung oder einem der gleich gestellten Verbände (RAD, NSFK) angehörten. Fördermitglieder, die nicht politisch organisiert waren, bezahlten mindestens 2 RM und verpflichteten sich, den "NSKK-Mann" oder die „Deutsche Kraftfahrt" zu abonnieren. Der betreuende Motorsturm erhielt 50\% der Korpsangehörigenbeiträge. ${ }^{142}$ Zur Vereinfachung verblieben ab 1. September 1939 die Korpsbeiträge und die Angehörigenzahlungen beim Sturm. ${ }^{143}$ Die Motorstürme überwiesen am Ende jeden Quartals Geldbeträge, die 150 RM überstiegen, auf das Konto der NSKK-Korpsführung. ${ }^{144}$

Tatsächlich wäre es ohne erhebliche staatliche und private Zuwendungen nicht möglich gewesen, die Arbeit des NSKK auf gesellschaftliche Bereiche auszudehnen. Das NSKK finanzierte sich über Gelder aus dem Reichsetat. ${ }^{145}$ Dazu kamen Zuschüsse der Industrie und des Deutschen Automobilclubs (DDAC) für besondere Projekte und Einrichtungen des NSKK. ${ }^{146}$

\section{Die Schulung der Breitengliederung: Der Dienst im Motorsturm}

Die kleinsten Einheiten und politischen Keimzellen des NSKK waren die Motorstürme. Dort fand das gemeinschaftliche Leben des Korps statt und erhielten die Mitglieder eine Ausbildung durch den Sturmführer ${ }^{147}$ und ehrenamtliche Referenten. In einer Verfügung des Korpsführers vom 28. April 1936 heißt es über Sinn und Zweck der Stürme: „Der Motorsturm ist die unterste, aber wichtigste Einheit der Breitengliederung. Im Motorsturm wird das weltanschauliche Leben gehegt und gepflegt, das motortechnische Können gefördert, die Begeisterung für den Motorsport geweckt." 148

77 vom 5. 1. 1937, BArch NS 24/6. Die Verwaltungsdienststellen der Motorstaffeln wurden mit Wirkung vom April 1937 aufgelöst und das Vermögen verteilt; vgl. Mitteilung der Kassenverwaltung des NSKK vom 27.4. 1937 und Schreiben des NSKK-Chefstabsführers vom 28. 5. 1937, BArch NS $24 / 1$.

141 Vgl. Schreiben der Motorbrigade Franken an die Verwaltung vom 9. 6. 1937 und der Motorgruppe Franken an die Motorstandarte 95 vom 17.1. 1938, BArch NS 24/46.

142 Vgl. Korpsbefehl Nr. 20a vom 23. 3. 1938, BArch NSD 42/9.

143 Gemäß der Verfügung des Korpsführers vom 30. 9. 1939, BArch NS 24/26.

$144 \mathrm{Vgl}$. Mitteilung des Reichskassenverwalters an die Verwaltungsführer vom 13.4. 1940, BArch NS 24/28.

145 So das Verordnungsblatt der Korpsführung München vom 15. 8. 1935: „Finanzierung“, IfZ $\mathrm{Db}$ 30.01. Dennoch bestehen Unklarheiten bezüglich der Finanzabläufe innerhalb des Korps. Fragen nach der Höhe der Reichsmittel, nach den Spendeneingängen, nach den direkten Zuweisungen an die Motorgruppen usw. müssen aufgrund fehlender Quellen offen bleiben.

146 Vgl. allgemein: Müller: Stoßarmee, S. 195. Zur Finanzierung der NSKK-Einrichtungen vgl. S. 224 und $263 \mathrm{f}$. sowie das Kapitel „Die Beziehungen zwischen Automobilindustrie und NSKK" dieser Arbeit.

147 Das Personalamt legte im August 1937 fest: Die Voraussetzungen für die Ernennung zum Sturmführer sind eine mindestens zweijährige Führung eines Motorsturms, die Parteimitgliedschaft und der Dienstgrad „Sturmführer“; Verordnungsblatt der Korpsführung vom 1. 9. 1937, IfZ $\mathrm{Db} 30.01$.

148 Verfügung des Korpsführers vom 28. 4. 1936, betr. Sturmdienst, BArch NS 24/2. 
Die Kopfstärke eines Sturmes sollte 100 Dienst tuende Männer nicht unterschreiten, doch gab es auch Stürme, die bis zu 150 Mann stark waren. ${ }^{149}$ Ein- bis zweimal in der Woche trafen sich die aktiven Mitglieder zum Sturmabend, dazu kamen Übungsfahrten am Wochenende. ${ }^{150}$ Der Sturmwart war für die reibungslose Durchführung des Dienstes verantwortlich. ${ }^{151}$ Der Dienst im NSKK erstreckte sich auf die Übungsbereiche: Kolonnenfahren, Kartenkunde, Märsche, Turnspiele, Kleinkaliberschießen, Sport, Verkehrserziehung, technisches und ideologisches Grundwissen. ${ }^{152}$

Höhepunkt im Sturmleben war die Verleihung und Weihe des Sturmstanders. Damit wurde der Sturm gleichberechtigt in die Reihe der Stürme aufgenommen. Die Weihe fand zumeist an großen Gedenktagen der Bewegung statt und wurde von Propagandafahrten, motorsportlichen Veranstaltungen und Konzerten begleitet. ${ }^{153}$ Neben den Standerweihen waren auch die Vereidigungen der NSKKAnwärter durch den Standartenführer jeweils am 20. April und am 9. November Anlass für lokale Feiern. ${ }^{154}$ Verantwortlich für die einheitliche Ausbildung in der Breitengliederung war ab 1937 der Inspekteur für Ausbildung. Er erstellte Richtlinien für den Dienst und regelte die Aus- und Fortbildung der Führer und des Führernachwuchses. ${ }^{155}$

Die Antrittsstärke der Motorstürme war nicht einheitlich und abhängig vom Gemeinschaftsleben und der Arbeitsbelastung der Mitglieder im Sturm. Die Motorbrigade Kurpfalz-Saar meldete für das 1. Halbjahr 1937 eine gute Antrittsstärke von $75 \%$ bis $90 \%$. Besonders bei den jüngeren Mitgliedern kamen Motorsport und Verkehrserziehung sehr gut an. „Alten Parteigenossen“ missfiel indes der militärische Dienst und die Unterweisungen, die sie als schablonenhaft und langweilig empfanden. ${ }^{156}$

Ab 1935 erhielt das NSKK wie die SA das Recht und die Pflicht, jährliche Reichswettkämpfe innerhalb des Korps durchzuführen. Ziel dieser Wettbewerbe

149 Vgl. die Weisung des Korpsführers an die Kraftfahr-Inspekteure vom 4. 10. 1934, BArch NS 24/112. Die Mitgliederstärke schwankte jedoch häufig zwischen 80 und 150 Mitgliedern; vgl. Aufbau der Motorstandarte M 86 München, BArch NS 24/19; Stärkemeldungen der Motorstürme 16/M 77, 17/M 77, 19/M 77 der Staffel II/M 77 (Coburg) vom März 1934, BArch NS 24/3.

150 Die Ausbildungsinhalte, die pro Monat vermittelt und geübt werden sollten, wurden auf vier bis sechs Wochentage und zwei Tage am Wochenende verteilt, Ausbildungsplan der M 77 vom Mai 1936, BArch NS 24/537; NSKK-Korpsführung (Hrsg.): Das NSKK, S. 7; Mitteilungen für Motorsturm 12/M 31, 1939, Deutsche Bücherei Leipzig, ZA 27457. Im Krieg wurde der Dienst eingeschränkt; vgl. Mitteilungen für Motorsturm 12/M 31, 1940, ebenda.

151 Vgl.Verfügung des Korpsführers vom 28. 4. 1936, betr. Sturmdienst, BArch NS 24/2.

152 Vgl. NSKK-Korpsführung (Hrsg.): Ausbildungsheft, BArch NS 24/52; Ausbildungsplan der M 77 vom Mai 1936, BArch NS 24/537.

$153 \mathrm{Vgl}$. Standerweihe des Eberswalder Motorsturms 1/M 207 am 16. 7.1933 in Freienwalde, BLHA Potsdam, Rep. 61 C Nr. 370; Verfügung des Korpsführers vom 30. 6. 1938, betr. Verleihung und Weihe von Sturmstandern, BArch NS 24/331.

154 Vgl. Aktivitäten der Motorstandarte 78 im November 1936, BArch NS 24/2.

155 Vgl. Korpsbefehl 25 vom 15.11. 1937, BArch NSD 42/9; Krenzlin: Das NSKK, S. 38 f.

156 Vgl. 1. Halbjahresbericht 1936 der Motorbrigade Kurpfalz-Saar an die Motorobergruppe Süd, LA Speyer, T 65 Nr. 66. 
war es, die Dienstfreude und die Einsatzbereitschaft der Stürme zu ermitteln und nötigenfalls zu steigern. ${ }^{157}$ Die Motorstürme dokumentierten über das ganze Jahr hinweg die sportlichen, technischen und dienstlichen Leistungen der Aktiven. 158 Dazu kamen besondere Leistungsprüfungen, die das weltanschauliche Wissen der Mitglieder, die körperliche Fitness und die Verkehrsregeln abfragten. ${ }^{159}$ Motorstürme, die besonderes Engagement zeigten, erhielten die Auszeichnung „Siegerstürme“. Diese Art Leistungsanreiz war ein geeignetes Mittel, um den Ausbildungsstand insgesamt zu erhöhen, doch wurde die Einführung nicht überall positiv aufgenommen. Der damalige NSKK-Gruppenführer Wagener kommentierte nach dem Krieg, dass der Reichswettkampf etwas für die "gedemütigte SA “ gewesen sei, mit dessen Einführung das NSKK von der Öffentlichkeit „in die Nähe des Überflüssigkeitskomplexes der SA gerückt" wurde. ${ }^{160}$

\section{Ausbildungsinhalte}

Korpsführer Hühnlein beschrieb 1938 das NSKK als Zusammenschluss von Führern und Männern, die technisch und handwerklich geschult, sportlich gestählt und geistig ganz im Sinne des "Führers" ausgerichtet seien. ${ }^{161}$ Die Ausbildungsschwerpunkte dokumentieren den Versuch, dieses Ideal zu erreichen:

Ein wichtiges Element des Dienstes war die sportliche Ertüchtigung. Der Korpsbefehl vom 24. Oktober 1934 setzte die Richtlinien für den NSKK-Dienst fest. Einmal in der Woche trafen sich die aktiven Mitglieder zum Sturmdienst, der unter der Maxime stand: „Jede Übung muß ihn [den NSKK-Mann] körperlich und sportlich für das Vaterland ertüchtigen. "162 Zu den sportlichen Übungen zählten Marschieren, Kolonnenfahren, Kleinkaliberschießen und der Geländewehrsport. Anfänglich wurden die Geländeübungen des NSKK als „Sportveranstaltungen“ bezeichnet, da keine Berichterstattung über militärische Übungen erfolgen sollte. ${ }^{163}$ Sport im NSKK gliederte sich in Wehrsport und Kraftfahrsport. Der Wehrsport diente der körperlichen Ertüchtigung des NSKK-Mannes. Er erfolgte nach den Richtlinien des SA-Sportabzeichens. Das NSKK führte die Ausbildung und Prüfung zum Erwerb des Abzeichens und die Wiederholungsübungen selbständig durch. ${ }^{164}$ Das SA-Sportabzeichen war der Gradmesser für die körperliche

157 Vgl. Krenzlin: Das NSKK, S. 38f.

158 Der Bewertungsbogen für den Reichswettkampf 1936/1937 umfasste: A Innendienst: Räumlichkeiten, Innerer Dienst (Schriftwechsel, Briefbuch, Verwaltung), Pflege des Korpseigentums, Antrittsstärke und Fürsorgedienst; B Außendienst: Sturmappell und Ausbildungsstand; C Motor HJ; BArch NS 24/172.

159 Vgl. Durchführungsbestimmungen des Korpsführers, betr. Reichswettkampf 1937/38 vom 4. 12. 1937, BArch NS 24/56; Reichswettkampf des NSKK 1935/1936, BArch NS $22 / 545$.

160 G. L. Wagener: Warum sollte ich verschweigen, S. 641, StadtA Hannover.

161 Vgl. Bamberger Tageblatt vom 30. 3. 1938: „Die Motorisierung der deutschen Nation“ von Korpsführer Hühnlein.

162 Korpsbefehl Nr. 11 vom 24. 10. 1934, BArch NSD 42/9.

$163 \mathrm{Vgl}$. Schreiben des Pressereferenten der Staffel 207 an den Staffelführer vom 30. 11. 1933, betr. Richtlinien für die Pressereferenten, BLHA Potsdam, Rep. 61 C Nr. 370.

164 Das SA-Sportabzeichen konnte im Rahmen des allgemeinen Sturmdienstes, im Laufe von drei Monaten, erworben werden. Die Prüf- und Lehrscheine für die Ausbildung erhielten 
Leistungsfähigkeit der Mitglieder. Innerhalb der Motorstandarte München 86 hatten 1939 nur 27,5\% der Männer ihren Fitnesstest erfolgreich absolviert. ${ }^{165}$

Der Kraftfahrsport war ein wichtiges Betätigungsfeld des NSKK. Er gliederte sich in den Geländekraftfahrsport und in den Rennsport der Obersten Nationalen Sportbehörde. ${ }^{166}$ Nach den Richtlinien des Amtes Kraftfahrsport der Korpsführung führten die Motorgruppen alljährlich zahlreiche kraftfahrsportliche Veranstaltungen durch. Sie waren in die Sparten Gelände-, Orientierungs- und Zuverlässigkeitsfahrten unterteilt.167 Die sportlich rege Motorbrigade Kurpfalz-Saar veranstaltete zum Beispiel im 1. Halbjahr 1936 sieben Wettbewerbe. ${ }^{168}$ Bei den Veranstaltungen wetteiferten die Fahrer des NSKK mit denen der SA, der SS, des NSFK, der Wehrmacht, des DDAC, der Reichspost, der Reichsbahn und der Industrie um den Sieg. ${ }^{169}$

Der intern betriebene Kraftfahrsport im NSKK sollte weder Selbstzweck sein noch dem Vergnügen dienen, sondern war als „Lehrmeister für die motorische Wehrertüchtigung des deutschen Mannes" 170 gedacht. In den Stürmen unternahmen die Mitglieder mit dem Kraftfahrzeug, zumeist mit Leichtkrafträdern, einmal in der Woche einen allgemeinen Übungsabend, an dem auch Verkehrsunterricht und Fahrzeugtechnik auf dem Programm standen. Ein Sonntagvormittag im Monat war für den Motorgeländesport reserviert. Maßgeblich für den Geländesport war die Ausbildungsvorschrift "Winke für den Geländesport" (Berlin 1933). Im Vorwort heißt es: „Der eigentliche Motorsport im NSKK ist Spezialausbildung für Kraftfahrer aller Art, wie sie der Dienst am Motor im modernen Heer erfordert." Bereits 1933 war also zu erkennen, dass das NSKK seine Mitglieder sportlich und kraftfahrtechnisch ausbilden wollte, um den Anforderungen, die der moderne Krieg an die Militärkraftfahrt stellte, zu genügen. Im Sturmalltag fehlte jedoch häufig die Zeit für sportliche Übungen und Wettbewerbe, da das Training für den Reichswettkampf und die Teilnahme an Aufmärschen der Partei viel Zeit in Anspruch nahm. Außerdem, so berichtet ein Münchner Staffelführer, halte die Mitglieder die Angst vor teuren Reparaturen vom wagemutigen Geländesport ab. ${ }^{171}$

Kennzeichnend für das NSKK war neben dem Kraftfahrsport auch die motortechnische und handwerkliche Ausbildung, die im Gesamtausbildungsplan eine wesentliche Rolle spielte. Wo vorhanden, fand der Unterricht über Aufbau und Funktionsweise des Motors, sparsames Fahren und Reparaturen in technischen

NSKK-Führer auf Lehrgängen der SA, vgl. Anordnung des Korpsführers vom 21. 3. 1937 und Vereinbarung zwischen Stabschef der SA und Korpsführer vom 15. 3. 1937, betr. SA-Sportabzeichen, BArch NS 24/52.

165 Vgl. Stärkemeldung der M 86 vom 1. 8. 1939, BArch NS 24/65.

166 Vgl. Verordnungsblatt vom 1.2.1937 (München): „Sport im NSKK“.

167 Vgl. NSKK-Korpsführung (Hrsg.): Das NSKK, S. 9 f.

168 Vgl. 1. Halbjahresbericht 1936 der Motorbrigade Kurpfalz-Saar an die Motorobergruppe Süd, LA Speyer, T 65 Nr. 66.

169 Vgl. Krenzlin: Das NSKK, S. 37.

170 Ebenda.

171 Vgl. Halbjahresbericht der Motorstaffel II /M 86 an die Motorstandarte 86 vom 25.6. 1936, BArch NS 24/16. 
Lehrräumen statt. ${ }^{172}$ Doch war 1938 bei der überwiegenden Zahl der Motorstandarten keine Lehrwerkstätte vorhanden und der Zugang zu Industrie- und Handwerksstätten beschränkt. Insgesamt standen im Reichsgebiet 398 Werkstätten plus 30 bis 40 Werkstätten der Deutschen Reichspost zur Verfügung. ${ }^{173}$ Der Mangel an Lehrsälen wurde durch mobile Werkstätten ausgeglichen. Allen 22 Motorgruppen und -brigaden war 1936 jeweils ein Werkstattzug zugeteilt. ${ }^{174}$ Die mobilen Werkstattzüge dienten der technischen Überwachung der Dienstfahrzeuge und der handwerklichen Schulung der Männer in den Motorstürmen und der Jungen in den Motorsportscharen der $\mathrm{HJ} .{ }^{175}$ Soweit es ging, vermittelten ehrenamtliche technische Referenten in den Motorstürmen unter Einsatz von Lehrtafeln und Lehrfilmen technisches und handwerkliches Können. ${ }^{176}$ Die technische Ausbildung war an der Basis oftmals schwer durchzuführen, da der vorhandene Fahrzeugbestand klein war. ${ }^{177}$

Auch wenn die praktische Ausbildung im Fahren und Reparieren nicht allzu intensiv betrieben werden konnte, herrschte bei den Stürmen kein Mangel an Beschäftigung. $\mathrm{Zu}$ den wichtigen Unterrichtseinheiten, die auch theoretisch zu vermitteln waren, zählte die Verkehrserziehung. Jeder NSKK-Mann sollte Vorbild im Straßenverkehr sein. Um dies zu erreichen, stellte man den Motorstürmen vielfältiges Schulungsmaterial, bestehend aus Verkehrserziehungstafeln, Büchern, Verkehrsmodellen und Verkehrszeichen, zur Verfügung. ${ }^{178}$ An so genannten Verkehrstischen konnte man Verkehrssituationen praxisnah nachstellen. ${ }^{179}$

$\mathrm{Zu}$ den konstitutiven Elementen der Ausbildung in den Motorstürmen zählte die weltanschauliche Schulung. Sie beinhaltete NS-Propaganda zu den Themen: "Geschichte der NSDAP und des NSKK“, „Bolschewismus und Judentum“, "NS-Bevölkerungspolitik“ und „Vierjahresplan". 180 Alle vier Wochen fand ein Pflicht-Kameradschaftsabend zur Bekanntgabe wichtiger Befehle und zur Pflege der Tradition statt. An diesem Abend wurden die Mitglieder durch Abgesandte des Reichsschulungsleiters der NSDAP in nationalsozialistischer Weltanschauung unterrichtet. ${ }^{181}$ Im Sturm 4/M 86 (München) wurden 1938 zehn Schulungsvor-

172 Vgl. NSKK-Korpsführung (Hrsg.): Das NSKK, S. 7 f.

173 Vgl. Schreiben des Inspekteurs Technik an den Korpsführer vom 31. 8. 1938, betr. Auswertung der Halbjahresberichte 1.4. 1938 - 30. 9. 1938, BArch NS 24/100.

174 Vgl. NSKK-Korpsführung (Hrsg.): Das NSKK, S. 17.

175 Vgl. Bericht: Technik im Korps, BArch NS 24/220.

176 Vgl. Krenzlin: Das NSKK, S. 41.

177 Vgl. 1. Halbjahresbericht 1936 der Motorbrigade Kurpfalz-Saar an die Motorobergruppe Süd, LA Speyer, T 65 Nr. 66.

178 Vgl. Verordnungsblatt der Korpsführung vom 1. 12. 1937, betr.: Schulungsmaterial für Verkehrserziehung, IfZ Db 30.01. Vgl dazu das Kapitel „Das Ideal: Verkehrssicherheit auf den Straßen des, Dritten Reiches““.

179 Vgl. Verordnungsblatt der Korpsführung vom 15. 5. 1937, betr. Verkehrstische, IfZ Db 30.01 .

$180 \mathrm{Vgl}$. NSKK-Korpsführung (Hrsg.): Ausbildungsheft.

181 Auf Anordnung der Reichsleitung übernahm der Reichsschulungsleiter der NSDAP 1935 die weltanschauliche Schulung des Korps, das heißt, eine eigenverantwortliche Betätigung des Korps war in diesem Bereich nicht mehr möglich; vgl. Ankündigung des Korpsführers vom 14. 6. 1935, BArch NS 24/274. 
träge zu Themen „aktuellerer Art, wie die Judenfrage in Verbindung mit der Rassenlehre" gehalten. ${ }^{182}$ Für das Gebiet der weltanschaulichen Schulung und Erziehung wurden bei den Motorgruppen bis hinunter zu den Motorstürmen Schulungsreferenten eingesetzt, die in Verbindung mit den Gauschulungsämtern standen. ${ }^{183}$ Dazu traten noch die weltanschaulichen Referenten der Stürme und die NSKK-Führer, die auf den NSKK-Führungsschulen und von den Gauschulungsämtern weltanschaulich geschult wurden und die nationalsozialistische Ideologie weitergaben. Die Presseorgane des NSKK, „Der NSKK-Mann“ und die „Deutsche Kraftfahrt", förderten insbesondere in ihren Leitartikeln die Verbreitung nationalsozialistischen Gedankengutes. ${ }^{184}$

Anzunehmen ist, dass in der Praxis das Maß an politischer und ideologischer Indoktrination sehr unterschiedlich war. Die Motorbrigade Kurpfalz-Saar betrieb 1936 die weltanschauliche Ausbildung sehr intensiv. Sie erstreckte sich auf den Besuch politischer Versammlungen der Partei, Schulungsabende innerhalb der Stürme und Trupps, Besuch von Veranstaltungen der NS-Kulturgemeinde und die Teilnahme an weltanschaulichen Lehrgängen der NSDAP. Die Männer zeigten nach Einschätzung der Brigadeführung großes Verständnis und Interesse für diese Themen. ${ }^{185}$ Bei Dienstkontrollen der Stürme durch höher gestellte Einheiten wurde regelmäßig das „weltanschauliche Wissen“ abgefragt. ${ }^{186}$

Jedes NSKK-Mitglied war sich bewusst, dass „Mangel an nationalsozialistischer Gesinnung" Grund für eine Dienstenthebung und Entlassung war. ${ }^{187}$ Dies machen die folgenden Beispiele aus dem Dienstalltag deutlich: Motor-SA-Männer wurden im Februar 1934 aufgefordert, nationalsozialistische Tageszeitungen zu lesen. Wer sich weigerte, eine NS-Tageszeitung zu bestellen, obwohl er eine andere Zeitung las, war sofort auszuschließen. ${ }^{188}$ Der Inspekteur Technik erließ das Verbot, dass Bestellungen für das Korps oder die Motorsportschulen in Betrieben getätigt wurden, in denen Juden beschäftigt waren. ${ }^{189}$ Ein NSKK-Sturmmann wurde unehrenhaft entlassen, weil er das Geschäft eines Juden betreten und sich bei diesem für antijüdische Vorfälle entschuldigt hatte. ${ }^{190}$ Ein Staffelbefehl for-

182 Bericht des Sturms 4/M 86 an die M 86 vom März 1939, betr. Reichswettkampf, BArch NS 24/412.

183 Vgl. Krenzlin: Das NSKK, S. 29.

184 Vgl. Der NSKK-Mann vom 10. 12. 1938: „Deutsche Kraftfahrt ohne Juden“ und vom 26. 11. 1939: „Der Weltjude schreit“. Als die Zeitung „Der NSKK-Mann“ in einem Artikel von 1938 gegen „jüdisch beeinflusste Unternehmen“ polemisierte, protestierte der Vorsitzende des RDA Allmers. Korpsführer Hühnlein nahm die Redaktion mit dem Hinweis in Schutz, es habe nicht nur auf dem Gebiet der Presse eine „Verjudung" gegeben; Schreiben von Hühnlein an Allmers vom 1. 4. 1938, BArch NS 24/675.

185 Vgl. 1. Halbjahresbericht 1936 der Motorbrigade Kurpfalz-Saar an die Motorobergruppe Süd, LA Speyer, T 65 Nr. 66.

186 Dienstkontrollberichte, BArch NS 24/360.

187 Vgl. Entscheidungen der Korpsführung Berlin, Amt für Gnadensachen, 1940, BArch NS 24/64.

$188 \mathrm{Vgl}$. Staffelbefehl der Motorstaffel II/M 77 vom 7. 2. 1934, BArch NS 24/3.

189 Schreiben des Inspekteurs Technik an die MSS Südwest vom 24. 3. 1936, betr. Marx und Traube, BArch NS 24/490.

$190 \mathrm{Vgl}$. Staffelbefehl der Motorstaffel II/M 77 vom 26. 1. 1935, ebenda. 
derte die NSKK-Mitglieder 1935 auf, Verbindungen mit Juden abzubrechen, da der Jude nicht in die deutsche „Volksgemeinschaft" gehöre. ${ }^{191}$

Sowohl die allgemeine weltanschauliche Schulung, die judenfeindliches Denken und Handeln begründete und lancierte, als auch die Anweisungen an die NSKK-Mitglieder, keine geschäftlichen und persönlichen Beziehungen zu Juden zu unterhalten, entsprachen in jeder Hinsicht der nationalsozialistischen Normsetzung.

\section{Selbstverständnis und Ziele des NSKK}

„Das Nationalsozialistische Kraftfahr-Korps ist der Banner- und Willensträger des Motorisierungsgedankens im neuen Deutschland und erfüllt ihn mit dem vorausstürmenden Geist des Nationalsozialismus, [...]."192 Diese Definition machte das NSKK als Werbeträger der Motorisierung kenntlich und schrieb ihm einen gesellschaftlichen Auftrag zu. ${ }^{193}$ Das Selbstverständnis des NSKK basierte jedoch nicht nur auf diesem Auftrag, sondern beinhaltete mehrere Identitäten, die den Kategorien politische Kampfgliederung, Wehrsportgruppe, Schulorganisation und Transportverband zuzuordnen sind. Da das NSKK daraus Ziele entwickelte, Aufgaben ableitete und seinen Dienst gestaltete, ist es wesentlich, diese Identitäten darzustellen.

\section{Das politische Selbstverständnis}

Da der Motorisierungsgedanke nach Auffassung des NSKK mit der nationalsozialistischen Weltanschauung korrespondierte, konnte diese Aufgabe folglich nur einer nationalsozialistischen Organisation übertragen werden. Aus diesem Grund legte die Korpsführung Wert auf die Feststellung, dass das NSKK keine simple Vereinigung von Kraftfahrzeugbesitzern sei, sondern ein Zusammenschluss von Nationalsozialisten. Der Vereinigungszweck lautete demgemäß: „Das Korps ist die Organisation der nationalsozialistischen Kämpfer, die sich freudig und mit Begeisterung für die Motorisierung einsetzen. "194 Diese Selbstbeschreibung des Korps enthält im Kern eine politisch-ideologische Rechtfertigung seiner Existenz. Die NS-Weltanschauung diente gleichermaßen als Existenzbegründung und Zielsetzung. Im Korpsbefehl vom 22. September 1934 heißt es in Bezug auf die Arbeit des NSKK: „Ihr Inhalt ist die Erhaltung und Entwicklung des nationalsozialistischen Ideengutes auf ureigenstem Gebiete: Förderung des deutschen Kraftfahrwesens, des Sport- und Wehrgedankens, der Kraftverkehrs-Wirtschaft und -Technik. ${ }^{\prime 195}$

$191 \mathrm{Vgl}$. Staffelbefehl der Motorstaffel II/M 77 vom 8. 2. 1935, ebenda.

192 Deutsche Kraftfahrt vom November 1935: „Korpsführer Hühnlein über den Reichswettkampf des NSKK“.

193 Zur Bedeutung dieser Definition und zu den daraus erwachsenden Aufgaben vgl. das Kapitel „Ideologie und Praxis der NS-Motorisierungspolitik“.

194 NSKK-Korpsführung (Hrsg.): Das NSKK, S. 5.

195 Korpsbefehl Nr. 2 vom 22. 9. 1934, BArch NSD 42/9. 
Das Bekenntnis zum Nationalsozialismus bildete nicht nur den weltanschaulichen Hintergrund der Arbeit, sondern definierte jedes einzelne Mitglied des NSKK als politischen Kämpfer:

„Der NSKK-Mann ist immer und in erster Linie politischer Soldat Adolf Hitlers. Die Idee, das Weltanschauliche steht allen seinem Handeln voran und wird von ihm auf allen Aufgabengebieten des Korps als der großen Erziehungsschule der Motorisierung zur Anwendung gebracht." 196

Aufgrund dieses Diktums war die Mitgliedschaft nicht abhängig vom Besitz eines Führerscheins oder Fahrzeugs; entscheidend für den Eintritt war die „Liebe zum Motor" und der Wille, das „Mehr an Pflichten des politischen Soldaten auf sich zu nehmen".197

Diese von der Korpsführung angestrebte klare politische Ausrichtung rieb sich mit dem weit verbreiteten Image des NS-Kraftfahrkorps. Hühnlein stand in der Pflicht, die Rolle des NSKK zu erklären und angesichts von kursierenden „Fehlinformationen“ immer wieder öffentlich zu definieren bzw. zu dementieren:

„Wir sind keine Techniker, wir sind keine Kraftfahrer, keine Chauffeure, keine Spediteure und keine Transporteure, die mancher in uns vielleicht sieht. Wir sind die freiwillige technische Armee des Volkes. Wir sind unserer inneren Struktur und geschichtlichen Entwicklung nach die ,Motorisierte SA' " 198

An der Art und der Vielzahl ähnlich lautender Beteuerungen ist abzulesen, dass Adolf Hühnlein sich in seiner gesamten Dienstzeit als Korpsführer gegen Fremdzuschreibungen wehren musste. Da die Motor-SA und das NSKK im August 1934 nur aus machttaktischem Kalkül und pragmatischen Gründen fusioniert und zur selbständigen Gliederung erhoben worden waren, stand die politische Akzeptanz des NSKK von Anfang an in Frage. Dies war eine ungünstige Ausgangsposition, um sich neben SA und SS als gleichwertiger Baustein der NSDAP zu profilieren. Vergleichbar des Treueschwurs der SS, „SS-Mann, deine Ehre heißt Treue“, installierte man zur Einschwörung der NSKK-Mitglieder die Formel „Treu, opferwillig, einsatzbereit!“199

Doch Treueschwüre allein reichten nicht aus. Es galt, insbesondere den Führern und Männern der NS-Bewegung, die die weltanschauliche „Festigung“ und den politischen Gehalt des NSKK anzweifelten, den Sinn und Zweck des NSKK zu vermitteln. Der Korpsführer brandmarkte bei einem Appell der NSKK-Motorbrigade Leipzig 1937 das Misstrauen der nationalsozialistischen Kameraden:

„Noch sind sich leider hier und da Angehörige anderer Gliederungen der Partei über das Wesen und die Aufgaben des NSKK nicht richtig im klaren. Oft hört man, wenn vom Korps gesprochen wird: ,Das sind die Männer, die Transporte ausführen, von denen man einen Wagen

196 Geleitwort für das Buch von Krenzlin: Das NSKK.

197 "Nationalsozialistisches Kraftfahr-Korps", in: Meyers Lexikon, Bd. 8, 81940, S. 154.

198 Krafthand vom 6. 8. 1938: „Es ist ein großer Stolz, NSKK-Mann zu sein!“ Ähnliche Formulierungen auch in Der NSKK-Mann vom 18. 3. 1939: „Weltanschauung und Motor“.

199 Hühnlein: NSKK als Wegbereiter der deutschen Kraftfahrt, S. 20; NSKK-Korpsführung (Hrsg.): Das NSKK, S. 23. 
anfordern kann, wenn man umsonst fahren will, das ist so eine Art Speditions- und Transport-Unternehmen. “200

Bei Ansprachen bekräftigte er immer wieder: „Unser Inhalt ist Soldatentum und politisches Kämpfertum! “201 Auch wenn Hühnlein mit Nachdruck auf die politische Funktion seiner Gliederung pochte, blieben Zweifel, denn als motorisierte Gliederung der NSDAP zählte es zu ihren Aufgaben, Transport- und Repräsentationsaufgaben für die Partei auf allen Ebenen zu übernehmen. Da das NSKK sich selbst als die Verkörperung der motorisierten Kraft der Bewegung bezeichnete, lag es nahe, dass Angehörige der Partei, der SA und der SS darin eine rein praktisch-funktionale Aufgabe erkannten. ${ }^{202}$ Diese Reduzierung auf Transportaufgaben erregte das Missfallen der NSKK-Führer. Einerseits wurde das NSKK von der Partei zur Durchführung und entsprechenden Ausschmückung ihrer Veranstaltungen in Anspruch genommen, andererseits wurde ihm aber der politische Auftrag abgesprochen. Viele Parteigenossen setzten das NSKK zudem mit dem von ihnen vermuteten NSKK-Autoclub aus der Zeit vor 1933 gleich. In Anspielung auf den unterstellten Vereinsstatus kursierte im „Dritten Reich“ hinter vorgehaltener Hand der Scherz, dass die Abkürzung N.S.K.K. für „Nur Säufer Keine Kämpfer" stehe. ${ }^{203}$ Dieses vom Volksmund in die Welt gesetzte Wortspiel spricht für das hartnäckige Image des NSKK als Autofahrertreff, in dem das gesellige Miteinander am Biertisch mehr zählte als das politische Kämpfertum. Eine ähnlich despektierliche Auflösung der Abkürzung N.S.K.K. unternahm ein Leutnant, der die NSKK-Männer im Krieg „NS-Kurven-Kasperl“ nannte. ${ }^{204}$ Offensichtlich konnte der Korpsführer mit seiner Argumentation, die darauf baute, das NSKK als die „Motorisierte SA“ und als „motorisierte[s] Kampfinstrument des Führers“ $205 \mathrm{im}$ politischen Leben zu etablieren, nicht restlos überzeugen.

\section{Das paramilitärische Selbstverständnis}

Das NSKK strebte innerhalb seiner Gliederung eine Verbindung aus Motorkraft und militärischen Elementen an. Es knüpfte dabei vor allem an das Image der „motorisierten Streitkraft“ der Bewegung an, das die Motor-SA bereits vor 1933

200 Der NSKK-Mann vom 3. 7. 1937: „12000 NSKK-Männer am Völkerschlachtdenkmal“.

201 Der NSKK-Mann vom 17. 9. 1938: „Unser Inhalt ist Soldatentum und politisches Kämpfertum!“

202 In einem Korpsbefehl von 1935 wurde das NSKK folgendermaßen charakterisiert: „Das NSKK verkörpert die motorisierte Kraft der Partei [...]“, Korpsbefehl Nr. 12a vom 25. 7. 1935, BArch NSD 42/9; Organisationsbuch der NSDAP, 1936, S. 394 f.

$203 \mathrm{Vgl}$. Schreiben des Rechtsanwaltes an die Spruchkammer München vom 27. 9. 1948, Entnazifizierungsakte Ritter von Denk, Amtsgericht München. Der 1959 erstmals publizierte und im Jahr 2002 wieder aufgelegte Roman von Rudolf Lorenzen „Alles andere als ein Held“ zeichnet das NSKK als Gliederung, deren Mitglieder dem Alkohol besonders zusprachen; vgl. ebenda, S. 19, 95, 159.

204 Dieses Wortspiel wurde mit drei Tagen Arrest bestraft; vgl. Schreiben des Sturmführers eines Münchner Motorsturms an den Obergruppenführer von Städtler vom 28. 4. 1941, BArch NS 24/830; Schreiben desselben an die Motorstandarte 86 vom 31. 3. 1941, BArch NS 24/712.

205 Hühnlein: NSKK als Wegbereiter der deutschen Kraftfahrt, S. 19. 
verkörperte. Militärische Bezeichnungen wie „Kampftruppe“206 sollten dem NSKK nach dem Aufstieg zur Gliederung helfen, das unbeliebte Vereinsimage abzustreifen. Hitler ermutigte das NSKK in seinem Bemühen, auch im militärischen Bereich Schubkräfte zu entwickeln. Als 5500 Männer der westfälischen Motor-SA und des NSKK mit 3000 Fahrzeugen am 9. Juli 1933 an ihm vorbeizogen, rief er aus, was viele NSKK-Führer nur zu hoffen wagten: „Das ist die Kavallerie der Zukunft. "207 Das NSKK verkörperte die für NS-Ideologen ideale Mischung aus modernem Soldaten- und politischem Kämpfertum. In Bezug auf die Entwicklung der Reichswehr stand der Ausspruch Hitlers für die Absichtserklärung, Pferdestärken und menschliche Kräfte durch den Einsatz motorisierter Kampf- und Transportmittel abzulösen.

Die Verbindung aus Technik und militärischer Schlagkraft beim NSKK spiegelte auch die Übernahme des Liedgutes der motorisierten Truppenteile wider. Das Panzerwagenlied, der Marsch der Kraftradschützen und das Kradschützenlied zählten zu den bevorzugten Sing- und Marschliedern des NSKK. ${ }^{208}$ Im Kraftradschützenlied, das in Militärkreisen um 1930 aufkam, heißt es: „Wir sind die Kraftradschützen/ und fahren durch die Welt/ Wenn Staub und Steine spritzen/ das ist was uns gefällt/ Wenn wir bei Sturm und Regen/ Mit knatterndem Motor/ jagen dem Feind entgegen/ das ist Musik im Ohr." 209 Der Kradschütze, der bei Wind und Wetter über Stock und Stein, durch Wasser und über Berge fährt, wurde den NSKK-Mitgliedern als Leitbild vor Augen gestellt. In seinem Selbstverständnis als „Mannesschule der Motorisierung“ fungierte das NSKK als Vorschule für den wetterfesten „Fahrsoldaten“.

Auch wenn das NSKK großen Wert auf seine paramilitärische Ausrichtung legte und sich als "politische Armee“ 210 definierte, hatte das politische Selbstverständnis Vorrang vor dem militärischen Auftrag. In diesem Sinne machte der Korpsführer in einem Vortrag am 16. Dezember 1937 vor Offizieren aller drei Wehrmachtsteile im Reichskriegsministerium deutlich: „Man kann das NSKK z.B. nicht zu einer motorisierten militärischen Reserve machen. ${ }^{\text {"211 }}$ Der Korpsführer betonte die kulturelle Mission als Willensträger des Motorisierungsgedankens und trat auf diese Weise potenziellen Anforderungen der Wehrmacht, was die Verfügbarkeit des NSKK für militärische Zwecke anging, präventiv entgegen. Der Korpsführer begrenzte das NSKK darauf, das „Verständnis für die Notwendigkeit der Motorisierung und ihre ungeheure Wechselwirkung auf die Abwehrkraft der Nation zu wecken und zu vertiefen".212 Dass sich die Funktion des NSKK nicht im propagandistischen Werben erschöpfte, sondern praktisches Tun miteinschloss, zeigt ein weiteres Identitätselement des NSKK.

\footnotetext{
206 Der NSKK-Mann vom 12. 2. 1938: „Verkehrsfeinde sind Volksfeinde!“

207 Deutsche Kraftfahrt vom 15. 7. 1933: „Dortmund im Zeichen des Sturzhelms“.

208 Vgl. NSKK-Korpsführung (Hrsg.): Singen im NSKK.

209 Zit. nach: Die Geschichte der 6. (Preußischen) Kraftfahrabteilung, S. 83.

210 Hühnlein: Vortrag, gehalten am 16. Dezember 1937, S. 18.

211 Vgl. ebenda, S. 2.
}

212 Krenzlin: Das NSKK, S. 15. Ähnlich auch in: NSKK-Korpsführung (Hrsg.): Das NSKK: "Je höher der Stand der Motorisierung, desto stärker die Abwehrkraft der Nation“; ebenda, S. 5. 


\section{Das NSKK - „Erziehungs- und Schulungsstätte für die Motorisierung“213}

Das NSKK gab als Zielsetzung aus, die materielle und personelle Motorisierung des deutschen Volkes zu fördern. ${ }^{214} \mathrm{Als}$ ersten Schritt bedeutete dies, die Motorfreudigen, die Begabten und diejenigen, die beruflich mit dem „Motor“ im weitesten Sinne zu tun hatten, im NSKK zu integrieren. Auf dieses Weise sollte das NSKK als motortechnische Unterrichtsstätte ausgebaut werden. ${ }^{215}$ Das NSKK bezeichnete sich nicht selten als "Jungbrunnen und Kraftspeicher der motorisierten Nation"216, was darauf schließen lässt, dass es sich selbst als Keimzelle der Motorisierung und als geballte Ansammlung von Expertenwissen verstand. Aus dieser Definition leitete es nicht nur den Anspruch ab, das technische Wissen der Mitglieder zu fördern, sondern auch das Erziehungsziel, die deutsche Jugend an die Motorisierung heranzuführen.

So wie die NSDAP sich zum Erzieher des Volkes erklärte, so sahen sich MotorSA und NSKK als Erziehungsschule des Volkes in Verkehrsangelegenheiten.217 Dieses pädagogische Selbstverständnis beinhaltete den Auftrag, das Volk an einen wohl verstandenen Umgang mit dem kostbaren Gut „Motorisierung“ heranzuführen. Das NSKK strebte die führende Position als Verkehrserzieher im neuen Staat an.

\section{Das sportliche Selbstverständnis}

Auf die Frage, warum der SA-Mann in das NSKK eintreten sollte, antwortete ein Werbeschreiben 1934: „Weil der Motorsport Allgemeingut der jungen deutschen Generation werden muß und weil das NSKK als Ersatz für die scheidenden Alten die jungen, sportbegeisterten Männer braucht - Männer, die bereit sind, als Kraftrad-Melder oder Führer von Personen und Lastkraftwagen Dienst am Vaterland zu tun." ${ }^{218}$ Die hier sichtbare Koppelung von Sport und vormilitärischer Ausbildung prägte die Sportausübung innerhalb des NSKK. Aufgrund der militärischen Bedeutsamkeit der Motorisierung und des Werbeeffekts des Motorsports für die Motorisierung allgemein erging der Ruf des NSKK an die Gesellschaft: „Motorsport muß zum Volkssport werden!“219 Aus seinem Selbstverständnis als sportliche Gliederung heraus erhob das NSKK einen Führungsanspruch im Kraftfahrsport, der die gesamte Organisation des nationalen und internationalen Motorsportgeschehens im „Dritten Reich“ umfasste.

213 Der NSKK-Mann vom 18. 3. 1939: „Weltanschauung und Motor“; Vortrag von Korpsführer Hühnlein gehalten am 16. Dezember 1937, S. 3.

214 Vgl. NSKK-Korpsführung (Hrsg.): Das NSKK, S. 5.

215 Vgl. Hühnlein: Die vor- und nachmilitärische Wehrertüchtigung des NSKK, S. 81.

216 NSKK-Korpsführung (Hrsg.): Die Gliederung des NSKK, S. 4.

217 Vgl. Krenzlin: Das NSKK, S. 13.

218 Werbeschreiben der Motorstaffel II vom 22. 10. 1934 an die aus der HJ ausscheidenden Kameraden, BArch NS 24/3.

219 NSKK-Korpsführung (Hrsg.): Das NSKK, S. 4 f. 


\section{Die Mitglieder}

\section{Zusammensetzung und Entwicklung des Mitgliederbestandes}

Der Nationalsozialismus erhob den Anspruch, alle Volksschichten weltanschaulich zu durchdringen und organisatorisch zu erfassen. Den organisatorischen $\mathrm{Zu}$ griff auf die Kraftfahrer, die Führerscheinbesitzer und die Motorinteressierten nahm das NSKK vor. Zusammen mit der Motor-SA fungierte das NSKK als Sammelbecken für Auto- und Motorradfahrer, die sich und ihre Fahrzeuge in den Dienst der Bewegung stellen wollten. Als sich der Status des NSKK von einer Kraftfahrerreserve der SA in eine eigenständige Gliederung der NSDAP wandelte, suchte das NS-Kraftfahrkorps seine Mitgliederzahl zu erhöhen.220 Die Korpsführung hob im Oktober 1934 eine kurzzeitig verhängte Sperre für Neuzugänge in das Korps auf und forderte alle deutschen Führerschein- und Fahrzeugbesitzer zum Eintritt auf. 221

Die Mitgliedschaft setzte jedoch in der Folgezeit weder den Besitz eines Fahrzeugs noch das Vorhandensein eines Führerscheins voraus. Wären dies Grundbedingungen für die Aufnahme gewesen, hätte das NSKK seine Mitgliederbasis nur eingeschränkt erweitern können. Das NSKK stand NSDAP-Mitgliedern und „deutschen Männern“ offen, die „deutschstämmig“, politisch zuverlässig, körperlich geeignet und motorbegeistert waren. ${ }^{222}$ Ein Nachweis der arischen Abstammung des NSKK-Mannes und seiner Ehefrau musste spätestens dann erbracht werden, wenn eine Ernennung zum NSKK-Führer anstand.223

\section{Entwicklung der Mitgliederzahl}

Die Mitgliederzahl des NSKK einschließlich der Motor-SA erhöhte sich kontinuierlich. Zur Jahreswende 1932/33 leisteten laut NSKK-Angaben 30000 Aktive im Kraftfahrkorps und in den Motorstürmen Dienst. Bei der Inspektion der Berliner Motor-SA im Mai 1933 verkündete Hühnlein eine Gesamtstärke des NSKK von

220 Vgl. Protokoll der Führerbesprechung bei der Motorbrigade Darmstadt am 14. 6. 1935, HStA Wiesbaden, Abt. 483 Nr. 2983.

221 Vgl. Korpsbefehl Nr. 10 vom 16. 10. 1934 und Nr. 12a vom 25. 7. 1935, BArch NSD 42/9. In späteren Fassungen entfiel als Aufnahmevoraussetzung der Besitz einer Fahrerlaubnis oder eines Fahrzeugs; vgl. auch Korpsbefehl Nr. 12b vom 12.5. 1938, Neufassung von 12a, BArch NSD 42/9.

222 Vgl. Korpsbefehl Nr. 12b vom 12.5. 1938, Neufassung von 12a, BArch NSD 42/9.

223 Vgl. Schreiben der Motorstandarte 86 an die Staffeln und Stürme vom 23. 9. 1938, betr. Arische Abstammung, BArch NS 24/60. Der NSKK-Führer-Fragebogen umfasste Fragen nach der Mitgliedschaft in politischen Organisationen oder Geheimlogen vor dem Eintritt in das NSKK und Fragen nach der arischen Abstammung der Eltern, Großeltern und Ehefrau; vgl. Verordnungsblatt der Korpsführung vom 15.7. 1935: „Fragebogen über arische Abstammung“, IfZ Db 30.01. Wegen der Ubberbelastung der Standesämter wurde der Nachweis nicht für gewöhnliche NSKK-Männer und Unterführer eingefordert. 
70000 Mann; im Juli 1933 waren im NSKK und in den Motorstürmen der SA und SS bereits 100000 Mitglieder geführt. ${ }^{224}$

Der starke Mitgliederanstieg im Sommer 1933 ist zum einen auf den allgemeinen Eintrittsboom in die Organisationen der NSDAP zurückzuführen, zum anderen auf die intensiven Werbebemühungen des NSKK. Im Rahmen einer großen Werbekampagne wurden $600000 \mathrm{Kraftfahrern}$ illustrierte Werbeblätter zugesandt. ${ }^{225}$ Daneben gelang es, auch Kraftfahrer aus den Automobilclubs zum Eintritt zu bewegen. Die Werbung dehnte sich außerdem auf Beamte mit Kraftfahrzeugen oder Führerscheinen aus. Auf Veranlassung der Motorbrigade KurpfalzSaar suchten 1936 die zuständigen Standartenführer sämtliche Vorstände von Behörden wie Eisenbahn, Post, Stadtverwaltung und Finanzamt auf, um die in Frage kommenden Beamten zum Beitritt in das Korps zu veranlassen. ${ }^{226}$ Reichsbahndirektionen forderten ihre Mitarbeiter auf, in das NSKK einzutreten.227 Mit diesen gezielten Werbemaßnahmen gerieten die bisherigen Prinzipien der politischen Auslese: Freiwilligkeit und echte politische Überzeugung, immer mehr zur Makulatur. 228

Bis November 1937 stieg die Zahl der Mitglieder auf 300000 und überschritt im Laufe des Zweiten Weltkriegs die Halbe-Million-Mitglieder-Marke.229

Nach dem Einmarsch in Polen kam noch eine neue Gruppe von Mitgliedern hinzu: die so genannten „Volksdeutschen“. Bereits im Dezember 1939 waren in Lodz acht Stürme mit insgesamt 800 Männern aufgestellt worden. ${ }^{230} \mathrm{Im}$ Oktober 1940 wurden 3055 Männer der Motorstandarte M 114 in Posen und 2113 NSKKAnwärter in Litzmannstadt vereidigt. ${ }^{231}$

Der Aufbau neuer Formationen im "Warthegau“ wurde durch den Zuzug der Baltendeutschen und bald darauf der Deutschen aus Wolhynien, Galizien und der Cholmer Gegend extrem beschleunigt. Der Motorgruppe Wartheland unter der Führung von Brigadeführer Paul Hopp ${ }^{232}$ unterstanden im Februar 1941 bereits sechs Standarten mit weit über 100 Stürmen. ${ }^{233}$ Die Mitgliedschaft in einer NSGliederung war für viele „Volksdeutsche" gleichbedeutend mit einem Sympathiebeweis für das Regime. Da der Erwerb der deutschen Staatsbürgerschaft bei vielen verzögert wurde, weil sie, wie es hieß, Bindungen zum Polentum hätten oder darin aufgegangen seien, sollten sie sich erst im Arbeitseinsatz an der „Heimatfront“

224 Vgl. Oppermann: Unter den Sturmstandern, S. 83, 93, 97; Deutsche Kraftfahrt vom 15. 6. 1933: „Der Siegeszug des NSKK“.

225 Vgl. Deutsche Kraftfahrt vom 15. 6. 1933: „Der Siegeszug des NSKK“.

226 Vgl. 1. Halbjahresbericht 1936 der Motorbrigade Kurpfalz-Saar an die Motorobergruppe Süd, LA Speyer, T 65 Nr. 66.

227 Vgl. Schreiben des NSKK an den Reichsbahn-Rat Philipp vom 28.12. 1934, BArch NS 24/114.

228 Vgl. Hühnlein: Vortrag, gehalten am 16. Dezember 1937, S. 20.

229 Vgl. NSKK-Korpsführung (Hrsg.): Das NSKK, S. 3. Nach dem Stand vom 31. 7. 1940 betrug die Stärke des NSKK 470781 Personen; BArch-ZNS, SM.

230 Vgl. Windecker: Wir waren mit in Polen, S. 203.

231 Vgl. Der NSKK-Mann vom 12. 10. 1940: „Aus den Reihen“.

232 Paul Hopp, geb. 1900, Führer der Motorgruppe Wartheland. Vgl. zu seiner Person auch S. 460 dieser Arbeit.

233 Vgl. Der NSKK-Mann vom 8. 2. 1941: „Das NSKK im Osten am Werk“. 
und in den Organisationen der Partei durch besonderen Fleiß und besondere $\mathrm{Zu}$ verlässigkeit auszeichnen. Um ihren guten Willen zu zeigen, hatten sie die Möglichkeit, sich der SA und dem NSKK anzuschließen, nicht aber der SS und nur selten dem NSFK. Auch das erklärt die Popularität des Kraftfahrkorps. ${ }^{234}$ Die Mitglieder der neu aufgestellten NSKK-Einheiten wurden sofort nach ihrer Gründung in der nationalsozialistischen Weltanschauung unterwiesen und erhielten erste kraftfahrtechnische Instruktionen. ${ }^{235}$

Am 31. Juli 1941 gehörten dem NSKK genau 529181 Mitglieder an.236 Damit war das NS-Kraftfahrkorps nach der SA die mitgliederstärkste Gliederung der NSDAP. 237

\section{Korpsangehörige}

Interessierte konnten dem NSKK entweder als aktives oder als passives Mitglied beitreten. Deutsche "Volksgenossen“, die keinen aktiven Dienst in den Motorstürmen leisten wollten oder konnten, sich dem Korps aber „innerlich verbunden" fühlten, hatten die Möglichkeit, sich als Korpsangehörige eintragen zu lassen. Falls die Korpsangehörigen nicht bereits Parteimitglieder waren, mussten auch sie, wie die aktiven Mitglieder, zumindest die politischen und „rassischen“ Voraussetzungen zur Aufnahme in die Partei erfüllen. Auch Personen, die in anderen Gliederungen aktiv waren - Mitglieder der SA oder SS sowie Politische Leiter - konnten den Förderstatus als Korpsangehörige erwerben. ${ }^{238}$

Im Sommer 1933 entstanden innerhalb des NSKK einige wenige Frauengruppen. Die Führerin der ersten NSKK-Frauengruppe war die Sportfahrerin Maria Seliger aus Stettin, die mit einigen Clubkameradinnen aus dem Deutschen Damen-Automobilclub ausgetreten war. ${ }^{239}$ Nachdem das NSKK zur eigenständigen Gliederung aufgestiegen war, passte das weibliche Element offenbar nicht mehr

234 Vgl. die „Verordnung über die Deutsche Volksliste und die deutsche Staatsangehörigkeit in den eingegliederten Ostgebieten" vom 4. 3. 1941, abgedruckt in: Pospieszalski: Niemiecka Lista Narodowa w „Kraju Warty“, S. $141 \mathrm{f}$.

235 Vgl. Schreiben der Motorgruppe Danzig vom 15. 1. 1940 mit dem Ausbildungsplan für die beauftragten Führer im besetzten Gebiet und Schreiben des Obersturmführers Gerhard Nickel vom 16. 1. 1940, BArch NS 24/141. Das NSKK beanspruchte auch im Gau Wartheland, in alle mit der Motorisierung in Zusammenhang stehende Fragen miteinbezogen zu werden; vgl. Schreiben der NSKK-Motorgruppe Wartheland, Oberführer Hopp, an den Reichsstatthalter Gauleiter Greiser vom 23. 5. 1940, Archiwum Panstwowe Poznan, Best. Reichsstatthalter im Reichsgau Wartheland in Posen Nr. 1244.

236 Vgl. Bericht „Das NSKK im Kriegseinsatz“, 2. Folge, Stand: 1. 10. 1941, StadtA Leipzig, Kap. 3 Nr. 70.

237 Ein regionales Beispiel: 1944 zählte die Partei im Elsass 21809 Mitglieder, die SA 12000, die SS 2500, das NSFK 1795 und das NSKK 11333 Mitglieder; vgl. Schreiben des Chefs der Zivilverwaltung im Elsaß an den Chef der Reichskanzlei Dr. Lammers: „Bericht über die Lage vom 19. 1. 1944“ (Kopie), BArch SS-HO Nr. 1760.

238 Vgl. Verordnungsblatt des NSKK, Führer der Motorbrigade Niedersachsen vom 1. 2. 1937, HStA Hannover, VVP 17 Nr. 2417.

239 Auf die Gründung von Frauengruppen im NSKK weisen nur wenige Informationen hin; vgl. ein Bild von Maria Seliger mit Bildunterschrift in: Deutscher Sport vom 25. 8. 1933. Sie bestanden wahrscheinlich nur kurze Zeit. Weitere Informationen zum Thema Frauen im NSKK, im Automobilclub und im Motorsport auf Seite $217 \mathrm{ff}$. und $305 \mathrm{f}$. dieser Arbeit. 
zu dem kämpferischen Auftrag und dem völkischen Verständnis der „braunschwarzen Motorkämpfer". Im Verordnungsblatt vom 15. Oktober 1934 wurde den Frauen jeglicher aktiver Dienst im NSKK untersagt. ${ }^{240}$ Sie zählten zu den außerordentlichen Mitgliedern, für die die Aufnahmebedingungen „besondere Eignung zum aktiven Motorsport oder zum Fürsorge-Dienst " galten. ${ }^{241}$ Die Zahl der weiblichen Korpsangehörigen betrug 1938300 und soll bis 1943 auf rund 2000 gestiegen sein. 242

Die Möglichkeit der Fördermitgliedschaft fand besonders bei leitenden Angestellten, Betriebsleitern, Ingenieuren und Technikern aus der Kraftfahrzeugbranche und dem Handwerk großes Interesse. So wurden die Vorstandsmitglieder der Daimler-Benz AG, Kissel, Hoppe, Nibel, Schippert und von Jungenfeld ab Juli 1933 Fördermitglieder. Das Unternehmen stellte 1933 zudem die Anmeldungen von 62 aktiven und 306 passiven Mitgliedern in Aussicht. ${ }^{243}$ Auch eine Aufstellung der Korpsangehörigen des Münchener Sturms 18/M 86 vom Februar 1939 zeigt, dass Ingenieure unter den 34 Angehörigen am stärksten vertreten waren. Die restlichen Mitglieder setzten sich aus Künstlern, Akademikern, Kaufleuten und Direktoren zusammen. ${ }^{244}$

Korpsangehörige waren von der aktiven Teilnahme am „Sturmdienst“ mit der Begründung befreit, ihnen fehle dafür die Zeit.245 Berufliche Verhinderung als akzeptablen Rechtfertigungsgrund dafür anzusehen, sich einer aktiven Dienstleistung zu entziehen, zeugte von einem großen Entgegenkommen des Korpsführers gegenüber den Korpsangehörigen, die derartige Pflichtübungen vermutlich aus Gründen der Bequemlichkeit und aus mangelndem Interesse ablehnten. Fast entschuldigend erklärte der Korpsführer 1936:

„Ein großer Teil der Gefolgschaftsführer, Betriebsleiter, Ingenieure, Techniker, Werkmeister oder kaufmännischen Angestellten würde sich mit Freuden gleichfalls in den aktiven Dienst des Korps einreihen, wenn nicht das gigantische Aufbauwerk der deutschen Kraftfahrzeugindustrie den vollen Einsatz der Person erforderte."246

Die Rückendeckung des Korpsführers war vonnöten, da die aktiven Mitglieder die Korpsangehörigen häufig als Drückeberger ansahen, die nur aus repräsentativen Gründen zum Korps gehören wollten. ${ }^{247}$ Dass Korpsangehörige bei den

240 Vgl. auch Verordnungsblatt der Korpsführung vom 15. 10. 1934: „Frauen im NSKK“, IfZ Db 30.01.

241 Vgl. Korpsbefehl Nr. 12 a vom 25. 7. 1935, BArch NSD 42/9.

242 Berlin hatte mit 7772 die meisten Korpsangehörigen, gefolgt von Leipzig mit 2820; Auszug aus der Stärkemeldung für Korpsangehörige vom 31. 10. 1938, BArch NS 24/161. Die Zahl von 2000 im Jahre 1943 beruht auf Aussagen aus dem Umfeld der Korpsführung; Eidesstattliche Erklärung von Hermann Rösing vom 8. 9. 1948, Entnazifizierungsakte Kraus, Amtsgericht München.

$243 \mathrm{Vgl}$. Schreiben von Kissel an Weckert vom 18. 7. 1933, DCC-Konzernarchiv, Best. Kissel 9.5 .

244 Vgl. Aufstellung der Korpsangehörigen des Sturms 18/M 86 vom Februar 1939, BArch NS 24/14.

245 Vgl. Korpsbefehl Nr. 20 vom 7. 2. 1936, BArch NSD 42/9.

246 Ebenda.

247 Zeitmangel und körperliche Gebrechen seien nur Ausreden, so die Kritiker; vgl. Halbjahresbericht der M 153 Heidelberg vom 16. 6. 1937, LA Speyer, T 65 Nr. 66. 
Dienst tuenden NSKK-Männern einen schlechten Ruf genossen, belegt auch die Tatsache, dass altbewährte NSKK-Männer es als "tiefe Kränkung" empfanden, sich aus beruflichen oder aus Altersgründen in die Reihe der Korpsangehörigen einordnen zu müssen. Um dieser "Schmach“ zu entgehen, bestanden für altgediente Mitglieder zeitweise Reserve-Trupps, die den Motorstürmen angeschlossen waren. 248

1936 betrug die Zahl der Korpsangehörigen knapp 16000.249 Danach forcierte die Korpsführung ihre Anstrengungen, Angestellte aus der Kraftfahrzeugindustrie, Betriebsleiter, Ingenieure und Techniker an das NSKK zu binden. ${ }^{250} \mathrm{Bis}$ Oktober 1938 erhöhte sich die Zahl auf rund 32000.251 Auch Firmen stand es offen, sich als Korpsangehörige eintragen zu lassen. 1938 machten 310 Unternehmen von dieser Möglichkeit Gebrauch. ${ }^{252}$ Trotz der steigenden Zahl der Korpsangehörigen ordnete Hühnlein 1938 an, dass noch mehr Korpsangehörige geworben werden sollten, die „durch ihren Beruf oder aus Interesse am Motor an sich zu uns gehören würden "253, oder die bisher der Bewegung fern standen. ${ }^{254}$ Die Einflussmöglichkeit des NSKK auf Manager und Ingenieure aus der Motorenindustrie war ein überzeugendes Argument, das für die Institution der Korpsangehörigen sprach. Zudem erhöhte es das Reservoir an potenziell verfügbaren Fahrzeugen und brachte finanzielle Vorteile. ${ }^{255}$ Die Tatsache, dass eine große Anzahl Korpsangehöriger statt der obligatorischen 2 RM Korpsangehörigen-Beitrag 3 bis $20 \mathrm{RM}^{256}$ pro Monat an die Korpsführung bezahlte, sprach aus Sicht der Korpsangehörigen für ihre Bereitschaft, sich vom aktiven Dienst frei zu kaufen. Der Anreiz für die Stürme, Korpsangehörige zu werben, stieg ab 1. Mai 1938, als die Beiträge der Korpsangehörigen direkt an die Motorstürme flossen. ${ }^{257}$ Trotz der

248 Vgl. Verfügung des Korpsführers vom 29. 1. 1937, betr. „Reserve“-Trupps, BArch NS 24/2; Verfügung des Korpsführers vom 29. 1. 1937, BArch NS 24/278.

$249 \mathrm{Vgl}$. Auszug aus der Stärkemeldung für Korpsangehörige vom 31.10. 1938, BArch NS 24/161.

250 Vgl. Korpsbefehl Nr. 20 vom 7. 2. 1936, BArch NSD 42/9.

251 Vgl. Meldung des Personalamtes vom 31. 10. 1938, BArch NS 24/162. Wenn es darum ging, die Wichtigkeit des Korps in der Öffentlichkeit herauszustellen, vergrößerte Hühnlein die Mitgliederzahlen gemäß seinem Wunschdenken: Er sprach im Dezember 1937 von 50000 Korpsangehörigen statt wahrheitsgemäß von 30000 ; vgl. Hühnlein: Vortrag, gehalten am 16. Dezember 1937.

252 Vgl. Meldung des Personalamtes vom 31. 10. 1938, BArch NS 24/162. Firmen wurde bereits 1933 angeboten, sich als Korpsangehörige zu einem Monatsbeitrag zwischen 5 bis 100 RM eintragen zu lassen; Deutsche Kraftfahrt vom 15.6. 1933: „Korpsführung“.

253 Korpsbefehl Nr. 20 a, vom 23. 3. 1938, BArch NSD 42/9.

254 Vgl. Aufforderung der M 95 an die Einheiten vom 26. 1. 1938, BArch NS 24/35.

$255 \mathrm{Vgl}$. 1. Halbjahresbericht 1936 der Motorbrigade Kurpfalz-Saar an die Motorobergruppe Süd, LA Speyer, T 65 Nr. 66.

256 Vgl. Verfügung des Korpsführers vom 14. 12. 1935, betr. Beitrag der Korpsangehörigen, BArch NS 24/162.

257 Vgl. Ankündigung des NSKK-Reichskassenverwalters zum 1. 5. 1938, BArch NS 24/14. Der Führer der Motorstandarte 95 erklärte seinen Staffeln und Stürmen mit Schreiben vom 22. 4. 1939: „Eine größere Anzahl von Korpsangehörigen im Sturm nützt nicht nur dem Sturm in finanzieller Hinsicht, sondern stärkt hauptsächlich seine Einsatzbereitschaft durch zusätzliche Fahrzeuge“; Schreiben des Führers der M 95 an die Staffeln und Stürme vom 22. 4. 1939, BArch NS 24/35. 
unverkennbaren Vorteile wusste Korpsführer Hühnlein um die Negativseiten einer passiven Mitgliedschaft. Er stellte 1938 fest, dass Rechtsanwälte, Beamte und Ingenieure, die bisher außerhalb der Gliederungen standen, den Eintritt in eine Parteigliederung zur beruflichen und persönlichen Vorteilnahme einsetzten, z.B. um schneller in die Partei aufgenommen zu werden. ${ }^{258}$ Die Organisationsform „Korpsangehörige“ bestand bis 1943 und hatte kurz vor ihrer Auflösung 100000 Mitglieder. 259

\section{Politische Zusammensetzung}

Wer dem Korps angehören wollte, sollte Parteimitglied sein oder zumindest die Voraussetzungen erfüllen, um in die Partei aufgenommen zu werden. Nichtparteigenossen hatten einen Extra-Beitrag und eine Zahlung in die Hilfskasse der NSDAP zu entrichten. ${ }^{260} \mathrm{Um}$ zu betonen, dass es sich beim NSKK-Mann um einen im "Ideengut des Nationalsozialismus innerlich gefestigten, harten, stets einsatzbereiten Kraftfahrer" handle, stellte der Korpsführer im November 1934 die unzutreffende Behauptung auf, das Korps umfasse zum größten Teil Parteiangehörige. ${ }^{261}$ Tatsächlich aber betrug der Anteil der NSDAP-Mitglieder im NSKK, laut Parteistatistik 1935, genau 31,5\%. Damit lag der Prozentsatz der NSDAPMitglieder innerhalb des NSKK unter dem der SS mit 48,9\%, aber wesentlich über dem Anteil der SA mit 23,2\%.262 Offensichtlich war eine Doppelmitgliedschaft in der NSDAP und im NSKK reizvoll. Über die Gründe kann man spekulieren: Die motorisierten Parteigenossen profitierten von Serviceleistungen, die das NSKK und der neu entstandene Einheitsclub DDAC anboten, und nutzten das NSKK als neuen gesellschaftlichen Bezugspunkt. Im Gegensatz zur elitären SS - und das erklärt den niedrigeren Prozentsatz der Parteimitglieder - nahm das NSKK ungeachtet der Parteimitgliedschaft alle Aspiranten auf, die sich motorbegeistert gaben. Mit 31,5\% Parteigenossen im NSKK lag die Quote wiederum höher als in der SA. Dies kann darauf zurückzuführen sein, dass Tausende von politisch Neuinteressierten nach der Aufnahmesperre der NSDAP ab 1. Mai 1933 in die SA strömten und die Quote an NSDAP-Mitgliedern nach unten drückten. 263

258 Vgl. Mitteilung des Amtes Verkehr der Korpsführung vom 25. 5. 1938 (Abschrift), BArch NS 24/161. Korpsangehörige bekamen keine Dienstbescheinigung, die sie zum Eintritt in die NSDAP empfahl. Korpsangehörige, die seit 1.10. 1934 Mitglied waren, erhielten jedoch eine Bescheinigung über ihre Zugehörigkeit zum Korps mit einer Bestätigung, dass sie die Ziele des NSKK unterstützt hatten; vgl. Verfügung des Korpsführers vom 3. 5. 1937, betr. Aufnahme von Korpsangehörigen in die Partei, BArch NS 24/2; Schreiben der M 86 an die Korpsführung vom 29. 10. 1937, BArch NS 24/14.

259 Der Korpsführer löste die Institution auf, da der Verwaltungsaufwand zu groß war und keine Betreuung mehr gewährleistet werden konnte. Die Korpsangehörigen wurden aufgefordert, sich aktiv zur Verfügung zu stellen; vgl. Verfügung des Korpsführers vom 5. 5. 1943, BArch NS 24/58.

260 Vgl. Anordnung des Inspekteurs der MSS vom 16. 9. 1938, betr. Mitgliedsbeiträge, BArch NS 24/281.

261 Vgl. DDAC-Wochenschrift vom 2. 11. 1934: „Vor neuen Aufgaben!“

262 Vgl. Parteistatistik der NSDAP, Bd. III, München 1935, S. 72.

263 Da die NSDAP mit Beitragsanträgen überschwemmt wurde, verhängte sie zum 1. 5. 1933 


\section{Altersstruktur}

Das NSKK verfügte über einen hohen Prozentsatz an altgedienten Soldaten und Frontkämpfern. ${ }^{264}$ Unter den 300000 Mitgliedern waren 193770000 Weltkriegsteilnehmer (23,3\%). ${ }^{265} \mathrm{Da}$ das NSKK aber nicht als Altherrenriege in die Annalen der Partei eingehen wollte, sondern als Eliteeinheit aktiver Kämpfer und als "Jungbrunnen der Motorisierung", verstärkte es die Nachwuchsarbeit in der Altersgruppe unter 35. Der Großteil der aktiven Mitglieder war wunschgemäß zwischen 20 und 35 Jahre alt. Im Juni 1939 umfasste die Motorstandarte 86 München 4179 Mitglieder. In Altersklassen unterteilt waren 703 (16,8\%) Mitglieder unter 20, $2365(56,6 \%)$ zwischen 20 und 35, 700 (16,8\%) zwischen 36 und 45, und 411 (9,8\%) über 45 Jahre alt. 266 Auch die Geburtsdaten der Mitglieder des Motorsturms 2/M 164 Saargemünd ergeben ein ähnliches Bild: 12\% gehörten der Altersklasse unter $20 \mathrm{Jahren}$ an, $61,5 \%$ der Männer waren zwischen 20 und 35, 25\% zwischen 36 und 45 Jahre alt, und nur $1,5 \%$ hatten bereits das 45 . Lebensjahr überschritten. 267

Bei den Korpsangehörigen des Motorsturms in Saargemünd (2/M 164) allerdings zeigte sich, wie bereits die Beschreibung der Korpsangehörigen vermuten lässt, ein anderes Bild. Von 87 untersuchten Korpsangehörigen war keiner unter 20 , dagegen aber $44 \%$ über 45 Jahre alt. 268 Dass sich ältere Mitglieder häufig als Korpsangehörige eintragen ließen, war ganz im Sinne der Korpsführung, da eine Überalterung dem selbst gesteckten Ziel des NSKK, eine einsatzfähige Gliederung $\mathrm{zu}$ werden, entgegengestanden hätte. ${ }^{269}$

\section{Berufsstruktur}

Das NSKK registrierte die Berufe der Mitglieder. Das Personalamt stellte am 31. Mai 1938 folgende Berufsschichtung der 262756 Mitglieder (ohne die Motorgruppen Ostland und Alpenland) fest:
1. Arbeiter:
ca. $34 \%$
2. Angestellte:
ca. $23 \%$
3. Selbständige
Handwerker:
Kaufleute:
ca. $11 \%$
ca. $9 \%$
Freie Berufe:
ca. $7 \%$
4. Beamte:
ca. $6 \%$
5. Bauern:
ca. $3 \%$
6. Sonstige:
ca. $7 \%$

einen Aufnahmestopp, der formal bis 1939 galt. Ab 1. 5. 1937 war der Beitritt für die Mitglieder der Gliederungen und Beamte jedoch wieder zulässig.

264 Vgl. Völkischer Beobachter vom 1. 7. 1939: "Wehrerziehung im NSKK“.

265 Vgl. NSKK-Korpsführung (Hrsg.): Das NSKK, S. 5.

266 Vgl. Stärkemeldung der M 86 vom 1. 8. 1939, BArch NS 24/65.

267 Aus den Geburtsdaten von 208 Mitgliedern des Motorsturms 2/M 164 Saargemünd, LA Speyer, T 65 Nr. 48.

268 Vgl. Aufstellung der Korpsangehörigen des Motorsturms 2/M 164 Saargemünd vom 31. 12. 1941, ebenda.

269 Vgl. Appell an die Sturmführer vom 6. 3. 1941, BArch NS 24/152. 
Der Anteil der Arbeiter lag beim NSKK unter dem Reichsdurchschnitt der männlichen Gesamtbevölkerung, der 1933 mit 55,1\% angegeben wurde. Dafür aber hatte das NSKK wesentlich mehr Angestellte und Selbständige in seinen Reihen, als der Reichsdurchschnitt mit 11,8\% bzw. 11,9\% dies erwarten ließe. ${ }^{270}$ Auffällig ist die geringe Beteiligung von Bauern im Korps, die mit 3\% weit unter der Gesamtquote von $14 \%$ im Reich lag. ${ }^{271}$ Korpsführer Hühnlein missfiel der seiner Meinung nach zu geringe Studentenanteil. Da nur 3224 von 156000 Studenten dem NSKK angehörten, drängte der Korpsführer auf eine verstärkte Werbung. 272

Die NSKK-Statistik über die Berufsstruktur der Mitglieder ist insgesamt wenig aussagekräftig, weil Arbeiter nicht unterteilt waren in qualifizierte Handwerker oder angelernte Fabrikarbeiter. Aus der Aufstellung ist außerdem nicht herauszulesen, in welchen Branchen die Berufsgruppen tätig waren. Ein genauerer Blick auf die Berufe der Angehörigen in einigen Motorstürmen gibt Aufschluss: Es ist nahe liegend, dass das NSKK als die motorisierte Gliederung der NSDAP sehr viele Arbeiter, Angestellte und Betriebsführer aus der Automobilindustrie und dem Kraftfahrzeughandwerk anzog bzw. zum Eintritt aufforderte. Das bestätigen Stichproben: 16,5\% der Mitglieder des Motorsturms 21/M 78 (Ansbach) waren am 1. August $1936 \mathrm{im}$ Kraftfahrzeuggewerbe tätig. 273

Die Auswertung von 433 Personalien der Motorstandarte M 26 Eberswalde ergab, dass ausgebildete Fachhandwerker (nicht mitgezählt: Friseure, Bäcker oder Fleischer) wie Klempner, Monteure, Elektriker und Schlosser mit $26 \%$ in der Standarte vertreten waren. Dazu sind noch 5,6\% Autoschlosser und Mechaniker, also die Automobiltechnik-Experten, hinzuzurechnen, so dass insgesamt $31,6 \%$ der Mitglieder dem Sturm dank ihrer Ausbildung handwerklich von Nutzen sein konnten. ${ }^{274}$ Dieser hohe Anteil findet sich auch in den Motorstürmen BerlinCharlottenburg 22/M 29 und Saargemünd in Elsaß-Lothringen 2/M 164 wieder, in denen rund $20 \%$ der Mitglieder Handwerksberufe in Metall verarbeitenden und technischen Berufen ausübten. ${ }^{275}$

270 Vgl. die Angaben in: Jamin: Zwischen den Klassen, Tabelle IV-3-1, S. 243.

271 Unter den männlichen Erwerbspersonen in Deutschland waren 1933 Beamte mit 6,5\% vertreten und Bauern (Selbständige und Mithelfende) mit 14\%; vgl. ebenda. Einschränkend muss angemerkt werden, dass es unwahrscheinlich ist, dass die Berufsstruktur des NSKK, alle in der Landwirtschaft Tätigen zu den „Bauern“ rechnet, wie es der Aufstellung von Mathilde Jamin zu entnehmen ist. Bei der Berufszählung des NSKK bleibt mit $7 \%$ ein sehr hoher Restwert an sonstigen Berufen übrig, bei Jamin dagegen mit nur $0,6 \%$ ein geringer Rest.

272 Vgl. die Verfügung des Korpsführers vom 12. 10. 1937, betr. NSDStB, Werbung unter den Hoch- und Fachschulstudierenden, BArch NS 24/279.

$273 \mathrm{Vgl}$. Verzeichnis des Motorsturms 21/M 78 (Ansbach) nach dem Stand vom 1. 8. 1936, StA Nürnberg, Rep. 503, NSKK 2.

274 Unter den 433 ermittelten Berufen waren landwirtschaftliche Berufe so gut wie nicht vertreten. Forstarbeiter waren mit 15, so bezeichnete Arbeiter mit 33, Studenten mit 9 und Beamte mit 13 Personen vertreten. Unter den 87 sonstigen Mitgliedern gab es viele Handwerksberufe wie Bäcker, Fleischer, Schriftsetzer; vgl. Motorstandarte Eberswalde, BArch-DH ZB II 1269 A. 9.

275 Vgl. Personalangaben des Sturms Berlin-Charlottenburg 22/M 29, BLHA Potsdam, Rep. 61 C. In der Aufstellung des Motorsturms 2/M 164 Saargemünd von 1941 sind die ursprünglichen Berufe (nicht Soldaten) verzeichnet, LA Speyer, T 65 Nr. 48. 
Von den 433 untersuchten Personen der Standarte in Eberswalde gab es überdies einen Anteil von 6\% Ingenieuren und $6 \%$ Berufskraftfahrern, die das Bild einer Gliederung, in der technisch-handwerkliche Berufsgruppen und Kraftfahrer stark vertreten waren, komplettieren. ${ }^{276}$ Der Motorsturm in Saargemünd wies mit 30\% eine besonders hohe Anzahl professioneller Kraftfahrer auf. 277 NSKKMänner aus der Kraftfahrzeugbranche erhöhten das Ausbildungsniveau des NSKK und waren dessen Image als kompetenter Ansprechpartner für Motorisierungsfragen förderlich. Im Kfz-Handwerk und -Gewerbe stark vertreten, gelang es dem NSKK jedoch nur, eine geringe Zahl an Industriearbeitern anzusprechen. Das Kraftfahrkorps richtete so genannte Werkstürme in den großen Betrieben der Automobilindustrie ein, doch erreichten sie wenige hundert Personen, also nur einen geringen Teil der Werksangehörigen. ${ }^{278}$

Bei den 18\% Kaufleuten, Händlern und kaufmännischen Angestellten der Motorstandarte Eberswalde handelte es sich um eine Berufsgruppe, die aus geschäftlichen Gründen häufig motorisierte Fortbewegungsmittel in Anspruch nahm. Berufliche Gründe und die Tatsache, dass Autos Repräsentationsobjekte waren, dürften auch Gastwirte angezogen haben, die in allen drei untersuchten Einheiten eine rege Beteiligung zeigten.

Landwirtschaftliche Berufe waren in der Berufsaufstellung von Eberswalde und Saargemünd, naturgemäß auch in Berlin, vollkommen unterrepräsentiert. Diese Beobachtung bestätigt auch die allgemeine Berufsstatistik des NSKK. 279 Das NSKK konzentrierte seine Standorte mehr in Städten, wo es sich den freien Zugang zur Industrie und zu den Autowerkstätten erhoffte. Da Landwirte zeitund ortsgebunden sind, konnten sie an entfernteren Zusammenkünften oft nicht teilnehmen. Auch beschränkte sich der Motorisierungswille der Bauern oft auf landwirtschaftliche Nutzfahrzeuge.

Dass in Eberswalde, abgesehen von 11 Ärzten unter 433 Mitgliedern, relativ wenig Freiberufler zu finden waren, mag auch an der Berufsstruktur der 40000Einwohner-Stadt gelegen haben, denn der Anteil im Motorsturm 22/M 29 BerlinCharlottenburg lag höher. ${ }^{280}$ Aufgrund der Nähe zur Technischen Hochschule gehörten dem 75 Mann starken Motorsturm in Berlin-Charlottenburg außerdem 13 Studenten an. Lokale Unterschiede, die Einfluss auf die Berufsstruktur hatten, müssen also berücksichtigt werden.

Insgesamt zeigten die untersuchten Stürme eine sozial polymorphe Struktur mit einem deutlichen Übergewicht an Arbeitern und Angestellten, die aus beruflichen Gründen mit Kraftfahrzeugen zu tun hatten. Dies nahm auch der spätere Bundeskanzler Kurt Georg Kiesinger ernüchternd zur Kenntnis, der bei seinem

276 Vgl. Motorstandarte Eberswalde, BArch-DH ZB II 1269 A. 9.

277 Vgl. Motorsturm 2/M 164 Saargemünd, LA Speyer, T 65 Nr. 48.

278 Nach internen NSKK-Schätzungen vom November 1936 hatte das BMW-Unternehmen 6000 bis 7000 Werksangehörige, von denen aber nur weniger als 500 dem NSKK angehörten; vgl. Mitteilung der Motorstandarte M 86 an die Korpsführung vom 16. 11. 1936, BArch NS 24/11. Zu den Werkstürmen vgl. auch die Seiten $144 \mathrm{f}$. und $343 \mathrm{f}$. dieser Arbeit. 279 Vgl. Motorstandarte Eberswalde, BArch-DH ZB II 1269 A. 9.

280 Neben Freiberuflern und akademischen Berufen gab es unter den 75 Mitgliedern 6 Kraftfahrer und 10 Personen mit kaufmännischen Berufen; BLHA Potsdam, Rep. 61 C. 
Eintritt in das NSKK 1934 angenommen hatte, das NSKK würde eine mehrheitlich distinguierte Mitgliederschaft aufweisen: „Nicht Repräsentanten bürgerlicher Provenienz, sondern Lastkraftwagenfahrer, Autoschlosser und kleine Einzelhändler mit ihren Lieferwagen bevölkerten den Motor-Sturm“, stellte er in seinen Erinnerungen fest. ${ }^{281}$

Die Berufsstruktur der passiven Mitglieder, der Korpsangehörigen, unterschied sich jedoch von der der aktiven Mitglieder. Von 167 Sturmmitgliedern des Motorsturms in Saargemünd leisteten sechs Meister und zwei Unternehmer aktiven Dienst $^{282}$, während unter den 91 Korpsangehörigen 10 Meister und 2 Unternehmer zu finden waren. Auffällig in der Berufsstruktur der Korpsangehörigen generell war die Vielzahl an Meistern, Juristen, Ingenieuren, Direktoren und Künstlern. ${ }^{283}$ Die Korpsangehörigen, so lässt sich zusammenfassen, waren im Durchschnitt älter, hatten ein höheres Bildungsniveau und sozial höher stehende Berufe als die aktiven Mitglieder.

\section{Zielgruppen}

Fahrzeugbesitzer und Führerscheininhaber

Obgleich grundsätzlich jeder „arische" Deutsche in das NSKK aufgenommen werden konnte, richtete das NSKK seine Werbung auf bestimmte gesellschaftliche Gruppen. Gezielt wurden Kraftfahrzeugbesitzer geworben.284 SA-Männer, die Überweisungsanträge an das NSKK stellten, wurden dann aufgenommen, wenn sie Führerschein, Fahrzeug oder besonderes Talent für den Motorsport vorweisen konnten. In kleineren Städten wurden speziell die Kraftfahrzeugbesitzer zu Werbeveranstaltungen eingeladen. ${ }^{285} \mathrm{Da}$ auch 1938 immer noch zu wenige Fahrzeughalter in den Reihen des Korps standen, erließ die Korpsführung einen Befehl, wonach die Halter von Kraftfahrzeugen als aktive oder wenigstens als passive Mitglieder geworben werden sollten. Im Gebiet der Motorstandarte 46 Hanau waren im November 1938 von 25000 Kraftfahrzeughaltern nur 1200 Personen Mitglieder im NSKK. 286 Dieses Beispiel zeigt, dass den Werbebemühungen nur beschränkter Erfolg beschieden war. Der Großteil der motorisierten Volksgenossen sah offenbar keinen Grund, ins NSKK einzutreten, und ein weiterer Teil der

281 Kiesinger: Dunkle und helle Jahre, S. 173.

282 Vgl. Motorsturm 2/M 164 Saargemünd, LA Speyer, T 65 Nr. 48.

$283 \mathrm{Vgl}$. Aufstellung der Korpsangehörigen des Motorsturms 2/M 164 Saargemünd vom 31. 12. 1941, LA Speyer, ebenda. Unter den 34 Korpsangehörigen des Münchner Sturms 18/M 86 waren ein Kammersänger, ein Professor, ein Bankdirektor und vor allem Ingenieure vertreten; vgl. Verzeichnis der Korpsangehörigen im Sturm 18/M 86 vom Februar 1939, BArch NS 24/14.

${ }^{284}$ Mitgliederwerbung innerhalb der SA und SS wurde untersagt. Allgemeine Werbeschreiben richteten sich an Führerscheininhaber; vgl. OSAF-Führungsamt an den Führer der Gruppe Bayerische Ostmark vom 15.2. 1936 (Abschrift), in der diese Richtlinie zur Kenntnis gebracht wurde; StA Amberg, NSDAP-Kreisleitung Roding/Neuburg Nr. 8.

285 Vgl. Schreiben der Motorstandarte 46 an den Motorsturm 15/M 46 Schlüchtern vom 17. 8. 1938, HStA Wiesbaden, Abt. 483 Nr. 7287.

286 Vgl. Standartenbefehl der NSKK-Motorstandarte 46 vom 29. 11. 1938, HStA Wiesbaden, Abt. 483 Nr. 7222. 
Fahrzeugbesitzer zog die Nur-Mitgliedschaft im Einheitsautomobilclub DDAC vor.

Innerhalb des Kraftfahrkorps selbst - und dies mag erstaunen - war nur eine Minderheit der Aktiven im Besitz eines Kraftfahrzeugs. Von den 85 Mitgliedern eines Pionierzugs in Coburg fuhren 1934 gerade mal drei einen Kleinwagen und einer ein Kraftrad; von den 48 Personen eines Nachrichtenzuges besaßen vier einen Kleinwagen und vier Krafträder. ${ }^{287}$

Weitere Beispiele liefern prozentuale Vergleichszahlen: Die Stichprobe eines Motorsturms in Saarbrücken ergab, dass auf 21 Mitglieder nur 3 Fahrzeugbesitzer - also 14\% - kamen. ${ }^{288} \mathrm{Im}$ Sturm 11/M 95 der Motorstandarte Coburg verfügten im Juni 1938 38,7\% der Mitglieder über ein Fahrzeug, ${ }^{289}$ im Sturm 15/M 95 in Lichtenfels waren es 29\% der Mitglieder, ${ }^{290}$ und in der Motorstandarte 2/M Saar mit Sitz in Saarbrücken betrug der Anteil der Kraftfahrzeugbesitzer 21\%.291 Einen überaus hohen Prozentsatz an Kraftfahrzeugbesitzern wies die Motorstaffel II der Motorstandarte 86 (München) im Dezember 1935 auf: 22,7\% der 1080 Mitglieder fuhren Motorräder und 19,2\% ein Auto. Damit lag der Motorisierungsgrad mit 42,3\% sehr hoch. ${ }^{292}$ Dies war aber nicht auf den gesamten Münchner Raum übertragbar. Von den 4179 Mitgliedern, die 1938 der Motorstandarte München angehörten, brachten 1104 ein Privatfahrzeug ein, was einem Anteil von $28,8 \%$ entsprach. ${ }^{293}$

Sturmführer beklagten mancherorts die anhaltend hohen Steuern und Benzinkosten, die es vielen Mitgliedern unmöglich machten, ihre Motorräder in Betrieb zu nehmen. Der Scharführer des Sturms 21/M 138 meldete der Korpsführung im Januar 1939, dass seit Jahren die Hälfte der Motorräder abgemeldet sei. ${ }^{294}$

Geht man von einem Motorisierungsgrad der NSKK-Stürme von rund 30\% aus, war dies gemessen am Verbreitungsgrad des Kraftfahrzeugs innerhalb der deutschen Gesellschaft ein hoher Wert. Legt man jedoch den Anspruch des NSKK als "motorisierte Gliederung der NSDAP“ als Maßstab an, war diese Zahl absolut ungenügend.

Ein ähnliches Bild ergab sich, wenn man die Führerscheinzahlen betrachtet. Die Annahme, die überwiegende Mehrheit der selbst ernannten "Motorkämpfer" sei im Besitz eines Führerscheins gewesen, stellt sich schnell als Trugschluss heraus. In dem im Juni 1938 beim Reichswettkampf zum Siegersturm erkorenen Motor-

287 Vgl. Stärkenachweis des Pionierzugs der Staffel II/M 77 Coburg vom Oktober 1934, BArch NS 24/3.

288 Eine Stichprobe unter den Mitgliedern, deren Nachname mit A oder B begann, bestätigt die geringe Führerschein- und Fahrzeugzahl; vgl. Personalangaben des Sturms 2/M Saar in Saarbrücken, LA Speyer, T 65 Nr. 235.

289 Vgl. Personalangaben des Motorsturms 11/M 95 Coburg vom 1. 6. 1938, BArch NS 24/ 56.

290 Vgl. Siegersturm 15/M 95 Lichtenfels, Stärkemeldung vom 3. 6. 1938, ebenda.

291 Vgl. Stärkemeldung des Sturms 2/MSaar der Motorgruppe Kurpfalz-Saar vom 31. 3. 1939, LA Speyer, T 65 Nr. 157.

292 Vgl. Halbjahresbericht der Motorstaffel II/M 86 vom 25. 6. 1936, BArch NS 24/16.

293 Vgl. Stärkemeldung der M 86 vom 31. 1. 1938, BArch NS 24/65.

294 Vgl. Schreiben des Scharführers des Sturms 21/M 138 an die Korpsführung vom 26. 1. 1939, BArch NS 24/312. 
sturm aus Lichtenfels hatten zwar 82\% der NSKK-Männer einen Führerschein, doch war dies ein überdurchschnittlich hoher Wert. „Nur“ $75 \%$ der Mitglieder der Motorstandarte 86 München waren im Januar 1938 im Besitz eines Führerscheins. ${ }^{295}$ Über noch weniger Führerscheininhaber verfügte der Motorsturm in Saarbrücken, in dem die Quote $42 \%$ betrug. ${ }^{296}$ Die meisten Führerscheinbesitzer - rund 60 bis $70 \%$ - hatten den Führerschein Klasse III für Motorräder. ${ }^{297}$

In einem vertraulichen Schreiben vom 29. März 1938 an die Führer der Motorgruppen legte der Korpsführer offen:

„So oft ich die Motorstürme besichtige, stelle ich fest, dass ein Drittel und mehr NSKK-Männer nicht im Besitze des Führerscheins sind. Ich bin mir bewußt, daß der Erwerb des Führerscheins bei vielen NSKK-Männern dadurch erschwert ist, daß diese die Kosten für Fahrschulausbildung nicht aufbringen. ${ }^{298}$

Diese für das NSKK hohe Quote von führerscheinlosen Mitgliedern galt es zu vermindern. Dem Ansinnen standen neben den Prüfungskosten und dem Verbot, unentgeltlichen Fahrunterricht intern durchführen zu lassen, auch das Fehlen von Dienstfahrzeugen für Fahrschulzwecke entgegen. Eine Art Imagerettung für das NSKK bedeutete deshalb die Einführung einer neuen Führerscheinklasse am 13. November 1937. Das NSKK nahm innerhalb seiner Gliederung die Prüfung für die neue Führerscheinklasse IV (Kleinkrafträder bis $250 \mathrm{ccm}$ ) eigenständig vor und konnte nun aktiv dazu beitragen, dass es den „führerscheinlosen“ NSKKMann nicht mehr gab. ${ }^{299}$ Die Motorstandarte München steigerte die Zahl seiner Führerscheinbesitzer dadurch von $75 \%$ im Jahre 1938 auf $85 \%$ im Jahre 1939.300

Deutlich wird, dass sich für das NSKK nicht nur etablierte Fahrzeugbesitzer, sondern auch in immer stärkerem Maße junge Männer interessierten, die sich selbst kein Fahrzeug leisten konnten. Die Schaffung einer mitgliederstarken Organisation hatte Priorität vor der Bildung einer motorisierten Eliteeinheit. Anschauliches Beispiel dafür ist der Tagesbefehl vom Oktober 1936, der den fahrzeuglosen Mitgliedern vorschlägt: „Mit gleichem Stolz soll aber auch der dem NSKK angehörende Radfahrer einen kleinen NSKK-Wimpel an seinem Fahrrad

295 Von 3747 Mitgliedern waren Anfang 1938968 ohne Führerschein; vgl. Stärkemeldung der M 86 vom 31. 1. 1938, BArch NS 24/65.

296 Vgl. Personalangaben des Sturms 2/MSaar in Saarbrücken, LA Speyer, T 65 Nr. 235.

297 Vgl. Kl. I: 1 346, Kl. II: 564, Kl. III: 2011, Sonderklasse: 14; Stärkemeldung der M 86 vom 31. 1. 1938, BArch NS 24/65. Im Siegersturm 15/M 95 Lichtenfels hatten $68 \%$ der Führerscheinbesitzer Führerschein Kl. III; Stärkemeldung vom 3.6. 1938, BArch NS 24/56.

298 Schreiben des NSKK-Korpsführers an die Führer der Motorgruppen vom 29. 3.1938 (vertraulich), BArch NS 24/155. Auch der Führer der Motorgruppe Hessen bestätigte für sein Gebiet, dass über ein Drittel der Mitglieder nicht im Besitz des Führerscheins waren; Schreiben der Motorgruppe Hessen an den Inspekteur Technik vom 6. 4. 1938, BArch NS 24/139.

299 Vgl. Schreiben der Motorgruppe Leipzig an den Inspekteur Technik vom 14. 4. 1938, BArch NS 24/139. Die Führerscheinklasse 4 wurde in der „Verordnung über das Verhalten im Straßenverkehr" vom 13.11. 1937 eingeführt, doch galt für bisher führerscheinfreie Kraftfahrzeuge eine Übergangsfrist bis 1. 10. 1938.

300 Die Führerscheine der 4179 Mitglieder verteilten sich wie folgt: Kl. I: 1247, Kl. II: 540, Kl. III: 2070, Kl. IV: 542, Sonderklasse: 14, ohne: 613; Stärkemeldung der M 86 vom 1. 8. 1939, BArch NS 24/65. 
anbringen “301 - ein schwacher Trost für alle unmotorisierten Mitglieder des NSKraftfahrkorps.

\section{Im Kraftfahrzeugwesen tätige Berufsgruppen}

Das NSKK dehnte seine Werbebemühungen auf alle Berufsgruppen aus, die professionell mit dem Kraftfahrwesen zu tun hatten. Beispielsweise wurden ehemalige Angehörige motorisierter Truppenteile gezielt geworben. ${ }^{302}$ Als Mitglieder und Führer von NSKK-Einheiten waren sie hervorragend geeignet, das soldatische und technische Niveau zu erhöhen.

Sehr nützlich waren für die Korpsführung auch die persönlichen Beziehungen zu Wissenschaftlern: Um über neueste Forschungen auf dem Gebiet des Kraftfahrwesens informiert zu sein, hielt das NSKK Kontakt zu Hochschul-Forschungseinrichtungen. Das NSKK warb Professoren für das NSKK, die ehrenhalber mit einem NSKK-Führerrang bedacht wurden: z. B. NSKK-Obertruppführer Beck, Professor an der TH Dresden ${ }^{303}$, NSKK-Sturmführer Max Edelmann, Professor an der TH München ${ }^{304}$, NSKK-Oberführer Ernst Storm, Professor und ab 1938 Rektor der Technischen Hochschule Berlin, ${ }^{305}$ Mitglied im Stab der Korpsführung A. W. Schmidt, Rektor an der TH München ${ }^{306}$ und NSKK-Sturmführer Wunibald Kamm, Leiter des Forschungsinstituts für Kraftfahrwesen und Fahrzeugmotoren der TH Stuttgart.

Die wichtigste Zielgruppe des NSKK aber waren die in der Automobil- und Zubehörindustrie und im Handwerk Tätigen. Der Korpsführer gab in seiner Verordnung vom 12. Februar 1934 die Richtung vor: So mache der Ausbau der Technik in der Breitengliederung es erforderlich, möglichst viele Ingenieure, Werkmeister und Mechaniker in das NSKK aufzunehmen. Die Führer der Einheiten sollten, wie es in der NS-Terminologie hieß, „technisch durchgebildetes Menschenmaterial" im Bereich der Einheit erfassen und prüfen, ob es sich zum Eintritt eigne. ${ }^{307}$ Dass dieses Ziel erreicht worden ist, geht bereits aus der Berufsstruktur hervor, nicht aber, wie es erreicht worden ist. Die Methoden der Anwerbung durch das NSKK und die Handlungsspielräume der Umworbenen können im Fall des Kraftfahrzeughandwerks exemplarisch dargestellt werden:

Da handwerkliches Können als Kern der Motorisierung gesehen wurde, stellten die 150000 Berufsangehörigen des Kraftfahrzeughandwerks das wichtigste Reser-

301 Verordnungsblatt der Korpsführung vom 1. 11. 1936: „Tagesbefehl an das NSKK!“ vom 13. 10. 1936, IfZ Db 30.01 .

302 Die Führung der 7. Division des Reichsheeres beklagte im Schreiben an das Generalkommando VII vom 9. 12. 1935, dass die Beitrittsforderungen der Motorstandarte 87 München einem Zwang gleichkämen; BArch-MA, RH 26-7/373.

303 Vgl. Der NSKK-Mann vom 17. 8. 1940: „Holzgas im Kraftfahrzeugbetrieb“.

$304 \mathrm{Vgl}$. Liste der NSKK-Führer zur besonderen Verfügung der Korpsführung vom Inspekteur Technik an die Korpsführung vom 29. 7. 1938, BArch NS 24/85.

305 Vgl. Der NSKK-Mann vom 8. 10. 1938: „Korpsgeist - Frontgeist“.

$306 \mathrm{Vgl}$. Schreiben des Inspekteurs Technik an die Kraftfahrinspektion Süd vom 12. 11. 1935, BArch NS 24/461.

307 Vgl. Verfügung des Korpsführers vom 13. 2. 1935, BArch NS 24/73. 
voir an ausgebildeten und technisch versierten Fachleuten dar. ${ }^{308}$ Als Multiplikatoren konnten die Autoschlosser und Mechaniker ihr technisches Wissen an die Stürme weitertragen. Die von NS-Politikern propagierte „enge Verbundenheit der Fachhandwerker mit dem NSKK" ${ }^{309}$ war auch geeignet, die Besitzer von Werkstätten dazu zu bewegen, ihre Räume für die technische Ausbildung der Motorstürme und der Motor-HJ sowie für Reparaturarbeiten zur Verfügung zu stellen. Der Korpsführer beteuerte zwar 1941 öffentlich: das NSKK sei „keine Zwangsinnung für Berufskraftfahrer, Fahrlehrer, Sachverständige, Spediteure, Angehörige des Kraftfahrzeug-Handwerks, der Kraftfahrzeug-Wirtschaft [...]“310, doch in der Realität schreckte er bereits vor dem Krieg nicht davor zurück, immensen Druck auf diese Berufsgruppen auszuüben - zu wichtig war die Mitarbeit der Kfz-Handwerker, Fahrlehrer und Berufskraftfahrer für das Gelingen der Ausbildungsarbeit des NSKK. ${ }^{311}$ Der Reichsinnungsverband des Kraftfahrzeughandwerks gab 1937 und im folgenden Jahr Namen und Adressen der Kraftfahrzeughandwerker an die Motorstandarten des NSKK weiter. Die Standartenführer wiesen die Sturmführer an, die in ihrem Bereich ansässigen Handwerker aufzusuchen "und durch Unterschreiben des Aufnahmeformulars aufzunehmen". ${ }^{312}$ Bei Ablehnung war eine Begründung erforderlich. Durch dieses Verfahren erhielt das NSKK Kenntnis davon, wer bereits Mitglied des NSKK war, wer noch geworben werden musste und wer aus welchem Grund den Beitritt verweigerte. ${ }^{313}$ Dieses Kontrollinstrument ermöglichte es dem NSKK, massiven Druck auf die Kraftfahrzeughandwerker auszuüben.

Die Beziehungen zwischen dem Reichsinnungsmeister des Kraftfahrzeughandwerks, Friedrich Stupp, im Range eines NSKK-Obersturmführers, und der Korpsführung gestalteten sich kooperativ, und auch die Verbindungen, die die Stäbe der Motorgruppen zu den Bezirksinnungsmeistern unterhielten, beschrieben die Verantwortlichen als "eng". ${ }^{314}$ Auf den Innungsversammlungen des Kraftfahrzeughandwerks wurden die Meister wiederholt aufgefordert, sich dem NSKK anzuschließen. Die Werbung der Innungsmeister und der Druck der ansässigen Motorstürme für den Beitritt zum NSKK zeigten Wirkung: Im Februar 1939 gehörten nach Korpsangaben rund 80\% der Handwerksmeister dem NSKK

308 Vgl. Institut für Konjunkturforschung: Drei Jahre Motorisierung, S. 6.

309 Machemer: Reichsautobahn und Kraftfahrzeughandwerk, S. $34 \mathrm{f}$.

310 Appell an die Sturmführer vom 6. 3. 1941, BArch NS 24/152.

311 Auf Geheiß des Korpsführers sollten sämtliche Omnibusfahrer zur Aufnahme in das Korps bewegt werden. Die Stürme mussten alle Fahrer melden, die entweder Mitglied oder bisher Nicht-Mitglied des NSKK waren; Schreiben des Standartenführers der M 77 Coburg an den Sturm 21/M 77 vom 29. 9. 1937, BArch NS 24/620.

$312 \mathrm{Vgl}$. Anweisung der Motorstandarte 86 an die Motorstürme 31-35/M 86 vom 5. 8. 1937, $\mathrm{BA} . \mathrm{h}$ NS 24/14.

313 Vgl. Anweisung der M 51 Edenkoben an sämtliche Einheiten vom 19.11. 1938, LA Speyer, T 65 Nr. 173.

314 Vgl. Halbjahresberichte 1938 A-N vom 1. 4. 1938 - 30. 9. 1938, BArch NS 24/100; vgl. die Liste der Führer, die dem Korpsführer zu besonderen Zwecken zur Verfügung standen, BArch NS 24/85. 
an. Innerhalb der Düsseldorfer Standarte bildete sich sogar ein Handwerksmeister-Sturm. ${ }^{315}$

Trotz dieser hohen Prozentzahl kritisierte der Korpsführer die mangelnde Einsatzbereitschaft der Handwerksmeister, die sich häufig nur als Korpsangehörige der Gliederung anschlossen und damit eine aktive Mitwirkung verweigerten. ${ }^{316}$ Der Wunsch des Korpsführers nach einem größeren Engagement dieser Berufsgruppe lässt darauf schließen, dass viele Leiter von Kraftfahrzeugbetrieben dem NSKK in erster Linie nur formal beitraten und nur in geringem Maße bereit waren, ihre Werkstätten für die Mitglieder der Motorstürme zu öffnen. ${ }^{317}$ Die Zahl von rund 400 Werkstätten, die das Handwerk dem NSKK im September 1938 insgesamt zu Übungszwecken zur Verfügung stellte, war zu gering, um das Ausbildungsniveau der Breitengliederung umfassend heben zu können. ${ }^{318}$

Als das NSKK im Januar 1939 den Auftrag erhielt, die vor- und nachmilitärische motorische Schulung der deutschen Jugend zu übernehmen, waren die Handwerksmeister für das NSKK nicht nur aus politischem Gleichschaltungsbestreben, sondern auch aus militärischen Erfordernissen heraus bedeutsam. ${ }^{319}$

\section{Mögliche Beitrittsmotive}

Aus den zeitgenössischen Quellen lassen sich die persönlichen Motive der Mitglieder für den Beitritt zum NSKK nicht ermitteln. Dennoch ist es möglich, aus dem Selbstverständnis der Gliederung, aus der Zusammensetzung der Mitglieder und aus der Zielgruppen-Analyse Erkenntnisse in dieser Richtung zu gewinnen. Die Aussagen ehemaliger Mitglieder nach dem Krieg, niedergelegt in Spruchkammerprotokollen, in Memoiren und in Interviews verdeutlichen darüber hinaus die unterschiedlichen Motivlagen - dies mit der Maßgabe, dass aufgrund der zeitlichen Distanz und des Rechtfertigungsbedürfnisses der Quellenwert dieser Dokumente eingeschränkt ist. Die auf diese Weise ermittelten Beitrittsgründe lassen sich grob in drei Kategorien einteilen: Politische Gründe, berufliche Gründe, Sport- und Technikbegeisterung.

315 Vgl. Krafthand vom 11. 2. 1939: „Meistersturm im NSKK gebildet“.

316 Die Motorstandarte M 75 Niederrhein berichtete, dass sich sehr viele Handwerker nach Aufforderung durch die Innungsmeister für den Beitritt entschieden, dass die meisten jedoch entweder einen Rückzieher machten oder sich als Korpsangehörige einschrieben. Ähnliches berichtete auch die Motorgruppe Niedersachsen; vgl. Halbjahresberichte 1938 A-N vom 1. 4. 1938 - 30. 9. 1938, BArch NS 24/100.

317 Vgl. Krafthand vom 25. 2. 1939: „Reichsleiter Korpsführer Hühnlein“.

318 Vgl. Mitteilung des Inspekteurs Technik an den Korpsführer vom 31. 8. 1938; Auswertung der Halbjahresberichte vom 1. 4. 1938 - 30. 9. 1938, BArch NS 24/100

319 Der Korpsführer, der den Reichsinnungsmeister um Hilfe bat, rechnete aus, dass er mehr als 100000 handwerklich geschulte Männer aus dem Kraftfahrzeughandwerk benötigte, um den Ausbildungsauftrag der vor- und nachmilitärischen Ausbildung erfüllen zu können, Schreiben des Korpsführers an die Führer der Motorobergruppen u.a. vom 24. 2. 1939 (vertraulich), BArch NS 24/156. 
Politische Gründe

Mitglieder, die vor 1933 in die Motor-SA und das NSKK eingetreten waren, sind als Förderer der nationalsozialistischen Bewegung einzustufen. Die Mitgliedschaft symbolisierte die Bereitschaft, den Aufstieg der NSDAP tatkräftig zu unterstützen. Dies galt in noch stärkerem Maße für SA- oder NSKK-Mitglieder, die auch der NSDAP angehörten. Nach der Machtübernahme hegten die Neumitglieder Sympathien für eine Gliederung, die Politik und Technik in sich vereinigte. Ungeachtet dessen, ob der Beitritt aus politischer Überzeugung erfolgte oder aus dem Bedürfnis heraus, weltanschauliche Anpassung zu demonstrieren, war er doch in jedem Fall politisch motiviert.

Als die NSDAP für neue Mitglieder geschlossen worden war, bot die Mitgliedschaft im NSKK eine gute Ausgangsbasis, um nach der Lockerung der Aufnahmesperre am 1. Mai 1937 in die Partei aufgenommen zu werden. NSKK-Mitglieder, die im aktiven Dienst inzwischen politische Meriten gesammelt hatten, traten überwiegend in die Partei ein. Durch die Aufnahme des größten Teils der NSKKMitglieder in die NSDAP wurde der Nichtparteigenossenbeitrag ganz gestrichen. ${ }^{320} 83 \%$ der NSKK-Mitglieder der Motorstandarte M 95 Coburg gehörten im Juni 1938 der NSDAP an. ${ }^{321}$ Der Beitritt zum NSKK konnte also in den Jahren 1933 bis 1937, wie dies auch bei der SA zu vermuten ist, als Ersatzhandlung für die unrealisierbare Parteimitgliedschaft stehen. ${ }^{322}$ Dass für viele Mitglieder mit der Aufnahme in die Partei der Grund für eine aktive Mitgliedschaft in einer Gliederung entfiel, bestätigen auch Berichte des NSKK aus München. Der vermögende Teil des NSKK habe sich, so die Klage des Führers der Motorstandarte 86 im Juli 1937 , längst wieder ,in ein ruhiges Spießerleben zurückgezogen“ - gehöre dem NSKK also nicht mehr aktiv an. ${ }^{323}$

Auch in genau entgegengesetzter Hinsicht fungierte das NSKK als eine Art „Ersatzorganisation“. Durch den Eintritt in das NSKK war es möglich, einer Mitgliedschaft in der Partei oder den weitaus aggressiveren Gliederungen SA und SS auszuweichen. Der Verleger Franz Burda, der dem NSKK zwischen 1934 und 1937 angehörte, tat seine Mitgliedschaft nach dem Krieg als Belanglosigkeit ab. Den Eintritt kommentierte er sinngemäß mit den Worten: „Irgendwo musste man damals im Alter von 31 Jahren ja mitmachen. " 24 „Irgendwo" legt die Vermutung

320 Vgl. Anweisung der Kassenverwaltung des NSKK vom 1.7. 1937, betr. Nichtparteigenossenbeiträge, BArch NS 24/1.

321 Vgl. Schreiben der M 95 Coburg an die NSDAP-Gauleitung Bayer. Ostmark vom 20. 10. 1938 , BArch NS 24/32.

322 Mit dieser Funktion als „Ausweichorganisation“ erklärt Elmar Gasten die hohe Zahl an Nichtparteigenossen in der SA; vgl. ders: Aachen in der Zeit der nationalsozialistischen Herrschaft 1933-1944, S. 219; Heinz: „...die Reihen fest geschlossen“, S. 90 f.

323 Schreiben der M 86 an den Führer der Motorgruppe Hochland vom 28. 7. 1937, BArch NS 24/848. Besonders wohlhabende Selbständige ließen sich zu Korpsangehörigen umschreiben und zahlten bereitwillig den höheren Beitrag von 2 RM im Monat; vgl. Schreiben des Obersturmführers Heller an die Motorgruppe Hochland vom 25.7. 1939, ebenda.

324 Vgl. Köpf: Die Burdas, S. 36. 
nahe, der Beitritt sei ohne echte Überzeugung und aus einem gewissen Anpassungsdruck erfolgt.

Nach dem Prinzip „des kleineren politischen Übels“ verfuhr nach eigenen Aussagen auch der Geschichtsstudent und spätere bayerische Ministerpräsident Franz Josef Strauß. Auf Anraten eines Professors trat er 1937 dem NSKK bei, um sich dem an der Universität herrschenden politischen Druck zu entziehen und sein Studium fortsetzen zu können. Strauß wählte das NSKK, weil er Motorradfahrer war und einen Münchner Sturm (23/M 86) gefunden hatte, der in der Tradition des Stahlhelms stand. In den Reihen des NSKK hätten sich, so Strauß, im Gegensatz zur SS, wo es vor eifernden Scharfmachern wimmelte, „biedere“ Handelsleute, Prokuristen, Diplomingenieure, Architekten und Handwerker getummelt. In seiner Funktion als weltanschaulicher Referent, so berichtet Strauß in seinen Erinnerungen, habe er vor allem historische Vorträge gehalten. Bei Kriegsbeginn wurde er zu einer Kraftfahr-Ersatzbatterie der Artillerie einberufen. ${ }^{325} \mathrm{Im} \mathrm{Zu-}$ sammenhang mit einer Beitrittstypologie ist die Frage nach persönlichen Verantwortlichkeiten und dem Verhältnis von politischem Anspruch und Wirklichkeit irrelevant. ${ }^{326}$ Entscheidend ist das hier kreierte Bild des NSKK als „harmlose“ Gliederung, die sich sowohl vom Dienstalltag und von ihrem Charakter als auch von der Mitgliederzusammensetzung von der NSDAP, der SA und SS unterschieden habe.

Auch im folgenden Beispiel aus dem akademischen Raum wird das „kleinere politische Übel" als Beitrittsmotiv geltend gemacht. Als der frisch diplomierte Physiker Wilhelm Walcher Ende 1933 eine Assistentenstelle im physikalischen Institut der Technischen Hochschule Charlottenburg antreten sollte, wurde ihm von Kollegen angeraten, in irgendeinen „Verein“ einzutreten. Da er kein Parteimitglied war und sich auch sonst nie NS-politisch engagiert hatte, trat Walcher als Anwärter einem NSKK-Sturm bei. ${ }^{327}$

Als eine Art Scheinbekenntnis zum Nationalsozialismus beschreibt auch der Historiker Wolfram Fischer die Mitgliedschaft im NSKK. Aus seiner persönlichen Beobachtung heraus war das NSKK die ideale Organisation für regimedis-

325 Vgl. Strauß: Die Erinnerungen, S. 36; Der Monat vom März/April 1980, H. 1, „Aus einem deutschen Briefwechsel"; Bickerich: Franz Josef Strauß, S. 26.

326 Strauß rechtfertigte die Übernahme des weltanschaulichen Referats, das ihm den Dienstgrad eines Rottenführers einbrachte, folgendermaßen: „Um nicht in die peinliche Lage zu kommen, uns ideologische Vorträge anhören zu müssen, haben meine Freunde und ich beschlossen, den Posten des, weltanschaulichen Referenten' mit einem aus unserer Mitte zu besetzen“; Strauß: Die Erinnerungen, S. 36. Die Frage, ob Strauß seine Aufgaben als weltanschaulicher Referent unter Einbeziehung "rassenkundlicher" Belehrungen ernst nahm, oder ob er seine Kameraden bis Kriegsbeginn mit geschichtlichen Vorträgen unterhielt, kann hier nicht geklärt werden. Politisch links gerichtete Kritiker wie Bernt Engelmann sahen in seinem Werdegang einen Beleg für ihre These von der Kontinuität brauner Ideologien bis in die Zeit der Bundesrepublik; vgl. Engelmann: Das neue Schwarzbuch. Franz Josef Strauß, S. 21-31.

327 In der im Entstehen begriffenen Arbeit über die Biographie des Physikers Hans Kopfermann werden Physikerkarrieren in Deutschland beschrieben; vgl. Michael Kopfermann: Vergangenheit im Blickfeld eines Physikers. Hans Kopfermann 1895-1963 (Eine Wissenschaftsstudie), bisher nur online unter: <http://www.aleph99.org/etusci/ks/t2a3.htm>. 
tanzierte Bürger mit beruflichen, insbesondere akademischen Ambitionen. Es sei üblich gewesen, dass derjenige, der „in irgendeine Organisation der NSDAP eintreten mußte, aber eigentlich nicht wollte, in den NSKK eintrat. Das war ein Sportverband der Motorradfahrer" 328

Die starke Bereitschaft innerhalb der Studentenschaft, dem NSKK pro forma beizutreten, bestätigen Dienstkontrollberichte aus den Universitätsstädten. Darin heißt es, dass die Studenten sich „wegen gewisser Vorteile an der Universität“ 329 oder um zumindest "keine Unannehmlichkeiten in ihrem Studium zu erleiden" 330 , im NSKK anmeldeten, später aber nur eine geringe Motivation an den Tag legten. Der Führer einer Motorstaffel aus Würzburg berichtete in seinem Schreiben an die NSKK-Motorobergruppe Süd vom 17. Februar 1937:

„Nachdem nun heute die Universitäten von den Studenten bei Semesterantritt verlangen, daß sie SA, SS oder NSKK-Dienst leisten, melden sie sich zu Semesterbeginn bei den Stürmen an und schon beim nächsten Dienst fehlen bis zu 60\% und mehr mit der Entschuldigung, im Examen zu stehen oder anderer Ausreden. ${ }^{\text {" }} 331$

Zahlreiche Sturmführer beklagten ein „lässiges, opferloses und willensschwaches Verhalten" der Studenten. ${ }^{332}$ Die mangelnde Dienstbereitschaft eines großen Teils der studentischen NSKK-Mitglieder und die geringe Zahl an Privatfahrzeugen deuten darauf hin, dass der Wille zur politischen Absicherung bei den Studenten als Motiv für den Beitritt im Vordergrund stand. Diesem Ziel mag auch die Mitgliedschaft des Althistorikers Alfred Heuß im NSKK gedient haben. Er gehörte dem Nationalsozialistischen Deutschen Studentenbund und einem Leipziger Motorsturm, ab 1. Mai 1937 auch der NSDAP an. Diese „politischen Bekenntnisgesten" 333 halfen ihm, die 1937 gegen ihn erhobenen Zweifel an seiner politischen Zuverlässigkeit abzuwehren. Positive Beurteilungen, unter anderem auch vom Führer des Motorsturms 23/M 35, dem er angehörte, ermöglichten es ihm, dass er nach seiner Habilitation mit finanzieller Unterstützung des NS-Dozentenbundes die universitäre Laufbahn fortsetzen konnte. ${ }^{334}$

328 Wolfram Fischer führt diese Einschätzung auf Beobachtungen in der Familie zurück; vgl. das Interview mit dem Historiker, abgedruckt in: Hohls (Hrsg.): Versäumte Fragen, S. 102.

329 Schreiben des Motorsturms 12/M 78 (Erlangen) an die Motorstandarte M 78 vom 22. 4. 1937, BArch NS 24/750.

330 Schreiben der Motorstaffel IV/M 155 (Würzburg) an die NSKK-Motorobergruppe Süd vom 17. 2.1937, ebenda.

331 Ebenda.

332 Dienstkontrolle des Sturms 18/M 86 vom 31. 12. 1938, BArch NS 24/359. Klagen über wenig engagierte Studenten kamen auch aus Hessen, Tübingen und Freiburg; vgl. Schreiben der Motorgruppe Hessen an die Motorgruppe Hochland vom 14. 3. 1940, BArch NS 24/764; Schreiben der Motorbrigade Südwest an die Motorobergruppe Süd vom 3. 4. 1937, BArch NS 24/750. Als „Gegenmittel“ vereinbarten NSKK und Studentenbund das Freihalten bestimmter Tage für den Dienst im NSKK, Semesterbeurteilungen und weniger Beurlaubungen für Studenten; vgl. die Absprachen zwischen Studentenbund Gau München-Oberbayern und M 86 vom 1. 8. 1936, BArch NS 24/750.

333 Rebenich: Alfred Heuß, S. 673. Wie Stefan Rebenich betont, steht es außer Frage, dass Alfred Heuß trotz seiner Mitgliedschaften in NS-Organisationen als Person und als Wissenschaftler vollkommen immun gegenüber der NS-Ideologie blieb.

334 Als im Frühjahr 1937 die Erteilung einer Dozentur an Heuß anstand, bemängelten uni- 
Ähnliche Gründe führte auch der Politikwissenschaftler und Publizist Theodor Eschenburg (1904-1999) für seine Mitgliedschaft in der Motor-SS in den Jahren 1933/1934 ins Feld: Als Geschäftsführer eines Wirtschaftskartells war er daran interessiert, unter der Protektion einer politischen Organisation zu stehen, „um politischen Ärger" zu vermeiden. In die Motor-SS, die zu dieser Zeit noch vom Inspekteur der Motorstürme der SA und SS Hühnlein befehligt wurde, trat Eschenburg, nach eigenen Angaben, ein, weil er Autofahrer war, und die MotorSS den Eindruck einer harmlosen Sportorganisation erweckte. ${ }^{335}$

Die Frage, ob die Mitgliedschaft im NSKK für eine bewusste politische Überzeugung oder für ein Scheinbekenntnis stand, kann nur vor dem jeweiligen biographischen Hintergrund beantwortet werden. Fest steht, der Anteil von 31,5\% NSDAP-Mitgliedern im NSKK 1935 lag deutlich über dem der SA und spricht für eine politische Einsatzbereitschaft, die über eine rein passive Anpassungsleistung hinausging. ${ }^{336}$ Zugleich aber konnten Mitglieder ihre NSKK-Zugehörigkeit dazu nutzen, in eine politisch unauffällige Nische auszuweichen. Diese Art von politischer Alibifunktion - "irgendwo und irgendwie dabeigewesen zu sein“ prägte nach 1945 das Image des NSKK als der vermeintlich unpolitischsten politischen Gliederung im „Dritten Reich“.

\section{Berufliche Gründe}

Die Werbebemühungen des NSKK erstreckten sich auf alle mit dem Kraftfahrwesen in Zusammenhang stehenden Berufssparten. Nicht nur den im Kraftfahrzeughandwerk und der Motorenindustrie Beschäftigten, auch den im Handel Tätigen wurde mehrmals von der Innung des Kraftfahrzeughandels der Eintritt in das NSKK nahe gelegt. ${ }^{337}$ Automobilverkäufer gaben nach dem Krieg vor den Spruchkammern an, aus beruflichen Gründen die Mitgliedschaft erworben zu haben. ${ }^{338}$ Vor der Fusion zwischen NSKK und Motor-SA waren die Statusunterschiede zwischen SA und NSKK evident. Als Gründe für den Beitritt zum NSKK nannten Geschäftsführer und leitende Angestellte ihre berufliche Position und das Image des NSKK als unpolitischere Alternative zur SA. ${ }^{339}$

Mit geschäftlichen Erwägungen begründeten auch höchste Wirtschaftsrepräsentanten, Betriebsleiter und Direktoren ihren NSKK-Beitritt. Beim Fahrzeughersteller Hanomag in Hannover waren Betriebsleiter und Konstrukteure fast

versitäre und politische Gutachter seinen kritischen Geist und die fehlende nationalsozialistische Gesinnung. Gegen-Gutachten der Leipziger Kreisleitung und anderer Fürsprecher verhalfen ihm zu einer Dozentur und zu finanziellen Unterstützungsleistungen; vgl. ebenda, S. 667-669.

$335 \mathrm{Vgl}$. Eschenburg: Letzten Endes meine ich doch, S. $21 \mathrm{ff}$.

336 Vgl. Parteistatistik der NSDAP, Bd. III, 1935, S. 72.

337 Vgl. Entnazifizierungsakte, HStA Hannover, Nds. 171 Hannover Nr. 28379.

338 Vgl. Entnazifizierungsakte, HStA Hannover, Nds. 171 Hannover Nr. 3023.

339 Dies gaben ein Landesgeschäftsführer einer Versicherungsgesellschaft und ein Teilhaber einer Autofirma als Begründung für den Beitritt zum NSKK in ihren Entnazifizierungsverfahren zu Protokoll; HStA Hannover, Nds. 171 Hannover Nr. 30887 und Nds. 171 Lüneburg Nr. 10107. 
ausnahmslos aktive oder passive Mitglieder im NSKK. ${ }^{340}$ Ernst Hagemeier, Betriebsleiter der Adler Werke, der NSDAP-Mitglied und NSKK-Fördermitglied war, konnte bei der Entnazifizierung glaubhaft machen, dass ein Mindestmaß an Opportunismus notwendig war, um den schlechten Ruf des als „judenfreundlich“ geltenden Unternehmens in Parteikreisen zu verbessern. ${ }^{341}$ Der Vorsitzende des Reichsverbandes der Automobilindustrie Allmers und Korpsführer Hühnlein hätten den Parteieintritt empfohlen, um die Negativeinstellung der Partei und den daraus resultierenden ungünstigen Einfluss auf den Absatz zu beseitigen. ${ }^{342}$

Unmittelbar nach der Machtübernahme konnten Karrieristen durch ihre Mitgliedschaft in der NSDAP und im NSKK und durch politische Anbiederung berufliche Vorteile erlangen, die ihnen mehr Macht in Verbänden, Innungen und Betrieben der Automobilwirtschaft verschaffte. Als die Mitgliederzahl des NSKK jedoch anstieg, die NSKK-Führer bei den Fahrlehrern, Sachverständigen, Handwerkern und Berufskraftfahrern für eine Mitgliedschaft „warben“, und das NSKK immer mehr Einfluss im Kraftfahrwesen gewann, verlor die Zugehörigkeit zum NS-Kraftfahrkorps den Charakter eines Profilierungsinstruments. Da der Gruppendruck und die Sorge, berufliche Nachteile zu erleiden, zweifellos die Eintrittsbereitschaft erhöhten, verwandelte sich die „freiwillige“ Mitgliedschaft zunehmend in eine berufliche Norm.

Sport- und Technikbegeisterung

Obgleich sich das NSKK als Vereinigung von "nationalsozialistischen Motorkämpfern" definierte, stand es doch für jeden "arischen " Deutschen offen, der sich als "nationalgesinnt" und "motorfreudig“ ansah ${ }^{343}$ - Eigenschaften, mit denen sich viele technikbegeisterte Volksgenossen identifizieren konnten. Nicht zuletzt aus diesem Grund gaben die meisten ehemaligen Mitglieder nach dem Krieg als Hauptmotive für ihren Eintritt motorsportliche und technische Interessen an. ${ }^{344}$ So entstand das Bild einer Gliederung, in der die „Autonarren“ und diejenigen, die „Benzin im Blut“ hatten, zusammenkamen. ${ }^{345}$ Trotz des Defizits an Fahrzeugen innerhalb der Stürme kam man dem Kraftfahrzeug beim NSKK näher als anderswo. Man schraubte an Motoren, beschäftigte sich anhand von Verkehrsmodellen mit kniffligen Verkehrssituationen, und ab und zu ergab sich eine Möglichkeit, das Fahrzeug eines Kameraden lenken zu dürfen. Das benzinangetriebene Fortbewegungsmittel blieb auch in den dreißiger Jahren ein Objekt der Begierde mit Exklusivitätscharakter. Die Mitgliedschaft im NSKK wäre weniger attraktiv

340 Vgl. Entnazifizierungsakten: HStA Hannover, Nds. 171 Hannover Nr. 18384, 31523, 36003.

$341 \mathrm{Vgl}$. Entnazifizierungsakte Hagemeier, HStA Wiesbaden, Spruchkammer Frankfurt a. M. 520F.

342 Vgl. Anlage zur Entnazifizierungsakte Hagemeier, Erklärung des kaufmännischen Direktors L. vom 7. 10. 1947, HStA Wiesbaden, Spruchkammer Frankfurt a. M. ebenda.

343 Vgl. NSKK-Korpsführung (Hrsg.): Das NSKK, S. 5.

344 Vgl. Entnazifizierungsakte, HStA Hannover, Nds. 171 Hannover Nr. 30887.

345 Vgl. Interview der Verf. mit Herrn P., geb. 1908, ehemaliger Scharführer und Architekt, am 9. 3. 1999. 
erschienen, wenn der private Besitz eines Kraftfahrzeugs in dieser Zeit bereits zum Alltag der Mehrheit der deutschen Bevölkerung gehört hätte. ${ }^{346}$

Neben dem technischen Interesse wurde nach dem Krieg häufig der Motorsport als Beitrittsmotiv genannt. ${ }^{347}$ An motorsportlich Aktive, auch wenn sie nur Amateure waren, erging die Aufforderung, in das NSKK einzutreten. Ihnen wurde bereits für verhältnismäßig unbedeutende sportliche Siege eine Beförderung im Dienstrang zugesprochen. 348 Wer den Motorsport als Beweggrund für den NSKK-Beitritt nannte, den dürfte die politische Ausrichtung und die kämpferische Pose des NSKK zumindest nicht gestört haben. Vermutlich beeindruckten gerade solche Elemente und Darstellungsformen viele Motorsportfans. Hegte man eine Abneigung gegen alles Soldatische, hätte eine gemäßigtere Alternative darin bestanden, motorsportliche Leidenschaften im oder über den Einheitsautomobilclub auszuleben. ${ }^{349}$

\section{Das höhere Führerkorps}

\section{Die Korpsfübrer}

In der Geschichte des NSKK von der Machtübernahme bis zum Ende des Zweiten Weltkriegs gab es zwei Korpsführer, die an der Spitze des Kraftfahrkorps standen. Adolf Hühnlein war von 1933 bis 1942 die prägende Gestalt für die Entwicklung, den Aufbau und die Zielsetzung des NSKK. Daher kommt seiner Biographie, die in der Forschung bisher nur auf geringes Interesse stieß, Bedeutung zu.

Adolf Andreas Hühnlein wurde am 12. September 1881 in Neustädtlein (Oberfranken) geboren. Er stammte aus einer alten fränkischen Bauernfamilie. Mit 19 trat er in die Armee ein und fand Aufnahme als Fahnenjunker im 3. Bayerischen Pionierbataillon Ingolstadt. In der Folgezeit diente Hühnlein als Offizier in einer Pionier- und Telegrafentruppe. Er absolvierte eine zweijährige Ausbildung auf der Artillerieschule; danach besuchte er drei Jahre lang die Bayerische Kriegsakademie in München. Im Ersten Weltkrieg war er zuerst Adjutant der Inspektion des Bayerischen Ingenieurkorps, diente dann als Kompanieführer und Bataillonskommandant an der Front. Zuletzt fungierte er als Generalstabsoffizier im Generalkommando und im Stab des Chefs des Feldkraftfahrwesens. 350 Hühnlein war für Nachschubaufgaben verantwortlich und regelte nach dem Waffenstillstand die Übergabe von Kraftwagenparks an die Siegermächte. ${ }^{351}$ Wie an den genannten

\footnotetext{
346 So urteilt auch Edelmann: Vom Luxusgut, S. 178.

347 Vgl. Entnazifizierungsakten: HStA Hannover, Nds. 171 Hannover Nr. 18384; Nds. 171 Hildesheim Nr. 23787 und StA Düsseldorf, NW 1002 -C- 68447.

348 Vgl. Entnazifizierungsakte, HStA Hannover, Nds. 171 Hannover Nr. 37285.

349 Selten nur brachten öffentliche Kläger das Gegenargument, Motorsport hätte man auch als Mitglied im Automobilclub DDAC betreiben können; vgl. Entnazifizierungs-Hauptausschuß der Stadt Hameln vom 6. 10. 1948, Entnazifizierungsakte, HStA Hannover, Nds. 171 Hannover Nr. 2331.

350 „Adolf Hühnlein“, in: Männer im Dritten Reich, S. 112.

351 Vgl. Schirach: Die Pioniere des Dritten Reiches, S. 114.
} 
Aufgaben erkennbar ist, sammelte Adolf Hühnlein bereits im Ersten Weltkrieg Erfahrungen im militärischen Kraftfahrwesen.

Im Anschluss an den Krieg befehligte er eine Kompanie im Freikorps Epp und beteiligte sich an der Entmachtung der Räteregierung in München und an der Niederwerfung des Spartakusaufstandes im Ruhrgebiet. ${ }^{352}$ Der Kampf im Freikorps gegen sozialistische und kommunistische Bestrebungen bewirkte bei Hauptmann Hühnlein im Anschluss an den Krieg einen Politisierungsschub, den er später so beschrieb:

„Mein erstes Zusammentreffen mit dem Soldatenrat, jener zersetzenden Zeiterscheinung, die dem Jahre des Zusammenbruchs 1918 ihren unheilvollen Stempel aufdrückte, machte mich zum politischen Kämpfer. Nicht so sehr, daß politische Erwägungen - ich gestehe offen, mit diesen Problemen hatte ich mich als alter Offizier und Frontsoldat bis dahin kaum befaßt hierzu den Ausschlag gaben, als vielmehr das mir im Blute liegende instinktive Angehen gegen jegliche schwächliche Haltung und Mangel an Würde und Stolz." 353

Den Kampf gegen alles „Schwächliche“ und gegen das Hassobjekt Republik hatten nach dem Krieg Kampfverbände, Freikorps und völkische Gruppen aufgenommen, darunter auch die Deutsche Arbeiterpartei, für die Adolf Hitler 1919 als Werbeobmann unterwegs war. Hitler verfügte über propagandistische Fähigkeiten, die Vertreter anderer rechter Verbände in München nicht aufweisen konnten. ${ }^{354}$ Die persönliche Begegnung mit dem charismatischen Agitator schlug Hühnlein in Bann und prägte seine nationalsozialistische Gesinnung:

„Als ich 1919 in der Kaserne des bayerischen Leibregiments Adolf Hitler erstmals hörte und seine Gedankengänge des Sich-niemals-Beugens, Niemals-Kapitulierens, seine Weltanschauung in mich aufnahm, zog es mich zu ihm, hielt mich fest, und es entstand jene Gefolgstreue, die nur der Tod endet. “355

Im Gegensatz zu dem in der Studie des Historikers Ulrich Herbert über Werner Best beschriebenen Funktionsträger-Typus, der sich unabhängig von der Person Hitlers nationalsozialistischen Prinzipien verschrieben hatte, ${ }^{356}$ war Adolf Hühnlein das Musterbeispiel eines „Hitleristen“ - ein Anhänger, der sich von Hitlers Führerqualitäten, seinem entschlossenen und kompromisslosen Auftreten und seinem absoluten Machtanspruch angezogen fühlte.

Hauptmann Hühnlein wurde nach Auflösung der Freikorps in das Reichsheer übernommen und führte die 1. Kompanie des Pionierbataillons 7 an. ${ }^{357}$ Er sympathisierte nicht nur mit dem aufstrebenden Rednertalent Adolf Hitler, sondern übernahm mit ausgesuchten Stoßtrupps seiner Pionierkompanie den Schutz der

352 Vgl. Der NSKK-Mann vom 13. 9. 1941: „Soldat. Zum 60. Geburtstag unseres Korpsführers".

353 Ebenda.

$354 \mathrm{Vgl}$. Orlow: The Organizational History and Structure of the NSDAP, S. 212.

355 Der NSKK-Mann vom 13. 9. 1941: „Soldat. Zum 60. Geburtstag unseres Korpsführers“. Im Sommer 1919 wurde Hitlers Rednergabe erkannt, als er zu Offizieren und Soldaten sprach. Dies beeindruckte auch Hans Frank, der im September 1919 der Deutschen Arbeitspartei beitrat; Kershaw: Hitler 1889-1936, S. 167.

356 Ein wichtiger Anziehungspunkt war bei Best die „völkisch-organische“ Weltanschauung; Herbert: Best, S. 61, 522 ff.

357 Vgl. Horkenbach (Hrsg.): Das Deutsche Reich von 1918 bis heute, Jg. 1933, S. 511. 
ersten Hitlerversammlungen. ${ }^{358}$ 1923, inzwischen zum Major im Generalstab des Bayerischen Infanterieregiments VII aufgestiegen, hatte er das Referat über die „schwarze“ Ausbildung für alle Verbände in München unter sich. ${ }^{359}$ In dieser Eigenschaft hielt er auch enge Verbindungen zum „Kampfbund“, einem rechten Bündnis aus SA, Bund Oberland und Reichsflagge. ${ }^{360}$

Die politischen Umtriebe des bayerischen Offizierskorps blieben der Reichswehrführung in Berlin nicht verborgen. Sie missbilligte die politische Betätigung und den bayerischen Partikularismus. Als es nicht gelang, die abtrünnigen Offiziere davon zu überzeugen, ihre politischen Aktivitäten einzustellen, entließ man auffällige Agitatoren, darunter auch den Führer der Reichsflagge, Hauptmann Heiss, den Organisator der Reichskriegsflagge, Hauptmann Röhm, und schließlich auch auf indirektem Wege Major Hühnlein. ${ }^{361}$ Hühnlein wurde am 17. September 1923 sehr wahrscheinlich aus disziplinarischen Gründen zur Artillerieschule Jüterbog abkommandiert. ${ }^{362} \mathrm{Er}$ widersetzte sich der angeordneten Versetzung und reichte sein Abschiedsgesuch bei der Reichswehr ein. Bis zu seiner Verabschiedung am 16. April 1924 war er vom Dienst beurlaubt. In dieser Zeit engagierte er sich für die SA-Führung in München. Er war im Oktober 1923 Chef des Truppenstabes der SA für München und Bayern und beteiligte sich aktiv am Hitlerputsch im November 1923. ${ }^{363} \mathrm{Ihm}$ war im Falle eines erfolgreichen Putschversuchs die Rolle als Befehlshaber der Münchner Landespolizei zugedacht worden. ${ }^{364}$ Als er sich anschickte, zusammen mit dem amtierenden Polizeipräsidenten Pöhner die Polizeidirektion in München zu besetzen, wurde er verhaftet. 365

Die nationalsozialistische Legendenbildung besagt, dass Hühnlein eine halbjährige Haft in Stadelheim, Neudeck und Landsberg verbüßen musste; in Landsberg an der Seite des „Führers“. Tatsächlich aber war Hühnlein nicht unter den 39 Angeklagten im Prozess gegen Hitler. ${ }^{366} \mathrm{Da}$ auch für die Folgezeit keine Angaben

358 Vgl. Der NSKK-Mann vom 17. 9. 1938: „Unser Korpsführer - Reichsleiter“.

359 Dies gab Hühnlein bei seiner Vernehmung zu Protokoll; vgl. Schreiben Hühnleins aus der Schutzhaft in Landsberg an den Staatsanwalt vom 30. 1. 1924, StA München, Pol. Dir. München 6712; Dornberg: Hitlers Marsch zur Feldherrnhalle, S. 23.

360 Der im September 1923 in Nürnberg gebildete Kampfbund hielt enge Verbindungen zum Münchner Reichswehrkommando; vgl. Longerich: Die braunen Bataillone, S. 38, $41 \mathrm{f}$. Hühnlein war zudem Mitglied im Deutschvölkischen Offiziersbund; vgl. Rösch: Die Münchner NSDAP, S. 225, Anmerkung 103.

361 Vgl. Gordon: Hitlerputsch 1923, S. 137.

362 Tatsächlich ging die Initiative für ein Kommando außerhalb Bayerns vom bayerischen Gruppenkommando aus; BayHStA München-Kriegsarchiv, RwGrKdo 4, 743.

$363 \mathrm{Vgl}$. Rösch: Die Münchner NSDAP, S. 97.

364 Vgl. Gordon: Hitlerputsch, S. 236. Hühnlein bestritt bei seiner Vernehmung, vorher in die Pläne für den 8 . November eingeweiht gewesen zu sein. Er gab an, dass er in der Nacht in das Wehrkreiskommando gegangen sei, um sich dort dem neuen Reichswehrminister von Lossow und dem Führer der nationalen Armee, Ludendorff, zur Verfügung zu stellen; vgl. Bericht des 1. Staatsanwalts beim Volksgericht München 1 an die Verwaltung der Gefangenenanstalt Landsberg vom 16.1. 1924, StA München, Pol. Dir. München 6712.

365 Vgl. Dornberg: Hitlers Marsch zur Feldherrnhalle, S. 239-242.

366 Weder im Protokoll über den Hitlerprozess noch in der Presseberichterstattung dieser Zeit oder in den Unterlagen des BayHStA München ist etwas über eine Verurteilung 
über eine Anklage oder einen Prozess gegen Hühnlein vorliegen, lässt dies den Schluss zu, dass er die sechs Monate in Untersuchungshaft verbrachte. Gegen eine rechtskräftige Verurteilung spricht auch die Tatsache, dass ihm die Reichswehr 1924 einen ehrenvollen Abschied bereitete. 367

In den Jahren 1925 bis 1930 nahm Hühnlein eine politische Auszeit und übte eine kaufmännische Tätigkeit in der Reifenindustrie aus. 3681930 wurde er politisch wieder aktiv: Er trat als Quartiermeister und Chef des $\mathrm{Kraftfahrwesens} \mathrm{in} \mathrm{die}$ Oberste SA-Führung ein. ${ }^{369}$ Hühnlein gehörte zu den sporadischen Aktivisten, die in den Krisenzeiten der Republik Politik betrieben: 1919 im Freikorps, danach 1923 und dann erst wieder beim Eintritt als SA-Führer. ${ }^{370}$ Viele der späteren SAFührer, die zwischen 1927 und 1930 in die SA eingetreten waren, hatten wie Hühnlein eine militärische Karriere vorzuweisen. Die Anforderungen einer stärkeren Strukturierung und Vergrößerung der SA brachten es offensichtlich mit sich, dass Organisationstalent mehr gefragt war als völkischer Missionsgedanke. ${ }^{371}$ Hühnlein, der 1930 bereits 49 Jahre alt war, brachte Lebenserfahrung und militärische Fähigkeiten mit ein und passte auch in dieser Hinsicht in das dominierende Bild der SA-Führer, die besser gebildet und älter waren als die einfachen SA-Männer. ${ }^{372}$

Konflikte zwischen dem Chef der OSAF Pfeffer von Salomon und Hitler führten dazu, dass Hitler sich nach einem Nachfolger umsehen musste. Die Wahl fiel auf Ernst Röhm, der 1928 als Militärberater nach Bolivien gegangen war. Hitler schrieb im Herbst 1930 wiederholt nach Südamerika, um ihn zur Rückkehr zu bewegen; dabei soll Adolf Hühnlein den Kontakt vermittelt haben. ${ }^{373}$ Röhm und Hühnlein kannten sich aus ihrer Zeit in der Reichswehr und verstanden sich nach Aussagen von Beobachtern gut. ${ }^{374}$ Ernst Röhm, der im Januar 1931 zum „Stabs-

Hühnleins erwähnt; vgl. Gruchmann u.a. (Hrsg.): Der Hitler-Prozeß 1924; Einschätzung des BayHStA München im Schreiben an die Verfasserin vom 21. 10. 1999.

367 Hühnlein schied nicht im Oktober 1923 aus der Reichswehr aus, wie in der NS-Biografieschreibung kolportiert, sondern erhielt seinen Abschied erst am 16. 4. 1924. Dieser erfolgte in Ehren und mit dem Recht, weiterhin Reichswehruniform tragen zu dürfen. Letzteres wäre durch eine rechtskräftige Verurteilung zu diesem Zeitpunkt ausgeschlossen gewesen, vgl. BayHStA München-Kriegsarchiv, RwGrKdo 4 Nr. 785. Auch Baldur von Schirach bestätigt die „Untersuchungshaft-Theorie“; Schirach: Pioniere des Dritten Reiches, S. 114.

368 Vgl. Degener (Hrsg.): Wer ist's?, 1935, S. 345; Schirach: Pioniere des Dritten Reiches, S. 114; "Adolf Hühnlein“, in: Männer im Dritten Reich, S. 112. Strittig ist, ob Hühnlein bereits 1925 für die SA wieder tätig war, wie es der Artikel in der Deutschen Kraftfahrt vom Juli 1942 „Abschied von Adolf Hühnlein“ nahe legt.

369 Vgl. Degener (Hrsg.): Wer ist's? 1935, S. 345.

370 Vgl. Campbell: The SA-Generals and the Rise of Nazism, S. 62 f. Campbell nannte diese Gruppe „The Defectors“, die „Abtrünnigen“, die der SA nicht fortwährend die Treue hielten, im rechten politischen Spektrum oft wechselten oder sich zwischenzeitlich auf berufliche Dinge konzentriert hatten.

371 Beachtliche 21 der 59 SA-Führer, die in diesem Zeitraum eintraten, waren wie Hühnlein Reichswehroffiziere; vgl. Campbell: SA-Generals, S. 57.

372 Vgl. Campbell: SA-Generals, S. 142.

373 Vgl. Dornheim: Röhms Mann fürs Ausland, S. 70.

374 Vgl. G. L. Wagener: Warum solite ich verschweigen, S. 536, StadtA Hannover. 
chef der SA “ ernannt wurde, setzte die Personalpolitik seines Vorgängers fort und besetzte die Führungspositionen mit ehemaligen Freikorpsführern und einer Reihe verabschiedeter Reichswehroffiziere, darunter Bekannte aus Röhms Münchner Tagen. Nun war ein schneller politischer Aufstieg garantiert. SAGruppenführer Hühnlein wurde am 1. Juli 1932 zum stellvertretenden Korpsführer des NSKK ernannt; am 1. Januar 1933 stieg er zum SA-Obergruppenführer, dem zweithöchsten Dienstgrad in der SA, auf. ${ }^{375}$ In seiner Funktion als einer der Stellvertreter Röhms trat Hühnlein Mitte Januar 1933 als Schlichter bei SAMachtkämpfen in Nürnberg auf. ${ }^{376}$ Unter Beibehaltung seiner Stellung als Chef des Kraftfahrwesens der SA wurde er am 30. April 1933 vom stellvertretenden Korpsführer zum Korpsführer des NSKK befördert. 377

In seinem weiteren Werdegang ernannte Hitler ihn 1936 ehrenhalber zum Generalmajor und stattete ihn am 8. September 1938 mit dem Titel Reichsleiter der NSDAP aus. Daran war kein bestimmtes Partei- oder Staatsamt geknüpft. Es erging jedoch der Generalauftrag des „Stellvertreters des Führers“, Rudolf Heß, die Partei in allgemeinen Verkehrsfragen gegenüber den Behörden zu vertreten. ${ }^{378}$

Seinen größten Einfluss übte Hühnlein als Führer des deutschen Kraftfahrsports und als Präsident der Obersten Nationalen Sportbehörde für die Deutsche Kraftfahrt aus. Im Zweiten Weltkrieg, genauer am 22. Februar 1940, ernannte ihn Göring zum „Beauftragten für den motorisierten Transport der Kriegswirtschaft". Adolf Hühnlein war in zahlreichen Gremien vertreten: Mitglied des Reichstags seit der 8. Wahlperiode 1933, Mitglied des Reichsverkehrsrates, der Reichsarbeitskammer, der Akademie für Deutsches Recht, des Verwaltungsrates der Deutschen Reichsbahn und des Verwaltungsrates der Gesellschaft für Reichsautobahnen. Obgleich er keine hohen Staatsämter im „Dritten Reich“ innehatte, zählte Hühnlein zu den reich dekorierten und vielfach ausgezeichneten NSDAPFührern. Er war Träger des Blutordens zur Erinnerung an den Hitlerputsch, Träger des Goldenen Parteiabzeichens der NSDAP und des Ehrenzeichens der HJ. Ihm war die Ehrenbürgerschaft der Städte Bayreuth und Bad Gandersheim ${ }^{379}$ und die Ehrenmitgliedschaft des Französischen Automobilklubs verliehen worden. Im Zweiten Weltkrieg überreichte ihm Hitler das Kriegsverdienstkreuz I. und II. Klasse mit Schwertern. Als Dank und Anerkennung für seine treuen Dienste beschenkte er Hühnlein außerdem zu seinem 60. Geburtstag mit 250000 RM. ${ }^{380}$ Diese großzügige Dotation war kein Einzelfall im „Dritten Reich“. Auch Großadmiral Raeder und Reichspostminister Ohnesorge erhielten Geldgeschenke in

\footnotetext{
$375 \mathrm{Vgl}$. Organisation der Obersten SA-Führung, S. 47, BArch NS 23/438.

376 Vgl. Hambrecht: Der Aufstieg der NSDAP in Mittel- und Oberfranken, S. 377.

377 Vgl. G. L. Wagener: Warum sollte ich verschweigen, S. 536, Stadt A Hannover.

378 Vgl. Der NSKK-Mann vom 22. 10. 1938: „Förderung der Motorisierung“.

379 Im Juni 1937 widmete ihm der Bayreuther Oberbürgermeister eine Granitplatte, auf der die Worte eingraviert waren: „Adolf Hühnlein, dem Schöpfer und Führer des NSKK, dem Sohne der bayerischen Ostmark, verleiht die Stadt Bayreuth das Ehrenbürgerrecht"; zit. nach Wotke: Die Ehrenbürger der Stadt Bayreuth, S. 109.

$380 \mathrm{Vgl}$. das posthume Spruchkammerverfahren zum Zwecke der Freigabe des Nachlasses von Adolf Hühnlein, Entnazifizierungsakte Hühnlein, Amtsgericht München.
} 
dieser Höhe. ${ }^{381}$ Offensichtlich vertraute Hitler nicht mehr ausschließlich auf die Wirkung seiner charismatischen Herrschaft, da er versuchte, führende Persönlichkeiten im Staat mit Geldgeschenken enger an sich zu binden. ${ }^{382}$ Hühnlein, 1941 bereits schwer erkrankt, tastete das Geld nicht mehr an. Er starb am 18. Juni 1942 an einem Krebsleiden. Ihm zu Ehren fand ein Staatsbegräbnis statt, und er erhielt posthum die wichtigste Auszeichnung des Staates: die höchste Stufe des Deutschen Ordens. ${ }^{383}$

\section{Die Persönlichkeit des Korpsführers}

Während seiner Amtszeit als Korpsführer kam Adolf Hühnlein mit vielen hochrangigen Repräsentanten aus Sport, Industrie, Politik und Militär in Kontakt. Der Autobauer Horch beschrieb Hühnlein als einen der „tatkräftigsten Männer“, die ihm im Leben je begegnet seien. ${ }^{384}$ Reichsverkehrsminister Freiherr von EltzRübenach dankte Hühnlein auf der IAMA 1936 für den „ungeheuren Schwung, welchen er in den Sport und die motorbegeisterte Jugend gebracht" habe. ${ }^{385}$ Anerkennung fand Hühnlein auch bei der Reichswehrführung, die dem ehemaligen aktiven Offizier der Vorkriegszeit mit Respekt begegnete. ${ }^{386}$ Der General der Panzertruppen, Heinz Guderian, beschrieb Hühnlein in seinen Erinnerungen als geraden, aufrechten Mann, mit dem man gut zusammenarbeiten konnte. Guderian folgte bereitwillig seiner Einladung zu einer SA-Tagung im Sommer 1933.387

Im Umgang mit Menschen galt Hühnlein als rauh und kantig. Wer ihm gut gesonnen war, beschrieb ihn als sachlich, offen und ehrlich, und wem seine Art missfiel, als schroff und plump. ${ }^{388}$ Hühnlein trat als Kritiker von Verschwendung und Großtuerei innerhalb des NSKK, der Partei, im Rennsport und in Industriekrei-

381 Zum System der Dotationen im „Dritten Reich“ allgemein, ohne auf den „Fall“ Hühnlein einzugehen, vgl. Überschär u.a.: Dienen und Verdienen, S. $218 \mathrm{f}$.; Bajohr: Parvenüs und Profiteure, S. $36 \mathrm{f}$.

382 Vor allem Architekten, Schriftsteller, NSDAP-Reichsleiter, Gauleiter und führende Offiziere der Wehrmacht erhielten Geldgeschenke. In Krisenzeiten nahm die Großzügigkeit noch zu, z.B. als sich infolge der Kapitulation Stalingrads 1943 die militärische Niederlage abzeichnete; vgl. Überschär u. a.: Dienen und Verdienen, S. 146.

383 Vgl. Deutsche Kraftfahrt vom Juli 1942: „Abschied von Adolf Hühnlein“. Vgl. auch BArch NS 24/846.

384 Horch: Ich baute Autos, S. 330.

385 Vgl. von Eltz-Rübenach auf dem Begrüßungsabend des RDA am 18. 2. 1936, in: RDA (Hrsg.): „Schrittmacher der Wirtschaft“, S. 31.

386 Vgl. G. L. Wagener: Warum sollte ich verschweigen, S. 705, StadtA Hannover.

387 Vgl. Guderian: Erinnerungen eines Soldaten, S. 24. Heinz Guderian (1888-1954), seit 1935 Chef der 1. Panzerdivision, 1938 Chef der schnellen Truppen und General der Panzertruppen. Erfolge als Panzerführer im Polen- und Frankreichfeldzug. Entlassung im Dezember 1941 wegen Differenzen mit Hitler, 1943 Ernennung zum Generalinspekteur der Panzertruppen. Sein Name ist eng verbunden mit dem Aufbau eigenständiger Panzertruppen und dem Gelingen der Blitzkriegstrategie in Polen, Frankreich und anfänglich auch in der Sowjetunion; vgl. Weiß (Hrsg.): Biographisches Lexikon, S. 168; Wistrich: Wer war wer, S. $103 \mathrm{f}$.

388 Nicht jedem, so Wagener nach dem Krieg, sagte Hühnleins offene Art und soldatische Derbheit zu; G. L. Wagener: Warum sollte ich verschweigen, S. 564, StadtA Hannover. 
sen auf. ${ }^{389}$ Für sich persönlich lehnte er den parvenühaften Lebensstil, den andere Parteiführer wie Hermann Göring oder Christian Weber pflegten, ab. ${ }^{390}$ „Seine sprichwörtliche Schlichtheit verachtet blendende Fassaden“, heißt es in einem Geburtstagsporträt über Hühnlein. ${ }^{391}$ Seine Anspruchslosigkeit war ein so hervorstechendes Charakteristikum, dass auch der Rennfahrer Rudolf Caracciola dieses Merkmal in seiner Beschreibung Hühnleins nach dem Krieg nannte: „Ein polternder, gutmütiger Mann, der an sein nationalsozialistisches Ideal glaubte, der sich nicht bereichert und nie versucht hatte, aus seiner Vormachtstellung Nutzen zu ziehen."392

Wie an seinen Ämtern und Auszeichnungen abzulesen ist, hatte Hühnlein im Rahmen seiner Möglichkeiten viel erreicht. Was ihm fehlte, waren staatliche Befugnisse, einflussreiche Parteiämter oder Bevollmächtigungen durch Hitler. Hühnlein wurde vom Reichsverkehrsminister zwar im Dezember 1933 beauftragt, alle im Kraftfahrwesen maßgeblichen Verbände in einem „Reichsausschuss der Deutschen Kraftverkehrswirtschaft “ zu einigen, doch gelang es nicht, sich an die Spitze dieses Ausschusses zu stellen, der Erzeuger, Verteiler und Verbraucher koordinieren sollte. ${ }^{393}$ Eine Zeit lang war Hühnlein in NSKK-Kreisen auch als Nachfolger des Reichsverkehrsministers im Gespräch. Wahrscheinlich hegte Hühnlein selbst Hoffnungen, Freiherr von Eltz-Rübenach 1937 ablösen zu dürfen. ${ }^{394}$ Doch den Karrieresprung schaffte er nicht. Abgesehen von machtpolitischen Gründen lagen die Ursachen in der Person des Korpsführers selbst: Ob-

389 Hühnlein rügte die Komfortwünsche der Industrierepräsentanten hinsichtlich der Unterbringung bei Sportveranstaltungen, Deutsche Kraftfahrt vom 22. 2. 1934: „Oberstaufen - die erste Schlacht der Sportcompagnie 34“. Ferner lehnte er im internen Dienstverkehr das Prahlen mit zusätzlichen Ämtern ab und forderte seine Führer zu Bescheidenheit auf; vgl. Mitteilungsblatt des NSKK vom 15. 8. 1940, betr. Schriftwechsel. Der Aufruf zur Bescheidenheit erging auch, als die Anzugsordnung in der Partei neu diskutiert wurde. Er erinnerte daran, dass dieser Aufwand mit der Situation der ärmsten Volksgenossen nicht zu vereinbaren sei; vgl. die Schriftwechsel zwischen dem 25.5. und 5.8. 1939, Heiber (Bearb.): Parteikanzlei Teil I, 23887, W. 11704041 f. (713).

390 Vgl. Eidesstattliche Erklärung des Fahrers von Hühnlein vom 20. 2. 1949, Entnazifizierungsakte Hühnlein, Amtsgericht München.

391 Deutsche Kraftfahrt vom September 1941: „Adolf Hühnlein“.

392 Caracciola: Meine Welt, S. 194. Im Widerspruch zu Hühnleins „Saubermann-Image“ stand eine Vorteilnahme für seine Tochter. Er kaufte für sie einen BMW mit Behördennachlass; Schreiben von Kraus an Hühnlein vom 21. 9. 1938, BArch NS 24/675.

393 Schreiben des Beauftragten des Reichsausschusses der Deutschen Kraftverkehrswirtschaft Hühnlein an die führenden Verbände vom 15. 12. 1933 (Abschrift), R 43 II/748. Nach Informationen von Werlin war Hühnlein für die Führung des neu zusammengestellten Reichsausschusses im Gespräch; vgl. vertrauliche Information Jakob Werlins an Kissel vom 29. 11. 1933, Roth u. a. (Bearb.): Die Daimler-Benz AG 1916-1948. Schlüsseldokumente, Dok. Nr. 41 S. 125 f. Vermutlich kam einem derartigen Ausschuss keine Bedeutung mehr zu, da im Rahmen eines organischen Aufbaus der Wirtschaft Wirtschaftsgruppen gegründet wurden, die die einzelnen Bereiche Produktion, Handel, Handwerk in der Kraftfahrzeugwirtschaft wieder aufteilten.

394 Vgl. G. L. Wagener: Warum sollte ich verschweigen, S. 643 ff., StadtA Hannover. Wagener vermutet, dass der Aufstieg Hühnleins durch Kritik an Hitlers Maßnahmen, die auch Goebbels gegen ihn aufbrachte, gescheitert sei. Es liegen jedoch keine Hinweise vor, die eine oppositionelle Haltung Hühnleins glaubhaft machen. 
wohl er bereits im Ersten Weltkrieg praktische Erfahrungen im militärischen Kraftfahrwesen gesammelt hatte, verfügte er nicht über die fachlichen Kompetenzen, die zur Leitung des Reichsverkehrsministeriums nötig waren. Außerdem unterschied er sich von der technischen Intelligenz im „Dritten Reich“ dadurch, dass er im Gegensatz zu den Bevollmächtigten Fritz Todt, Albert Speer, Gottfried Feder und dem Leiter der Organisation, Xaver Dorsch, keine Ingenieurausbildung absolviert hatte. Ging es darum, technische Sachverhalte zu erklären und mit eigenen Erfahrungen zu illustrieren, griff Hühnlein auf Vergleiche aus seinem Leben als Pionieroffizier zurück. 395

Ein anderer Grund, warum Hühnlein keine machtpolitisch bedeutsameren Ämter übertragen wurden, lag in seinem fortgeschrittenen Alter, das ihn innerhalb der Partei nicht als dynamischen Karrieristen auswies. Ein weiteres Hindernis auf dem Weg nach oben war die Tatsache, dass seine impulsive Art und sein häufig unangemessenes Auftreten wenig repräsentabel wirkten. Sein Erscheinungsbild war besonders bei Sportveranstaltungen Zielscheibe von Spötteleien. Von geringer Körpergröße und untersetzter Statur schritt er in seiner Uniform, manchmal in einem weißen Mantel, immer aber mit Sporen an den Stiefeln, die Paraden ab. Dies rief Heiterkeit hervor und brachte ihm bei Sportlern den Spitznamen „gespornter Heini" ein. ${ }^{396}$

Adolf Hühnlein zählte nicht zum inneren Führungsring um Hitler. Dies geht aus den in der Sache nebensächlichen, aber machtpolitisch aufschlussreichen Machtspielen um Titel und Namen hervor. Hühnlein nannte sich nach der Fusion von Motor-SA und NSKK am 23. August 1934 für kurze Zeit „Reichsführer des NSKK“. Diese Bezeichnung musste er jedoch auf Drängen des ebenso titulierten Reichsführers SS Heinrich Himmler ändern. ${ }^{397}$ Später konnte Hühnlein allerdings nicht verhindern, dass sich der Führer des NS-Fliegerkorps, General Christiansen, ebenfalls „Korpsführer" nannte. Hühnleins Protest scheiterte am Widerstand des mächtigeren Reichsluftfahrtministers Göring. 398

Dass Hühnlein ein Mann war, der in der zweiten Reihe stand, belegen auch die Tagebücher von Joseph Goebbels. Goebbels erwähnte ihn in seinen Aufzeichnungen der Jahre 1924 bis 1933 nur ein einziges Mal. Am 9. November 1932, dem Gedenktag des Hitlerputsches, notierte er: „Major Hühnlein spricht. Schaurig.“399 Auch in den folgenden Jahren fiel Hühnlein vor allem durch seine mangelhafte mündliche Ausdrucksfähigkeit auf. Im Mai 1937 besuchte Goebbels das AvusRennen, bei dem 400000 Zuschauer dem Sieger Hermann Lang zujubelten. Goebbels schrieb in sein Tagebuch: „Hühnlein hält eine unmögliche Rede. Alle lachen.

395 Er setzte beispielsweise die Wechselwirkung zwischen Straßenbau und Kraftfahrt mit der wechselseitigen Bedingtheit von Panzer und Angriffswaffe in Beziehung; vgl. Hühnlein: Der Kraftfahrer als Straßenbenutzer, S. 9.

396 Vgl. auch G. L. Wagener: Warum sollte ich verschweigen, S. 651, StadtA Hannover; Brauchitsch: Ohne Kampf, S. 59.

397 Vgl. DDAC-Wochenschrift vom 7. 9. 1934: „Tagesbefehl an Motor-SA und NSKK“; G. L. Wagener: Warum sollte ich verschweigen, S. 605 f., StadtA Hannover.

398 Vgl. G. L. Wagener: Warum sollte ich verschweigen, S. 864, StadtA Hannover.

399 Eintrag von Goebbels am 9. 11. 1932, in: Fröhlich (Hrsg.): Die Tagebücher von Joseph Goebbels, Teil 1, Bd. 2, S. 275. 
Blamabel für die Innung. “400 Hühnlein formulierte nicht nur ungeschickt, sondern auch unverständlich. Aus einer Mitteilung eines Motorsturms an die Motorstaffel geht hervor, dass die meisten Zuhörer einer Rede von Hühnlein den Inhalt nicht ansatzweise wiedergeben konnten. ${ }^{401}$ Trotz der Kritik war Goebbels kein erklärter Gegner des Korpsführers; vielmehr freute er sich darüber, dass Hühnlein 1938 zum Reichsleiter ernannt wurde und sagte ihm bei Sorgen um das NSKK seine Unterstützung zu. ${ }^{402} \mathrm{Zu}$ Hühnleins "Gegnern“ in Parteikreisen zählte Martin Bormann. Als eigentlicher Initiator des NS-Automobilkorps konnte er es nicht verwinden, dass die Führung des NSKK an Hühnlein übertragen worden war. ${ }^{403}$ Außerdem lehnte Bormann alle Führer, die aus dem Umkreis von Röhm und der SA kamen, kategorisch ab. 404

Auch wenn Hühnlein weder zur Führungsriege der NSDAP gehörte noch regelmäßig mit Hitler zusammentraf, zählte er allein aufgrund der langjährigen Kameradschaft mit Hitler und seiner Teilnahme am Hitler-Putsch zu den politisch verlässlichsten Getreuen des „Führers“. Hühnlein nahm jedes Jahr am 9. November an den Gedenkfeiern zur Erinnerung an den Marsch auf die Feldherrnhalle 1923 teil und stand zusammen mit den "Alten Kämpfern" und hochrangigen Nationalsozialisten in der ersten Reihe. ${ }^{405}$ Bei der alljährlichen Eröffnung der IAMA begleitete er Hitler bei seinem Gang durch die Automobilausstellung, informierte ihn über die Arbeit des NSKK und verkündete stolz die Spitzenleistungen und Siege, die der deutsche Motorrennsport im vergangenen Jahr erringen konnte. ${ }^{406}$

Adolf Hühnlein teilte die Weltanschauung des Nationalsozialismus. Er betonte die Wichtigkeit des Führerprinzips und trat für die Durchsetzung von „Rassenprinzipien “ in der Verkehrsgemeinschaft und im produzierenden Gewerbe ein. ${ }^{407}$ Jedoch tat er sich öffentlich selten als leidenschaftlicher Ideologe und antisemitischer Eiferer hervor. Sein Thema war und blieb die Motorisierung.

400 Eintrag von Goebbels am 31. 5. 1937, in: Fröhlich (Hrsg.): Die Tagebücher von Joseph Goebbels, Teil 1, Bd. 3, S. 158.

$401 \mathrm{Vgl}$. Mitteilung des Motorsturms 17/M 86 an die Motorstaffel II/M 86 vom 9.1. 1937, betr. Generalappell des Sturms anläßlich der Rede des Korpsführers, BArch NS 24/ 11.

402 Vgl. Eintrag von Goebbels am 9. 9. 1938, in: Fröhlich (Hrsg.): Die Tagebücher von Joseph Goebbels, Teil 1, Bd. 6, S. 78; Eintrag von Goebbels am 1. 2. 1939 „Er [Hübnlein] hat Sorgen um sein NSKK. Man nimmt ihm zuviel weg. Ich werde ihn unterstützen“, in: ebenda, S. 246.

403 Hühnlein hatte im Gegensatz zu Bormann, dessen Welt der Schreibtisch war, praktische Erfahrungen in der Führung von Einheiten; vgl. Lang: Der Sekretär, S. 57, 254.

404 In diese Richtung äußerte er sich anlässlich der Ernennung des SA-Gruppenführers Hühnlein im Oktober 1932 zu einem Stellvertreter Röhms; vgl. Schreiben von Martin Bormann an den Privatsekretär des Führers Rudolf Heß vom 5. 10. 1932, abgedruckt in: Lang: Der Sekretär, S. 450.

405 Ein Bild vom 9.11. 1938 zeigt Hühnlein in der ersten Reihe der Marschgruppe; abgedruckt in: Der NSKK-Mann vom 5. 11. 1938.

406 Vgl. Motorschau vom März 1938: „Der Führer sprach zum Bau des Volkswagens“.

407 Vgl. dazu ausführlicher das Kapitel „Diskriminierungs- und Gewaltmaßnahmen gegen Juden“. 
Willensbekundungen wie „Wir treiben unter allen Umständen die Motorisierung vorwärts!" 408 klangen oftmals wie Phrasen. Im Gegensatz zu Fritz Todt, der es vermochte, die Motorisierung und den Bau der Autobahnen in ein kulturelles Gesamtkonzept einzupassen, gab der Korpsführer praktischen Vorschlägen wie z. B. zur Verbesserung der Verkehrssicherheit den Vorzug. Zu dieser praxisnahen Lebenseinstellung passte sehr gut, dass Hühnlein die Deutschen 1941 aufforderte, sich idealistisches Träumen sowie „Dichten und Denken“ abzugewöhnen. ${ }^{409}$

Trotz persönlicher Schwächen und fachlicher Defizite war es doch vor allem seinen persönlichen Stärken zu verdanken, dass aus der jungen und mitgliederschwachen Organisation eine respektable Größe im Kraftfahrwesen erwuchs. Auch ohne konkrete Beauftragungen gelang es Hühnlein, Einfluss auf Sport, Vereine und das technische Sachverständigenwesen auszuüben und Kontakte zu Wehrmacht und Industrie zu knüpfen. Aufgrund seines Vorlebens als Offizier lag ihm die Rekrutenausbildung besonders am Herzen. ${ }^{410}$ Dieses erzieherische Anliegen, gepaart mit Organisationstalent und Durchsetzungsfähigkeit, qualifizierten ihn als Führerpersönlichkeit. Adolf Hühnlein war ein Mann der Praxis, ein perfekter Organisator, der auch in seinem politischen Wirken zeitlebens der militärische Führer blieb.

\section{Korpsführer Erwin Kraus - Der Mann fürs Technische}

Hühnlein, der bereits einige Jahre vor seinem Tod um seine lebensbedrohliche Krankheit wusste, hatte sich als Nachfolger im Amt des Korpsführers den Generalinspekteur für das deutsche Straßenwesen und Reichsminister für Bewaffnung und Munition, Fritz Todt, gewünscht. Todt kam jedoch im Februar 1942, wenige Monate vor Hühnleins Tod, bei einem Flugzeugabsturz ums Leben. Neuer Korpsführer wurde der bisherige NSKK-Obergruppenführer Erwin Kraus. Machtpolitisch gesehen war dies ein Nachteil, da Kraus - ein Mann ohne größeren Rückhalt in der Parteiorganisation - keinerlei politische Akzente zu setzen vermochte. ${ }^{411}$ Auf die Entwicklung des NSKK bezogen, war die Wahl allerdings von Vorteil, weil mit Kraus ein profunder Kenner des Kraftfahrkorps an die Spitze trat.

Anders als Hühnlein galt Kraus als ausgewiesener Experte auf kraftfahrtechnischem Gebiet. Der 1894 in Karlsruhe geborene Maschinenbauingenieur kämpfte im Ersten Weltkrieg in der Infanterie und bei der Fliegertruppe. Nach dem Krieg war er Mitglied in verschiedenen Freikorps. ${ }^{412}$ Nach Anstellungen in der Wirtschaft arbeitete er ab 1929 als freier Sachverständiger für Kraftfahrwesen und Maschinen in München und Stuttgart.

408 Aus der Rede des Korpsführers beim Begrüßungsabend der Automobilindustrie am 24. 2. 1937, abgedruckt in: RDA (Hrsg.): „Kraft des Motors, Kraft des Volkes“, S. 36.

409 Vgl. Der NSKK-Mann vom 24. 5. 1941: "Kämpfer und Schwärmer“ von Adolf Hühnlein.

410 Vgl. Deutsche Kraftfahrt vom Januar 1939: „Motorsportschule Niedersachsen eingeweiht".

411 Lang: Der Sekretär, S. 254.

412 Kraus war Flieger im Grenzschutz Ost und beteiligte sich an Kämpfen in Oberschlesien und im Baltikum. 
Seit 1923 Parteimitglied, fungierte Kraus bereits vor 1933 als technischer Berater des NSKK und der Motor-SA und hatte entscheidenden Anteil am Aufbau der beiden Organisationen. ${ }^{413} 1930$ bis 1933 befehligte er die Gruppenstaffel Südwest der Motor-SA in Stuttgart; in den nachfolgenden zwei Jahren arbeitete Kraus als Amtschef Technik und Kraftfahrinspekteur Süd. Seit 1935 hatte er das Amt des Inspekteurs für technische Ausbildung und Geräte des NSKK inne. Alle technischen Aspekte der Motorisierung in Bezug auf Dienstfahrzeuge, Treibstoffe, Motorsport, Motorsportschulen und Versuchsfahrten mit Ersatztreibstoffen fielen in seinen Aufgabenbereich. Aufgrund seiner fachlichen Kompetenz war er in allen technikrelevanten Fragen die rechte Hand Hühnleins. Die Industrie musste sich von ihm wiederholt Kritik gefallen lassen, verdankte ihm aber, der NSKK-Propaganda zufolge, guten Rat und manche vorteilhafte Neuerung. ${ }^{414}$ Seit 1936 gehörte Kraus dem Reichstag an. Er war 1933 bis 1942 Mitglied der Obersten Nationalen Sportbehörde für die deutsche Kraftfahrt und deutscher Delegierter in internationalen Rennsportgremien. Nach seiner Ernennung zum Korpsführer des NSKK am 21. Juni 1942 erhielt er nur eine weitere Beauftragung: Hitler übertrug ihm im November 1944 die motortechnische Beratung im Volkssturm und die Zusammenstellung von motorisierten Spezialeinheiten.

Nach Ende des Krieges wurde Kraus in Garmisch-Partenkirchen interniert. ${ }^{415}$ Die Spruchkammer Nürnberg stufte ihn 1948 in die Kategorie II „Belasteter“ ein. Sie legte ihm die Zahlung von $1000 \mathrm{RM}$ auf und verurteilte ihn zu einer Haftstrafe von drei Jahren und sechs Monaten, die zum Großteil durch die Internierungszeit als verbüßt galt. 416

\section{Die Motorobergruppenführer und Ehrenführer}

Neben dem Korpsführer trugen im NSKK eine Vielzahl von Amtsleitern, Inspektoren und Einheitsführern im Dienstrang von Standarten-, Gruppen- und Motorobergruppenführern Verantwortung. Persönlichkeiten, die für den Aufbau und die Entwicklung des NSKK bedeutsam waren, werden im Folgenden in ihrem politischen und beruflichen Werdegang kurz vorgestellt:

Nachdem das NSKK Ende August 1934 seine Selbständigkeit erhalten hatte, traten Führer der Motor-SA und des NSKK aus der SA aus und in das NSKK ein. Unter den 178 von Bruce Campbell untersuchten SA-Führern, die es zwischen

413 Kraus trat 1923 und zum zweiten Mal 1930 in die Partei ein; vgl. zur Person: BArch-DH ZA VI 3901 A. 31; BArch BDC Speer A-Z, Kraus Erwin: Fragebogen Military Government; Kienast (Hrsg.): Der Großdeutsche Reichstag, IV. Wahlperiode, S. 277.

414 Vgl. Zeitungsausschnitt vom 26. 5. 1944: „Erwin Kraus wird am 26. Mai 1944 50“, HStA Hannover, VVP 17 Nr. 2417.

415 Vgl. BArch BDC Speer A-Z Kraus Erwin: Fragebogen Military Government.

416 Gemäß der Kontrollratsdirektive Nr. 38 vom September/Oktober 1946 gab es folgende Kategorien: 1. Hauptschuldige; 2. Belastete (Aktivisten, Militaristen und Nutznießer); 3. Minderbelastete; 4. Mitläufer; 5. Entlastete; vgl. Ratz (Bearb.): Die Justiz und die Nazis, Dok. 16, S. 28ff; vgl. Spruch der Hauptkammer I Nürnberg vom 12. 11. 1948, Entnazifizierungsakte Erwin Kraus, Amtsgericht München; Nachricht in der Frankfurter Neuen Presse vom 15. 11. 1948, Presseausschnitt-Sammlung IfZ. 
1925 und 1945 zum Stabschef, Obergruppenführer und Gruppenführer gebracht hatten, nahmen nur Hühnlein als SA-Obergruppenführer und Josef Seydel als hauptamtlicher SA-Gruppenführer ranghohe Posten in der SA ein, bevor sie zum NSKK wechselten. Insgesamt traten im September 1934 und später ein Obergruppenführer (Hühnlein), zwei SA-Gruppenführer (Josef Seydel und ehrenhalber der Herzog von Sachsen-Coburg), sieben Brigadeführer, elf Oberführer und 12 Standartenführer von der SA in das NSKK über. ${ }^{417}$

Die meisten von ihnen waren Personen, die die Geschicke der motorisierten Formationen der NSDAP bereits seit der Gründungszeit begleitet hatten: Beispielsweise Helmut Oldenbourg, geboren 1892, der dem NSKK und der NSDAP seit 1930 angehörte. Er galt als Fachmann im Motorsport, wurde Stabsleiter beim Chef des SA-Kraftfahrwesens unter Hühnlein und war für die Aufstellung neuer Motoreinheiten zuständig. Nach der NS-Machtübernahme brachte er seine Erfahrungen in die Führung der Motorbrigade Hochland ein. Im Zweiten Weltkrieg diente Oldenbourg als Offizier der Kraftfahrtruppe IV. ${ }^{418}$

Eine wichtige Persönlichkeit, die die Entwicklung des NSKK von Anfang an förderte, ist der NSKK-Gruppenführer und Verleger der NSKK-Schrift „Deutsche Kraftfahrt", Theodor Oppermann ${ }^{419}$. Der 1889 in Minden geborene Titularprofessor trat nicht nur als Förderer des NSKK in Erscheinung, sondern kann als ein publizistischer Wegbereiter der nationalsozialistischen Bewegung insgesamt bezeichnet werden. Er gab nach dem Ersten Weltkrieg die rechtsorientierte "Deutsche Presse Korrespondenz" 420 und das Monatsblatt „Volk und Welt" heraus. Die „Deutsche Presse Korrespondenz“ verfügte über eine große publizistische Reichweite: Sie belieferte kleine rechtsstehende Heimatzeitungen und Lokalblätter, die sich keinen eigenen politischen Redakteur leisten konnten, zweimal wöchentlich mit Artikeln.

Oppermann gehörte seit 1931 der NSDAP und dem NSKK an und vertrat bereits 1932 die NSDAP als Abgeordneter im Reichstag. ${ }^{421}$ Dort bestimmte ihn die NSDAP-Fraktion ab Dezember 1932 zum Sachbearbeiter für Kraftfahrangele-

417 Vgl. Liste der zum NSKK im September 1934 oder später übergetretenen SA-Führer, BArch NS 23/438.

418 Unter $\mathrm{K}=$ Kraftfahrwesen ist der Name Oldenbourg zu finden, Diensteinteilung im Stabe der Obersten SA-Führung (1509/32), BArch BDC Research O. 407; Spruch der Spruchkammer München I vom 26.10. 1949, Entnazifizierungsakte Helmut Oldenbourg, Amtsgericht München.

419 Aufgrund des identischen Nachnamens wird Theodor Oppermann in Dokumenten vor und nach 1945 bisweilen mit Ewald Oppermann verwechselt. Letzterer wurde 1896 in Königsberg geboren, war Führer der NSFK-Gruppe 1 in Ostpreußen und Oberst der Luftwaffe. Er übernahm 1941 das Amt des Generalkommissars im Generalbezirk Nikolajew im Reichskommissariat Ukraine; vgl. Stockhorst: Fünftausend Köpfe, S. 313.

420 Die Verfasser der Artikel waren Politiker der Rechtsparteien und Wirtschaftsrepräsentanten. 1928 hatte die Korrespondenz 800 Zeitungen als Bezieher; vgl. G. L. Wagener: Warum sollte ich verschweigen. S. 393, StadtA Hannover. Da Wagener selbst einige Zeit in der Redaktion von Oppermann arbeitete, hatte er genaue Kenntnisse.

421 Vgl. Entnazifizierungsakte Theodor Oppermann (zum Zwecke der Vermögensfreigabe), HStA Hannover, Nds. 171 Hannover Nr. 90911. 
genheiten. ${ }^{422} 1933$ wurde er zum SA-Brigadeführer und stellvertretenden Führer des NSKK ernannt. ${ }^{423}$ Bei der Gründung des Einheitsautomobilclubs DDAC betraute Hühnlein Professor Oppermann mit dem Posten des stellvertretenden Präsidenten des DDAC. In der Folgezeit verschlechterten sich allerdings die Beziehungen zwischen dem Korpsführer und seinem Stellvertreter: Oppermann kritisierte die Einverleibung der „Deutschen Kraftfahrt“ in die NSKK-Korpsführung, und Hühnlein beanstandete Inhalt und Stil der Zeitung, die nach seinem Dafürhalten zu wenig kämpferisch sei und einer Kombination von „Gartenlaube und ADAC“ gleiche.424 Trotz der massiven Unstimmigkeiten wurde Oppermann 1940 zum NSKK-Obergruppenführer ernannt. Er entging militärischen Verpflichtungen durch eine Anstellung als Adjutant des Herzogs von Sachsen-Coburg. ${ }^{425}$ Kurz nach Ende des Krieges beging Oppermann in der Internierungshaft Selbstmord. ${ }^{426}$

Wie Röhm und Pfeffer von Salomon vor ihm, bevorzugte auch Hühnlein für die Besetzung von Führerstellen Männer mit militärischen Erfahrungen. Vorteile hatten diejenigen, die Hühnlein aus Kriegszeiten bekannt waren, wie z. B. Adolf Ritter von Denk, Rittmeister a. D. Er leitete 1934 das Führungshauptamt und wurde später Chefstabsführer des NSKK. ${ }^{427}$ Militärische Erfahrung war besonders wichtig bei Führern, die Einheiten befehligten oder an der Spitze der Kraftfahrinspektionen standen. Die Kraftfahrinspektion West in Köln wurde 1935 von NSKK-Gruppenführer Josef Seydel geführt. Wie Hühnlein war auch er Hauptmann im Ersten Weltkrieg, danach kämpfte er im Freikorps Epp. Als stellvertretender Führer der Reichskriegsflagge nahm er am Hitler-Putsch teil. Er war seit 1931 beim Stab der Obersten-SA Führung tätig und wechselte nach dem „RöhmPutsch“ zum NSKK. ${ }^{428}$ NSKK-Obergruppenführer Josef Seydel, der Opper-

422 Diese Funktion war nicht mehr als ein Zugeständnis an das NSKK. Da Kraftfahrangelegenheiten in der Fraktion nicht besprochen wurden, blieb dieses Amt bedeutungslos; vgl. Döring: „Parlamentarischer Arm der Bewegung“, S. 424.

423 Vgl. Stockhorst: Fünftausend Köpfe, S. $313 \mathrm{f}$.

$424 \mathrm{Vgl}$. Brief von Hühnlein an Oppermann vom 2.12. 1939 und Protokoll der Witwe von Oppermann vom 29.1. 1949, Entnazifizierungsakte Theodor Oppermann, HStA Hannover, Nds. 171 Hannover Nr. 90911. „Die Gartenlaube. Das illustrierte Familienblatt“, erschien von 1853 bis 1937 . Sie war eine populäre und unterhaltsame Zeitschrift für die ganze Familie. Nach dem Krieg nannte sie sich „Die neue Gartenlaube“.

425 Vgl. Entnazifizierungsakte Theodor Oppermann, HStA Hannover, Nds. 171 Hannover Nr. 90911.

426 Oppermann betonte in einem Brief an General Eisenhower vom 5. 4. 1945, dass die von ihm 1933 gegründete und herausgegebene Zeitschrift Deutsche Kraftfahrt jahrelang von den Nazis missbraucht worden sei und er keine Judenhetze betrieben hätte; BArch BDC Research, Theodor Oppermann.

427 Adolf Ritter von Denk, geb. 1886. Leitende Stelle in der Süddeutschen Waggonfabrik, 1933 Eintritt in das NSKK, Führer einer Kraftwagenstaffel, 1934 in die Korpsführung versetzt, 1941 zum NSKK-Obergruppenführer ernannt; vgl. Entnazifizierungsakte Ritter von Denk Amtsgericht München; BArch BDC SA, Ritter von Denk.

428 Josef Seydel, NSKK-Obergruppenführer, geb. 1887 in München, 1920 Landesleitung der Bayerischen Einwohnerwehren, 1923 stellvertretender Führer der Reichskriegsflagge, Teilnahme am Hitlerputsch, 1924 zu einem Jahr und drei Monaten Haft verurteilt, 1931 bis 1935 beim Stab der OSAF, Wechsel zum NSKK, seit 1932 MdR; vgl. Kienast (Hrsg): 
mann als stellvertretenden Korpsführer ablöste, führte im Zweiten Weltkrieg die Motorobergruppe Südost und organisierte den motorisierten Luftkriegseinsatz der Wiener Fahrbereitschaft. ${ }^{429}$

Bis zum höchsten Dienstgrad des Motorobergruppenführers brachte es auch der 1884 geborene Karl Offermann, ein Zollrat aus Baden. Hühnleins gute Erinnerungen an seine eigene Zeit als Pionieroffizier förderten nach Angaben von $\mathrm{Be}-$ obachtern den politischen Aufstieg Offermanns, der bei den Pionieren im Krieg gedient hatte. ${ }^{430}$ Offermann engagierte sich seit 1930 als Motor-SA-Sturmführer und übernahm 1935 die Führung der Kraftfahrinspektion Ost, die dann zur Motorobergruppe Ost erhoben wurde. Zusätzlich gehörte er seit 1936 dem Reichstag an und war seit 1937 Mitglied des Volksgerichtshofs. Im Krieg führte Offermann die Motorobergruppe Nordost, schied dann aber im Juli 1942 aus der aktiven Leitungsarbeit im NSKK aus. Ab 1943 war er als Regierungsdirektor in Berlin tätig. ${ }^{431}$

Ein weiterer NSKK-Obergruppenführer, der sich durch seine militärischen Fähigkeiten auszeichnete, war Hermann Höfle ${ }^{432}$. Er wurde 1898 geboren, absolvierte die Kriegsakademie und diente von 1916 bis 1934 als aktiver Offizier der Reichswehr. Im Anschluss übernahm er hauptamtlich die Führerausbildung im NSKK. Höfle war von 1935 bis 1939 Leiter der Reichsführerschule des NSKK und ab August 1937 Inspektor für Ausbildung in der Korpsführung. ${ }^{433} \mathrm{Im} \mathrm{Zwei-}$ ten Weltkrieg führte er zusätzlich die Motorobergruppe Ost und beaufsichtigte die NSKK-Verkehrskompanien im Korps. Hermann Höfle ist, abgesehen von den Korpsführern, der einzige NSKK-Funktionsträger, der einen über die Gliederung reichenden Bekanntheitsgrad erreichte. Dies allerdings erst, nachdem er von Himmler für die SS abgeworben wurde: Auf Bitten des RFSS Heinrich Himmler delegierte ihn Korpsführer Kraus im Juni 1943 zur SS, wo er den Rang eines SS-Gruppenführers einnahm und als Generalleutnant der Polizei fungierte. ${ }^{434} \mathrm{Er}$ hatte zuerst die Stelle des Höheren SS- und Polizeiführers in Braunschweig inne. Im September 1944 wurde er zum Deutschen General in der Slowakei ernannt. Höfle wurde 1947 in Bratislava zum Tode verurteilt und starb in der Haft. ${ }^{435}$

Der Großdeutsche Reichstag, IV. Wahlperiode, S. 389; Dornberg: Hitlers Marsch, S. 381; G. L. Wagener: Warum sollte ich verschweigen, S. 667, StadtA Hannover.

$429 \mathrm{Vgl}$. ÖStA Wien, Gauakten Nr. 274184 (Josef Seydel).

430 Vgl. G. L. Wagener: Warum sollte ich verschweigen, S. 667, StadtA Hannover.

431 Karl Offermann, Zollinspektor, 1929 Eintritt in die NSDAP; vgl. Karl Offermann BDC PK, Research O. 254; Stockhorst: Fünftausend Köpfe, S. 312.

432 NSKK-Obergruppenführer Hermann Höfle (geb. 1881) ist nicht zu verwechseln mit dem gleichnamigen SS-Hauptsturmführer und Referenten im Stabe des SS- und Polizeiführers in Lublin, geb. 1911, Leiter der Hauptabteilung Reinhard, 1944 Fachführer beim Höheren SS- und Polizeiführer Griechenland; vgl. Stockhorst: Fünftausend Köpfe, S. 201.

433 Hermann Höfle BArch BDC PK; Dienstleistungszeugnis für Höfle von Kraus vom 30. 6. 1943 bei seinem Ausscheiden aus dem NSKK, BArch Sammelliste 52, B1. 347. Höfle erwarb erst 1937 die Parteimitgliedschaft.

434 Vgl. Der NSKK-Mann vom 26. 6. 1943: „Neue Führer der Motorobergruppen Mitte und Ost".

435 Vgl. StA Nürnberg, Nürnberger Dokumente, Rep. 502 I, NO-3056 (Bl. 158-165). 
Auch Friedrich Ritter von Städtler (1885-1944), Major a.D., der bis zum Führer der Motorobergruppe Süd aufstieg, konnte sich dem Korpsführer durch seine Vita als Frontoffizier im Ersten Weltkrieg empfehlen. Neben einer Tätigkeit in der freien Wirtschaft war er bereits einige Jahre vor der NS-Machtübernahme für die SA tätig. Von Städtler wechselte nach dem „Röhm-Putsch“ zum NSKK.436

Die Mehrzahl der Führer im Range eines NSKK-Gruppenführers und -Obergruppenführers wiesen bei allen Unterschieden doch wesentliche Gemeinsamkeiten in ihrem Lebenslauf auf. In ihrem Werdegang treten drei Merkmale gehäuft auf: Erstens verfügte der ideale Führer über militärische Erfahrungen. Von Vorteil waren zweitens ein technischer Beruf bzw. praktische Erfahrungen in der Automobilwirtschaft. Die dritte Gemeinsamkeit vieler NSKK-Funktionsträger bestand in ihrer politischen Führungserfahrung, die sie bereits in der „Kampfzeit“ durch die Leitung von Motor-SA- oder NSKK-Einheiten erworben hatten. 437

Im Idealfall vereinigte der NSKK-Funktionsträger alle drei Merkmale in seiner Person, so z.B. der Stabsführer der Obersten Nationalen Sportbehörde für die deutsche Kraftfahrt (ONS), NSKK-Brigadeführer Leo von Bayer-Ehrenberg, Jahrgang 1888. Er diente zwischen 1907 und 1919 als Offizier und leitete von 1919 bis 1933 als Geschäftsführer, später als Direktor, verschiedene Niederlassungen der Zündapp GmbH. Nebenbei betätigte er sich ab 1932 als Kraftfahrsportreferent der Motorgruppenstaffel Berlin. Nach der Aufnahme in die NSDAP im Mai 1933 trat von Bayer-Ehrenberg in die Dienste des Chefs des Kraftfahrwesens der SA. ${ }^{438} \mathrm{Er}$ war bis zum Beginn des Zweiten Weltkriegs der Hauptverantwortliche im Amt Motorsport der Korpsführung Berlin. Im November 1941 wurde ihm die Führung der NSKK-Motorgruppe Luftwaffe übergeben. 439

Auch Kurt von Barisani kam dem NSKK-Führerideal sehr nahe. Der 1895 in Wien geborene Ingenieur nahm als Kriegsfreiwilliger am Ersten Weltkrieg teil. Er floh später aus Österreich in ein Hilfswerklager der SA. Nach dem "Anschluss“ Österreichs im März 1938 ernannte ihn Hühnlein zum Führer der Motorgruppe Ostmark. Von 1939 bis 1942 kommandierte von Barisani die Motorgruppe Thü-

${ }^{436}$ Vgl. Entnazifizierungsakte Ritter von Städtler, Amtsgericht München.

437 Die übrigen NSKK-Obergruppenführer, über die keine oder nur wenige Informationen vorliegen und zu denen sich keine merkmalrelevanten Details ermitteln ließen, seien hier aus Gründen der Vollständigkeit genannt: NSKK-Obergruppenführer Heinrich Sauer, geb. 1905, Kaufmann, 1923 Eintritt in die NSDAP, 1932 Stadtverordneter der NSDAP in Detmold, $1933 \mathrm{MdL}$ in Lippe, 1938 mit der Führung der Motorobergruppe Mitte beauftragt, 1942 Führer der Motorobergruppe Nordost, Mitglied des Reichtstags und Volksgerichtshofs seit 1938; vgl. Kienast (Hrsg.): Der Großdeutsche Reichstag, IV. Wahlperiode, S. 360; Stockhorst, Fünftausend Köpfe, S. 357. Weitere NSKK-Obergruppenführer, die im Laufe ihrer Karriere eine Motorobergruppe befehligten, waren: Wilhelm Müller-Seyfferth und Franz Emminger (Alpenland), Georg Ludwig Wagener, Erich Scheibner (Ost), Harry Kwalo (Mitte und Hauptamtschef im Stab der Korpsführung), Günther Pröhl und Thomson (Nord). NSKK-Obergruppenführer, die "nur“ Motorgruppen befehligten, waren: Emil Zimmermann (Hochland), Schnüll (Leipzig), Hans Klug (Niederrhein), Paul Nieder-Westermann (Westfalen-Süd), Karl Doerfler (Oberdonau); vgl. Supreme Headquarters Allied Expeditionary Force: Basic Handbook. The NSKK; Informationen aus BArch BDC.

438 Vgl. zu Leo von Bayer-Ehrenberg, BArch BDC PK und SA.

439 Vgl. zu seiner Person auch S. 280 und 451 f. dieser Arbeit. 
ringen, danach wurde er zum Reichsminister für Bewaffnung und Munition abgeordnet. 440

Berufliche Erfahrungen, die der Korpsführung von Nutzen sein konnten, brachte der 1891 geborene Schiffsingenieur Otto Schade mit. Er war Mitinhaber einer Elektronikfirma und später bei Carl Zeiss Jena tätig. Seit 1931 NSDAP- und NSKK-Mitglied, wurde ihm 1935 die Führung der NSKK-Motorbrigade Leipzig überantwortet. Von 1942 bis 1943 fungierte Schade als Inspekteur der Reichsmotorsportschulen im NSKK, danach als Führer der Motorgruppe Leipzig. ${ }^{441}$ Wie Schade brachte auch NSKK-Brigadeführer Ernst Zynen aufgrund seines beruflichen Hintergrundes eine gute Ausgangsbasis für eine Karriere beim NSKK mit. Der 1892 geborene Zynen arbeitete als Autokaufmann. ${ }^{442}$

Bei der „zweiten Generation“ von NSKK-Führern, die am Ersten Weltkrieg nicht teilgenommen hatten, legte man ein besonders starkes Augenmerk auf die technische Ausbildung. Beispielhaft hierfür ist der 1901 geborene NSKK-Gruppenführer Prinz Richard von Hessen, der eine Ingenieurausbildung absolviert hatte. Seit 1932 Mitglied des NSKK und der NSDAP, stieg er nach der Machtübernahme rasch zum NSKK-Brigadeführer, -Gruppenführer und -Obergruppenführer auf. 1943 stellte er seine Dienste dem Personalamt der Korpsführung, ein Jahr später der Inspektion der Motorsportschulen zur Verfügung. ${ }^{443}$

Auch der im gleichen Jahr geborene Nikolaus Eiden war Ingenieur. Er führte die Motorgruppe Rhein-Mosel, fungierte als Verbindungsführer zum Generalinspekteur für das deutsche Straßenwesen und stand an der Spitze der Transportbrigade Todt. Im Zweiten Weltkrieg wurde er zum NSKK-Obergruppenführer befördert. Er befehligte die Motorobergruppe West, widmete sich aber vor allem seiner Arbeit als Inspekteur der Transporteinheiten des NSKK. ${ }^{444}$

Heinrich Jürgensen, der Führer der Motorobergruppe Nord, passte ebenfalls in die Kategorie „technische Experten ohne militärische Vorerfahrung“. Der 1899 geborene Ingenieur gründete die Motor-SA in Schleswig-Holstein. Nach der Machtübernahme wurde er mit der Führung der Motorbrigade Nordmark beauftragt und 1935 zum Kraftfahrinspekteur Nord ernannt. ${ }^{445}$

Wie an vielen Führerbiographien abzulesen ist, wurden fast ausschließlich Männer in eine Führungsposition gehoben, die vor 1933 Motor-SA- oder NSKKEinheiten befehligt hatten. August Köbele, der Chef des Verwaltungsamtes der Korpsführung München und Reichskassenverwalter des NSKK, hatte 1931 einen NSKK-Sturm in Emmendingen (Baden) zusammengestellt. ${ }^{446}$ Adolf Jäger, der

440 Kurt von Barisani, 1935 Führer der Motor-SA im Stab des Hilfswerkes Nord-West, MdR seit 1938; BDC-DH; Kienast (Hrsg.): Der Großdeutsche Reichstag, IV. Wahlperiode, S. 152.

441 Vgl. zu Otto Schade BArch BDC, SA und RKK: 2100 Box 0402, file 06.

442 Vgl. Stockhorst: Fünftausend Köpfe, S. 461.

443 Vgl. zu Richard von Hessen BDC OPG; Entnazifizierungsakte, HStA Wiesbaden Spruchkammer Frankfurt.

444 Vgl. zu Nikolaus von Eiden BArch BDC SA; Kienast (Hrsg.): Der Großdeutsche Reichstag, IV. Wahlperiode, S. 194.

445 Vgl. G. L. Wagener: Warum sollte ich verschweigen, S. 667, StadtA Hannover.

446 August Köbele, Leutnant der Reserve einer Flugabteilung im Ersten Weltkrieg, Kauf- 
spätere Adjutant des Korpsführers, war während der „Kampfzeit“ in der badischen Motor-SA und im NSKK aktiv. ${ }^{447}$ Auch der 1935 zum Führer der Motorgruppe Schlesien ernannte Heinrich-Christian Schäfer-Hansen war bereits 1931 Mitglied der Motor-SA. 448

Mit Stolz verwies der Korpsführer darauf, dass ein Drittel der Mannschaft und der Führer aus der „Kampfzeit“ stammten. Für das höhere Führerkorps lag die Quote mit Sicherheit um einiges höher, denn der Korpsführer bevorzugte Bewerber, die sich durch ihren freiwilligen politischen Einsatz vor 1933 ausgezeichnet hatten. ${ }^{449}$ Ein langjähriges Engagement in der Motor-SA und im NSKK wurde als Zeichen der Bewährung und Loyalität gewertet. Da das NSKK im Gegensatz zur SS kein Karrieresprungbrett war, stand das politische Erfolgsstreben in der Werteskala hinter den Führungsqualitäten und der politischen Verlässlichkeit der Führer zurück. Bei den ranghohen NSKK-Führern der ersten Generation wie Oppermann, Seydel oder Offermann, die den Weltkrieg und die Zeit davor bewusst erlebt hatten, findet sich als Antriebsmoment ihrer politischen Betätigung das Motiv, Deutschland zu der Stellung in der Welt zu führen, die ihm vor dem verlorenen Krieg zukam. ${ }^{450}$ Diese revanchistische Haltung der "alten Kämpfer“ wurde bald durch die revolutionären Utopien der jungen, politisch ehrgeizigen Nationalsozialisten überholt, die eine neue Weltordnung entwarfen. ${ }^{451}$

\section{Ehrenführer und Ehrenrangführer}

Hochrangige Parteifunktionäre, Ministerialbeamte und Persönlichkeiten des gesellschaftlichen Lebens, die sich um das NSKK verdient gemacht hatten bzw. von denen sich die Korpsführung Fürsprache für ihre Belange erhoffte, wurden zu

mann, 1933 NSDAP-Beitritt, Chef des Verwaltungsamtes der Korpsführung München, 1935 vom Reichsschatzmeister zum Reichskassenverwalter des NSKK ernannt; BArch BDC PK.

447 Adolf Jäger, geb. 1906, Bankbeamter, Eintritt in die NSDAP 1930, 1933 in den Stab des Chefs des Kraftfahrwesens versetzt, Adjutant, 1937 Mitglied des Volksgerichtshofs, MdR seit 1938, im Krieg Oberleutnant in einem Panzergrenadierregiment; BArch-DH ZA VI 3905 A. 1; BArch NS 24/773.

448 Heinrich-Christian Schäfer-Hansen, geb. 1901, 1939 Obergruppenführer, Hauptmann der Reserve in einem Panzerkorps, seit 1939 Mitglied des Volksgerichtshofs, MdR seit 1936; Kienast (Hrsg.): Der Großdeutsche Reichstag, IV. Wahlperiode, S. 362.

449 Hühnlein: Vortrag, gehalten am 16.12. 1937, S. 20. "Freiwillige Dienstleistung" als Prinzip yerlässlicher politischer Auslese hielt der Korpsführer nicht bei den Mitgliedern, wohl aber bei den Führern sehr hoch.

450 Hühnlein äußerte diese Hoffnung in Bezug auf die "Weltgeltung" des deutschen Kraftfahrsports; vgl. DDAC-Wochenschrift vom 24. 8. 1934: „Stuck deutscher Bergmeister“.

451 Fast das gerade Gegenteil der Alters- und Sozialstruktur der NSKK-Führer findet sich bei den Mitarbeitern des Reichssicherheitshauptamtes, deren Biografien der Historiker Michael Wildt untersucht hat; vgl. ders.: „Die Generation des Unbedingten“. Das Führungskorps des RSHA bestand vorwiegend aus Männern, die aufgrund ihrer Jugend nicht im Ersten Weltkrieg gekämpft hatten, die politisch sehr ehrgeizig waren und vor ihrer Tätigkeit beim Sicherheitsdienst einen akademischen Beruf (Ärzte, Juristen, Studienräte) ausgeübt hatten. Auch wenn ein Vergleich der Personengruppen aufgrund der Aufgabenunterschiede abwegig erscheint, ist die relative Homogenität innerhalb der Gruppen interessant. 
Ehrenführern des NSKK ernannt. ${ }^{452}$ Dazu zählten Reichsinnenminister Wilhelm Frick, Reichsschatzmeister Franz Xaver Schwarz, Reichspostminister Wilhelm Ohnesorge, Reichsstatthalter Franz Ritter von Epp, Herzog Carl Eduard von Sachsen-Coburg, der Präsident des Volksgerichtshofs Roland Freisler sowie Ernst Brandenburg, Ministerialdirektor im Reichsverkehrsministerium. ${ }^{453}$ Der Herzog von Sachsen-Coburg und Ritter von Epp vertraten das NSKK seit der IV. Wahlperiode 1938 auch im Reichstag. ${ }^{454}$

Die Ehrenführer und Ehrenrangführer befehligten keine Einheit, sondern standen dem Korpsführer häufig für besondere Zwecke zur Verfügung. Der Dienststelle in Berlin waren 38 Führer zur besonderen Verwendung zugeordnet. Dazu zählten Parteifunktionäre wie der Adjutant des „Führers“, Fritz Wiedemann, und der Rundfunkexperte aus dem Reichspropagandaministerium, Eugen Hadamovsky. Aus dem behördlichen Bereich kamen Heinz-Heinrich Eras, Ministerialrat im Reichsverkehrsministerium, und Oberregierungsrat Virgil Schoor vom Reichsinnenministerium. Das NSKK intensivierte die Kontakte zu Verbandsführern der Industrie durch die Verleihung von Ehrenführerrängen. Wilhelm Scholz, der Präsident des Reichskraftwagen-Betriebsverbandes, wurde zum NSKKSturmhauptführer ernannt, Paul Hufenbecher, Geschäftsführer der Wirtschaftsgruppe Fahrzeugindustrie, und Otto Neef, Geschäftsführer in der Wirtschaftsgruppe Fahrzeugindustrie des RDA, erhielten den Rang eines NSKK-Obersturmführers. ${ }^{455}$

Gauleiter und Politische Leiter bedachte man mit NSKK-ObergruppenführerRängen, so z. B. Franz Hofer, Gauleiter und Reichsstatthalter in Tirol, ${ }^{456}$ Josef Wagner, Gauleiter von Schlesien, Karl Kaufmann, Gauleiter in Hamburg, und Josef Bürckel, Gauleiter der Saarpfalz und Reichsstatthalter in Österreich. ${ }^{457}$ Die Zahl der Ehrenrangführer konnte nicht beliebig erhöht werden, denn gerade hochrangige NS-Funktionäre und Staatsbedienstete waren bereits in andere NSGliederungen eingetreten und erhielten dort Ehrenränge. Trotzdem zeigen die zahlreichen Ernennungen, dass das NSKK seine "Fühler“ in alle Richtungen ausstreckte, um den Rückstand aufzuholen und das NSKK innerhalb der Partei, der Behörden und der Industrie lobbyistisch besser zu verankern.

452 Der Korpsbefehl Nr. $12 \mathrm{~b}$ vom 12.5. 1938, BArch NSD 42/9, unterschied zwischen NSKK-Ehrenführern, die als besondere Auszeichnung von Hitler ernannt wurden, und Ehrenrangführern, die vom NSKK einen Führerrang erhielten, weil sie sich in besonderem Maße für die Ziele des NSKK eingesetzt hatten.

453 Vgl. NSKK-Korpsführung (Hrsg.): Die Gliederung des NSKK, S. 7.

454 Vgl. Kienast (Hrsg.): Der Großdeutsche Reichstag, IV. Wahlperiode, S. 196.

455 Liste der z.V. und z.b.V. Führer der Dienststelle Berlin, BArch NS 24/314.

456 Hofer hat nach NSKK-Angaben lange vor dem Verbot der NSDAP in Österreich die motorisierten Einheiten im Gau Tirol-Vorarlberg geführt; BArch NS 24/733.

457 NSKK-Rangliste, S. 459 f., BArch NS 23/438. 


\section{Die Stellung des NSKK im Gefüge von Partei und Staat}

Der Einsatz des NSKK für die Partei konzentrierte sich auf die Bereiche: Motorisierungsangelegenheiten der Partei, Propaganda und Transport. Auf besondere Weisung des „Stellvertreters des Führers“ überprüfte der Inspekteur für technische Ausbildung und Geräte die von der Partei zur Personenbeförderung eingesetzten Lkw und Omnibusse. ${ }^{458}$ Daneben liefen Anträge der NSDAP und ihrer Gliederungen, in Bezug auf Anmietung von Lkw der Reichsbahn oder Ankauf von Fahrzeugen über den Schreibtisch des Inspekteurs für technische Ausbildung und Geräte. ${ }^{459}$ Er organisierte außerdem für die NSDAP den Bezug von verbilligten Kraft- und Schmierstoffen. 460

Nach außen machte das NSKK vor allem durch sein öffentlichkeitswirksames Erscheinungsbild von sich reden. Das NSKK hatte jährlich für die Partei zwei Großauftritte zu absolvieren: die Internationale Automobil- und Motorradausstellung und den Reichsparteitag. 1935 trat auf dem Reichsparteitag in Nürnberg das erste Mal ein geschlossener Block aus 10500 NSKK-Männern auf. Drei Jahre später präsentierten sich dem „Führer" in Nürnberg 12300 Aktive des NSKK in Marsch- und Fahrzeugkolonnen. ${ }^{461}$ Als personifiziertes Sinnbild des Motorisierungswillens der Partei fuhr vor der Marschsäule des NSKK eine Gruppe mit 45 Krädern an der Spitze. ${ }^{462}$ Der Auftritt des Korps war eine visuelle Anerkennung der Selbständigkeit des Korps. Darüber hinaus steigerte das Auftreten der Männer mit dem Helm und den Motorrädern die formative Ästhetik des nationalsozialistischen Regimes. Der Vorbeizug der "motorisierte[n] Streitmacht“ ${ }^{463}$ symbolisierte die von der Partei inszenierte Modernität des Regimes.

Den zweiten wichtigen Auftritt hatte das NSKK auf der alljährlichen Eröffnungsveranstaltung der Internationalen Automobilausstellung in Berlin. Dies war

458 Die Technischen Referenten übernahmen diese Aufgabe, Verfügung des Korpsführers vom 2. 11. 1936, BArch NS 24/93; Schreiben des Inspekteurs für technische Ausbildung und Geräte an das Amt Presse vom 14. 1. 1939, BArch NS 24/220; Die Technischen Referenten übernahmen diese Aufgabe; Verfügung des Korpsführers vom 2.11. 1936, BArch NS 24/93.

459 Anträge von Dienststellen und Organisationen der NSDAP auf Bereitstellung reichsbahneigener Fahrzeuge waren zunächst an das NSKK zu richten; vgl. Vertrag zwischen der Deutschen Reichsbahn-Gesellschaft vom 1.1.1936 und der NSDAP-Reichsleitung, BArch NS 24/114; Schreiben der Reichsbahndirektion Kassel an den Sturmbann I/83 vom 31. 7. 1935, BArch NS 24/172. Zum Erwerb von Fahrzeugen, die aus Heeresbeständen ausgemustert wurden, bedurfte es der Erlaubnis des NSKK; vgl. die Vollmacht des Inspekteurs Technik an das NSFK, Gruppe 3, für den Erwerb ausgemusterter Heeresfahrzeuge, BArch NS 24/115.

460 Vgl. Krenzlin: Das NSKK, S. 42; Schreiben des NSKK an die Reichsleitung der NSDAP vom 10. 6. 1938, betr. Bezug von verbilligtem Betriebsstoff, BArch NS 24/464; Schreiben des Inspekteurs Technik an das Rechtsamt vom 15. 4. 1936, BArch NS 24/483.

46186000 SA-Männer, 18000 SS- und 10500 NSKK-Männer marschierten in Nürnberg auf; vgl. Volz: Daten zur Geschichte der NSDAP, S. 58; Motorschau vom September 1938: "Das NSKK auf dem Parteitag in Nürnberg“.

462 Vgl. Anordnung des Korpsführers vom 16. 5. 1936, BArch NS 24/83.

463 Das Auto und Kraftrad vom März 1937: „Autoschau 1937 eröffnet...“. 
für Beobachter ein visuell beeindruckendes, weil perfekt inszeniertes Erlebnis. Nach Verlassen der Reichskanzlei schritt der Reichskanzler in Begleitung des Korpsführers die Front des NSKK-Ehrensturms ab. Danach machte sich ein motorisierter Zug, darunter auch das Diplomatische Korps und die erfolgreichen deutschen Rennfahrer, auf den Weg von der Reichskanzlei über den Kaiserdamm zur Ausstellungshalle. 1937 bildeten an der $7 \mathrm{~km}$ langen Anfahrtsstraße 10000 NSKK-Männer mit 2000 Fahrzeugen ein Ehrenspalier. 4641939 umrahmten 20000 NSKK-Männer die Strecke. 465 Bei seinem Eintreffen schritt Hitler dann die Ehrenformation des NSKK-Motorlehrsturms „Bernd Rosemeyer“ ab. Als Kulisse bei der Eröffnungsfeier dienten außerdem hunderte von Fahnen- und Standerträgern des NSKK sowie die Musik- und Spielmannszüge. ${ }^{466}$ Die zahlenmäßig erdrückende Präsenz des NSKK und sein choreographiertes Auftreten beherrschten das Bild.

Abgesehen von diesen Großveranstaltungen trat das NSKK als Gliederung der Partei bei vielen kleineren Veranstaltungen im kommunalen Rahmen auf. Ein Blick auf den Aufgabenkatalog der Motorstandarte 86 (München) aus dem Jahre 1936 zeigt, dass abgesehen von Sportereignissen vor allem Repräsentationsaufgaben für die Partei anfielen. Darunter waren Aufmärsche bei Maifeiern, bei sechs Kreistagungen der Partei, Beförderung ausländischer Diplomaten, Abstellung einer Ehrenformation und Fahrzeuge zur Einweihung des Hauses des Deutschen Rechts, Absperraufgaben bei besonderen Anlässen wie z.B. am 8./9. November zur Erinnerung an den „Marsch zur Feldherrnhalle“. ${ }^{467}$ Die Absperrung bei sportlichen und politischen Veranstaltungen durch NSKK-Männer war nicht nur eine rein organisatorische Maßnahme, sondern Teil einer Masseninszenierung für Presse und Film, in der die Allgegenwart der Partei demonstriert wurde.

Von großem Wert waren auch die Propagandafahrten des NSKK, mit denen es an seine Tradition aus der „Kampfzeit“ anknüpfte. Das NSKK wollte diese Gelegenheiten nutzen, der Partei „zu beweisen, daß es nicht etwa nur eine technische Gliederung, sondern einer der lebendigsten und beweglichsten Künder des politischen Willens der NSDAP“ sei. ${ }^{468}$ Bei der „Wahlpropagandafahrt“ für den „Führer" anlässlich der Abstimmung am 10. April 1938 im Gau Magdeburg-Anhalt besuchten NSKK-Einheiten die Mehrheit aller im Gau liegenden Dörfer. 469 In Coburg stellten die Motorstürme am 19. August 1934 jedem Wahlleiter der 17 städtischen Wahllokale fünf $\mathrm{Pkw}$ zur Verfügung:

464 Vgl. ebenda.

465 Vgl. Motorschau vom März 1939: „Der Führer stellt neue Aufgaben“; Der NSKK-Mann vom 18. 2. 1939: „Der Führer weist den Weg“.

466 Vgl. Deutsche Kraftfahrt vom März 1939: „Die größte Autoschau der Welt“.

467 Vgl. die Daten besonderer Begebenheiten im Jahre 1936 im Schreiben der M 86 an die Kreisleitung der NSDAP; BArch NS 24/11. Vgl. zur Vielzahl an Sonderdiensten den Bericht des Motorsturms 2/M 77 an die Standarte vom 29.7.1936, BArch NS 24/8 und den Bericht der M 55 (Stuttgart) vom 24. 11. 1937, BArch NS 24/777.

468 Schreiben der Motorbrigade Franken an die Gauleitung der NSDAP vom 15.3. 1936, betr. Wahlkampf, BArch NS 24/770.

469 Vgl. Der NSKK-Mann vom 16. 4. 1938: „Aus den Reihen des Korps“. 
„Als um 15.30 Uhr gemeldet wurde, daß ein Stadtbezirk eine Wahlbeteiligung von noch nicht $60 \%$ aufzuweisen hatte, wurden sofort und schlagartig sämtliche Kraftfahrzeuge in den Stadtbezirk geworfen, so daß um 17.30 die Wahlbeteiligung sich auf $96 \%$ erhöht hatte, dank der nachhaltigen Propaganda der MSA. “470

Eine repressivere Art von Wahlmobilisierung wandte das NSKK an, wenn die einfache Propaganda keinen Erfolg hatte. Dies zeigen zwei Beispiele: Als sich ein Landwirtsehepaar aus Holzminden am 29. März 1936 weigerte, zur Abstimmung zu gehen, wurde der Mann von einem NSKK-Trupp verprügelt und unter Misshandlungen ins Wahllokal gebracht. ${ }^{471}$ Aus Anlass derselben Abstimmung postierten sich an den Ausfallstraßen Münchens NSKK-Einheiten. Sie fungierten als Absperrdienst, dem die Aufgabe zukam, alle „säumigen“ Wähler vor dem Verlassen der Stadt zu den Wahllokalen zu geleiten. ${ }^{472}$

Die dritte wichtige Aufgabe, die das NSKK für die Partei übernahm, waren Fahrdienste und Veranstaltungsorganisationen. Es beförderte auch nach dem Regierungsantritt der NSDAP nationalsozialistische Redner. ${ }^{473}$ Nützlich erwies sich das NSKK für die Partei bei der Organisation von Großereignissen. Das Korps stellte bei den Parteitagen wie auch bei großen Veranstaltungen, z. B. dem Deutschen Juristentag 1936 oder dem Empfang des italienischen Regierungschefs Benito Mussolini am 25. September 1937, den Ordnungsdienst und kümmerte sich um die Beförderung der Ehrengäste. ${ }^{474}$ Für das Auswärtige Amt standen diplomatische Fahrbereitschaften mit NSKK-Fahrern bei den Werken Daimler-Benz, Auto Union und Opel bereit. ${ }^{475}$ NSKK-Korpsführer Hühnlein stellte dem Organisationskommittee der XI. Olympischen Spiele 1936 eine Sonderdienststelle mit dem Namen NSKK-Olympia-Kraftfahrstab zur Verfügung. Der Stab bestand aus 5000 Männern, die Hilfsdienste für die Polizei und die Gendarmerie übernahmen. Sie waren tätig im Autolotsendienst, in der technischen Beratung, der Unfallhilfe und im Straßenhilfsdienst und erfüllten Aufgaben in der Verkehrsbelehrung, der Parkplatzüberwachung und im Fahrdienst. ${ }^{476}$

Auch für den „Hilfszug Bayern“, einer mobilen Verpflegungsstation, die bei Großkundgebungen und Massenaufmärschen der Partei die Teilnehmer versorgte, stellte das NSKK Personal zur Verfügung. Die Mannschaft unter Führung

470 Meldung der Staffel an die Standarte vom 22. 8. 1934, Tätigkeitsbericht, Wahlschleppdienst am 19. 8. 1934, BArch NS 24/3.

$471 \mathrm{Vgl}$. Entnazifizierungsakte, HStA Hannover, Nds. 171 Hildesheim Nr. 49148.

472 Bericht der NSKK-Motorobergruppe Süd an den Korpsführer vom 29. 6. 1936, betr. Einsatz beim letzten Wahlkampf, BArch NS 24/770.

$473 \mathrm{Vgl}$. Rundschreiben der M 95 vom 24. 1. 1939, BArch NS 24/6.

474 Vgl. Schreiben der Motorbrigade Leipzig an das Polizeipräsidium vom 13.5. 1936, StadtA Leipzig, Vk.-A. 11.118; Programm zum Empfang des italienischen Regierungschefs Benito Mussolini am 25. 9. 1937, Befehle zum Staatsempfang und Aufträge, BArch NS 24/315, 433.

475 Vgl. Schreiben des Chefadjutanten des NSKK an die Motorgruppe Berlin vom 28. 1. 1939, BArch NS 24/140.

476 Die Männer stammten aus der Motorbrigade Berlin, Nordmark (Kiel), Mitte und Ostmark, Völkischer Beobachter vom 20. 8. 1936: „Korpsführer Hühnlein dankt dem ,NSKK-Olympia-Kraftfahrstab““; Die Polizei vom 20. 8. 1936: „Der Olympia Kraftfahrstab“. 
von NSKK-Standartenführer Borchert umfasste 160 Stammkräfte, die bei großen Einsätzen von bis zu 1000 Hilfskräften unterstützt wurden. Der Hilfszug, der 1933 aus sechs Motorfahrzeugen bestand, erhöhte die Zahl seiner Fahrzeuge kontinuierlich, so dass 1941 über 160 Fahrzeuge zur Verfügung standen. ${ }^{477}$ Die mobile Versorgungseinrichtung hatte ihren Einsatz bei Reichsparteitagen ab 1936, unterstützte 1938 die Versorgung der Westwallarbeiter, war im März 1939 in Prag stationiert und folgte nach Kriegsbeginn der Wehrmacht nach Warschau. ${ }^{478}$

Der Einsatz des NSKK für die Partei förderte im Falle der Olympischen Spiele und der IAMA sicherlich den Bekanntheitsgrad und die Reputation des Korps. Die Vielzahl an Sonderdiensten, vor allem im lokalen Bereich, konfrontierte das NSKK jedoch mit dem Problem, auf die Rolle als Taxiunternehmen und Absperrdienst der NSDAP reduziert zu werden. Vor Ort gab es oftmals Streitigkeiten zwischen den Politischen Leitern, insbesondere den Gau- und Kreisleitern und NSKK-Führern, weil die Hoheitsträger der Partei versuchten, das NSKK ausschließlich für eigene $Z$ wecke einzusetzen. ${ }^{479}$

\section{Rivalitäten und Machtproben}

Aus einer vertraulichen Mitteilung geht Hühnleins anhaltendes Ringen um Akzeptanz in der Partei hervor: „Ich selbst bin unablässig bemüht, jede Gelegenheit zu benutzen, um Ansehen und Geltung des Korps als selbständige Kampfgliederung zu unterstreichen. " 480 Der Korpsführer wachte über den Zusammenhalt der NSKK-Mitglieder untereinander und die Bewahrung einer spezifischen NSKKIdentität. Beispielhaft dafür ist das Protestschreiben von Hühnlein an den Reichspostminister, in dem er die Abwerbung von Postkraftfahrern aus den Reihen des NSKK zum NS-Fliegerkorps beklagte. ${ }^{481}$ Der Korpsführer sah es außerdem als seine dringliche Aufgabe an, die anderen Parteigliederungen darauf hinzuweisen, dass die für das NSKK charakteristischen „Hörnermärsche“ nur vom NSKK gespielt werden dürften. Dieser Geltungsdrang - in der Partei als „Gliederungs-

477 Vgl. Der „Hilfszug Bayern“ der NSDAP: Sein Entstehen, seine Entwicklung und seine Arbeit vom 10.6. 1941 (Typoskript), BArch NS 1/212. Vgl. auch die Beförderung von 128 NSKK-Männern durch den Korpsführer, die als Besatzung des Hilfszuges eingesetzt waren; Schreiben des Korpsführers an die Motorgruppe Hochland vom 1.11. 1939, BArch NS 24/763.

478 Vgl. ebenda. Der Hilfszug wurde als „modernstes Unternehmen für Massenverpflegung“ und als "Wunderwerk deutscher Technik" gefeiert; Bremer Zeitung vom 5.6. 1936: „Hilfszug Bayern“; Der NSKK-Mann vom 4. 11. 1939: „Das NSKK im befreiten Gebiet“. Der Hilfszug wurde Ende September 1939 von Generaloberst Blaskowitz mit der Verpflegung der Einwohnerschaft Warschaus beauftragt. Die in Warschau wohnenden 400000 Juden blieben von der Essensausgabe ausgeschlossen; vgl. Leistungsbericht über die Arbeit der NSV, Einsatzgruppe Warschau in der Zeit vom 30.9.-5.11.1939, BArchZNS ES: Hilfszug Bayern der NSDAP. 1940 stellte die NSDAP dem OKH den Hilfszug Bayern für die Dauer des Krieges zur Verfügung.

479 Vgl. Eidesstattliche Versicherung des Gruppenführers D. vom 15. 6. 1947, Entnazifizierungsakte Kraus, Amtsgericht München.

480 Vertrauliches Schreiben des Korpsführers vom 13. 3. 1939, BArch NS 24/156.

481 Vgl. das Telegramm Hühnleins an den Reichspostminister vom 14.1. 1938, BArch NS 24/155. 
egoismus" gebrandmarkt - erreichte seinen Höhepunkt, als Hühnlein 1939 an rund 20000 Politische Leiter Briefe verschickte, um ihnen die Nichterwähnung des NSKK in einem Zeitungsbericht vor Augen zu führen. 482

Das Gefühl der Benachteiligung in der Presseberichterstattung hielt an. Die Motorgruppe Hochland beschwerte sich noch 1942 beim Gaupresseamt München: „Es ist allmählich eine alltägliche Erscheinung, daß das NSKK in allen Artikeln überhaupt vollständig vergessen wird." ${ }^{483}$ Das Korps wurde von den Hoheitsträgern der Partei wie auch von Mitgliedern der SA und der SS häufig nicht als gleichberechtigt angesehen und deswegen mit Spitznamen wie „reaktionärer Automobilklub, Benzinkutscher, Schnauferlklub usw. “484 belegt.

Kompetenzgerangel und Grabenkämpfe beherrschten auch die Beziehungen der Korpsführung zu anderen Gliederungen und den angeschlossenen Verbänden. Das Verhältnis zur SA blieb seit der Trennung der beiden Gliederungen angespannt. SA-Führer beneideten das NSKK um die engen Beziehungen zur Wehrmacht. ${ }^{485}$

Der Kampf um die Anerkennung des NSKK schlug sich auch im Geplänkel um Titel nieder. 1936 wollte SA-Führer Lutze statt „Stabschef der SA“, „Stabschef des Führers" genannt werden. SS und NSKK protestierten in der Parteikanzlei erfolgreich gegen diese Titulierung, weil dadurch der Eindruck erweckt würde, dass auch SS und NSKK SA-Chef Lutze unterstellt seien. 486

Konkurrierende Interessen verschlechterten auch die Beziehungen zwischen NSKK und der Deutschen Arbeitsfront. Die Ursache lag vor allem in der Aufstellung von so genannten "NSKK-Werkstürmen“ in der Automobil- und Zubehörindustrie. Der Führer der Arbeitsfront Robert Ley versuchte, diese Zusammenschlüsse in den Werken zu verhindern, da den DAF-Werkscharen möglicherweise Mitglieder entzogen würden. ${ }^{487}$ Die Industrievertreter und NSKK-Funktionsträger versuchten zu beschwichtigen: Werkscharen der DAF sollen nicht durch

482 Vgl. die Aufzeichnung des NSKK-Chefadjutanten vom 31. 7. 1939, BArch NS 24/157; Abschrift des Schreibens von Hühnlein an den Kreisleiter Walter Hoffmann, Bad Landeck/Schlesien im Juli 1939, ebenda.

483 Beschwerde der Motorgruppe Hochland an das Gaupresseamt vom 20. 4. 1942, BArch NS 24/74.

484 Eidesstattliche Erklärung von Hermann Rösing vom 8. 9. 1948, Entnazifizierungsakte Kraus, Amtsgericht München.

485 Die Führer des NSKK wurden zu sämtlichen Herrenabenden und gesellschaftlichen Veranstaltungen der Wehrmacht eingeladen, und umgekehrt waren bei NSKK-Veranstaltungen Kommandeure und das Offizierskorps vertreten; vgl. Vierteljahresbericht der Motorbrigade Bayerische Ostmark vom 19. 12. 1935, StA München, NSDAP 1308.

486 Vgl. Briefwechsel mit der Adjutantur des Führers zwischen dem 7. und 12.5. 1936, in Heiber (Bearb.): Akten der Partei-Kanzlei der NSDAP, Teil I, Regest. Nr. 11475.

$487 \mathrm{Vgl}$. Schreiben der DAF an Daimler-Benz vom 23. 6. 1937, BArch NS 24/124; Aktennotiz über ein Schreiben Hühnleins an Ley vom 20.7. 1937, BArch NS 22/918. Von den 95000 Werkscharmännern 1937 gehörten 1070 dem NSKK an; Schreiben des Oberwerkscharführers an Rittweger vom 14. 5. 1937, ebenda. Der Kreisobmann der DAF-Rastatt beschwerte sich bei Daimler-Benz über einen Aufruf vom 8.5.1937 zur Bildung von Werkstürmen mit der Begründung, Ley erlaube die Aufstellung derartiger Stürme nicht; Schreiben des Kreisobmanns der DAF-Gauverwaltung Baden, Kreisverwaltung Rastatt vom 25. 6. 1937 an Direktor von Jungenfeld, BArch NS 24/123. 
Werkstürme verdrängt werden. Es seien lediglich solche Stürme der örtlichen Standarten gemeint, die ausschließlich aus Angehörigen eines Werkes bestehen. ${ }^{488}$ Die Bezeichnung „Werksturm“ wurde 1937 auf Befehl des Korpsführers vermieden und die Einheit durch eine Nummer gekennzeichnet. ${ }^{489}$ Für weitere Missstimmung sorgte die Forderung Leys an die Korpsführung, die geographische Gliederung des NSKK den Hoheitsgrenzen der Partei anzugleichen. ${ }^{490}$ Diese Machtprobe konnte Hühnlein für sich entscheiden. Die Grenzen des Korps blieben mit Genehmigung der Parteikanzlei an die Wehrbezirke angepasst.

Wollte das NSKK in bereits ausgehandelte Machtsphären der Partei eindringen, waren diesem Versuch Grenzen gesetzt. Das Angebot Hühnleins im Frühjahr 1936, die Überwachung und technische Durchsicht der Kraftfahrzeuge in der Partei zu übernehmen, wurde mit der Begründung abgelehnt, dass die Gliederungen derartige Einrichtungen schon besäßen. ${ }^{491}$ Besonders die SS, deren Motoreinheiten vom SS-Hauptamt geführt wurden, handelte autonom. ${ }^{492}$ Die SS regelte die Ausbildung selbst, pflegte den Erfahrungsaustausch mit militärischen Stellen und hielt Kontakte zu NSKK und Industrie. ${ }^{493}$ Eine eigene SS-Motorschule in Berne bildete hauptamtliche SS-Fahrer weiter und veranstaltete Geländesportlehrgänge. 1936 war bei jedem SS-Oberabschnitt mindestens eine Motorstandarte aufgestellt, die zwischen vier und sieben Stürme umfasste und deren Angehörige alle motorisiert sein sollten. ${ }^{494}$

Die junge Formation NSKK hatte es angesichts der Dominanz von Politischer Organisation, SA und SS schwer, sich politisch zu behaupten. Dies wird sowohl an der geringen Anzahl der NSKK-Führer, die als ehrenamtliche Richter zum Volksgerichtshof berufen wurden, als auch an der Benachteiligung des NSKK bei der Entsendung von Abgeordneten in den Reichstag deutlich. Das NSKK verfügte nie über mehr als $3 \%$ der Sitze. Daran änderte auch der Protest Hühnleins bei Reichsinnenminister Frick nichts. ${ }^{495}$

Zwischen 1933 und 1939 hatte das NSKK innerhalb der Partei, ihrer Gliederungen und Verbände ein weit verzweigtes Verbindungsnetz mit Verbindungsführern

488 Vgl. von Jungenfeld an den Kreisobmann der DAF in Rastatt vom 26. 6. 1937, betr. Bildung von NSKK-Werkstürmen, BArch NS 24/123.

489 Vgl. Kraus an den Stabsleiter beim Reichsorganisationsleiter vom 12.7. 1937 (vertraulich), BArch NS 24/115. Vgl. zu den Werkstürmen auch S. 343 f. dieser Arbeit.

490 Vgl. Schreiben Leys an Bormann vom 2. 7. 1938, in: Heiber (Bearb.): Akten der ParteiKanzlei der NSDAP, Teil I, Regest. Nr. 23125.

491 Vgl. Schreiben an den Korpsführer vom 18.5. 1936, BArch BDC Adolf Hühnlein PK.

492 SS-Oberführer Graf Bassewitz-Behr wurde 1939 mit der Leitung der neu errichteten Dienststelle „Inspekteur des Kraftfahrwesens der SS“ betraut; vgl. Reichsführer SS vom 10. 3. 1939, betr. Kraftfahrwesen der SS, NS 31/96, Bl. 23.

493 Vgl. Diensteinteilung 1934, NS 31/96, Bl. 4.

494 Vgl. Anlage zum Befehl des Chefs des SS-Hauptamtes vom 11.3. 1936, StA Marburg, Best. 327/2 a), Nr. 98, 101.

495 Unter den 162 ehrenamtlichen Richtern am Volksgerichtshof, von denen die Mehrzahl der Partei, SA und SS angehörten, waren am 1.8. 194412 NSKK-Führer, vgl. Koch: Volksgerichtshof, S. $526 \mathrm{ff}$. Mitglieder des Reichstags waren: 1933: zwei (nur der Korpsführer und sein Stellvertreter Theodor Oppermann), 1936: elf, 1938: 18, 1943: 20 Angehörige des NSKK; vgl. Hubert: Uniformierter Reichstag, S. 354, 368. 
zu allen wichtigen NS-Organisationen (DAF, NS-Volkswohlfahrt, Winterhilfswerk usw.) aufgebaut. ${ }^{496}$ Gleichwohl blieb das Korps auf seine anfängliche Rollenzuschreibung als Hilfsgliederung mit Transport- und Propagandaaufgaben festgelegt und wurde an politischen Entscheidungen der Partei nicht wesentlich beteiligt.

\section{Polykratische Strukturen im Kraftverkehrswesen}

Auch im Bereich der staatlichen Institutionen bemühte sich die Korpsführung, das NSKK zu verankern. Das NS-Kraftfahrkorps war jedoch eine von vielen Interessengruppen, die Einfluss auf die Verkehrsentwicklung nehmen wollten. Weitere Organisationen waren z. B. der Reichsverband der Automobilindustrie (RDA), die Deutsche Automobil-Treuhand GmbH, die Deutsche Auto-Liga, der Reichsbund der Kraftverkehrs-Technik im Reichsbund Deutsche Technik, die Forschungsgesellschaft für das Straßenwesen e.V. (im Nationalsozialistischen Bund Deutscher Technik) und die Automobil- und Flugtechnische Gesellschaft im Verein Deutscher Ingenieure.

Im Zuge der Bemühungen um einen „ständischen Aufbau der Wirtschaft" formierten sich im gewerblichen Verkehrswesen neue Gruppen. Der Handel mit Kraftfahrzeugen wurde in die Wirtschaftsgruppe Einzelhandel (Reichsgruppe Handel) eingegliedert und die Herstellung von Kraftfahrzeugen der Wirtschaftsgruppe Fahrzeugindustrie (Reichsgruppe Industrie) zugeteilt. Das Kraftfahrgewerbe bildete eine eigene Reichsverkehrsgruppe. Aus den Verkehrsträgern (Verkehrsgewerbe, öffentliche Verkehrsbetriebe, Generalinspektor für das deutsche Straßenwesen) und den Verkehrsnutzern (gewerbliche Wirtschaft, Gemeinden, Reichsnährstand u.a.) wurde ein Reichsverkehrsrat gebildet, der dem Reichsverkehrsministerium beratend zur Seite stand.

An der Zielsetzung, der Gestaltung und Ausführung der Motorisierung wirkten viele Ressorts mit, die zum Teil mit Sonderbevollmächtigten ausgestattet wurden. 1933 ernannte Hitler den Ingenieur Fritz Todt, der auch Leiter des Hauptamtes Technik der NSDAP war, zum "Generalinspektor für das deutsche Straßenwesen“. Er war nicht nur für den Autobahnbau, sondern auch für die Straßenaufsicht zuständig. ${ }^{497} \mathrm{Um}$ eine Konkurrenzsituation innerhalb der Partei in Verkehrsfragen zu verhindern, erließ der „Stellvertreter des Führers“ am 10. August 1938 eine Anordnung, die die Kompetenzen des NSKK festlegte. Heß beauftragte Hühnlein offiziell, die Entwicklung auf dem Gebiet der Verkehrsordnung und der Kraftfahrzeugwirtschaft zu beobachten, Anregungen zu geben und Vorschläge zu machen. Unter Verkehrsordnung war das Verhalten im Straßenverkehr, die Verkehrserziehung und die Bekämpfung von Verkehrsunfällen zu verstehen. In den Bereich der Kraftfahrzeugwirtschaft fielen: Fragen der Entwicklung der Kraftfahrzeuge, der Zulassung von Fahrzeugen und Fahrzeugführern zum Straßenver-

496 Vgl. Abschrift aus der Nationalsozialistischen Partei-Korrrespondenz vom 29. 4. 1936, NS 22/918.

497 Vgl. Kopper: Modernität oder Scheinmodernität?, S. 411. 
kehr, die Fahrschulen und Fahrlehrer, die Kraftfahrzeugsachverständigen, auch der Kraftfahrsport und die Ordnung des zwischenstaatlichen Straßenverkehrs.

In diesen Aufgabenfeldern war das NSKK befugt, die Partei gegenüber den Behörden zu vertreten. ${ }^{498}$ Todt, so hieß es in der Anordnung von Heß, solle sein Augenmerk im Auftrag der Partei auf verkehrspolitische Fragen (Straßenbau, Güterund Personenverkehr, Treibstoffversorgung) richten.

Die in den Anordnungen von Heß verwandten Begriffe "beobachten" und „Vorschläge einbringen“ zeigen, dass dem NSKK eine beratende Rolle im Staat zugedacht war. NSKK-Vertreter waren Mitglieder in Ausschüssen aller Art, die den Kraftverkehr betrafen, und wirkten mit bei Beratungen über neue Gesetze und Verordnungen. ${ }^{499}$ So wurde das NSKK, das Mitglied im Reichsverkehrsrat war, vom Reichsverkehrsministerium als Interessenvertretung des Kraftfahrers zu den Themen Reichsgaragenordnung und Haftpflichtversicherung gehört. ${ }^{500} \mathrm{Im}$ „Arbeitsausschuß des Beirats für das Kraftfahrwesen“ im RVM, der allerdings nur kurze Zeit tagte, führte Hühnlein den Vorsitz. ${ }^{501}$ Das NSKK war beim „Reichskommissar für die Preisbildung" an der Festsetzung von Höchstpreisen bei Instandsetzungsarbeiten an $\mathrm{Kfz}$ beteiligt. ${ }^{502}$. Außerdem arbeitete das NSKK im "Ausschuß der Reichsstelle für Typprüfung " und im Forschungsrat für das Kraftfahrwesen mit. 503

Einen weiteren wichtigen Sonderauftrag im Bereich der Motorisierung erhielt neben Fritz Todt Oberst Adolf von Schell, der am 15. November 1938 von Göring zum "Generalbevollmächtigten für das Kraftfahrwesen“ ernannt wurde. Seine Hauptaufgabe bestand darin, Verordnungen zur Typisierung und Normung von Kraftfahrzeugen zu entwerfen, um im Krieg die Herstellung der Fahrzeuge zu vereinfachen und die Ersatzteilbeschaffung zu erleichtern. ${ }^{504}$ Aus Anlass der Einsetzung des Generalbevollmächtigten machte Hermann Göring in seiner Funktion als Beauftragter für den Vierjahresplan den Unterschied zum NSKK deutlich. Er betonte, dass der Beitrag des NSKK zum nationalen Motorisierungsprojekt in der "Zusammenfassung, Erziehung, Schulung und Vorbereitung der menschlichen Kräfte" 505 bestehe.

498 Vgl. Anordnung des Stellvertreters des Führers vom 10. 8. 1938, betr. Förderung der Motorisierung, BArch NS 24/90; Krenzlin: Das NSKK, S. 32.

499 Bei Gesetzesvorlagen den Kraftverkehr betreffend wurde das NSKK neben dem Justizminister und dem Innenminister zu Rate gezogen, so z. B. bei der Vereinheitlichung der Kraftfahrzeug-Haftpflichtversicherung; Schreiben des Reichsministers der Justiz an den Reichsminister und Chef der Reichskanzlei vom 24. 4. 1939 Kabinettsvorlage, GStA PK Berlin, I. HA Rep. 151, Nr. 1584.

500 Vgl. die Bitte des RVM um Stellungnahme des NSKK vom 9. 1. 1936, BArch NS 24/483.

501 Vgl. Deutsche Kraftfahrt vom 15.6. 1933: „Der Siegeszug des NSKK“.

502 Vgl. Mitteilung des Inspekteurs Technik vom 11.3. 1939 an die Motorgruppen, betr. Höchstpreise für Instandsetzungsarbeiten an Kfz, BArch NS 24/156.

$503 \mathrm{Vgl}$. Schreiben des RVM an den Korpsführer vom 12. 2. 1938, betr. Ausschuß für Typprüfung von Kraftfahrzeugen und Kraftfahrzeugteilen, BArch NS 24/103.

504 Typenbeschränkungen waren besonders relevant in der Lkw-Produktion. Das Problem der Typenvielfalt trat erstmals beim Einmarsch in Österreich und in das Sudetenland 1938 auf; vgl. Edelmann: Vom Luxusgut, S. 198, $200 \mathrm{f}$.

505 Motorwelt vom 9. 12. 1938: „Die Motorisierung im Vierjahresplan“. 
Auch anhand dieser bewusst ungenau gehaltenen Formulierung wird ersichtlich, dass das NSKK auf konkrete Anweisungen von Seiten der Partei, der Vierjahresplan-Behörde oder des Reichsverkehrsministeriums warten musste, um aktiv sein zu können. Das NSKK erhielt Sonderaufträge wie die Überprüfung aller Fahrlehrer im Reich und die Durchführung von Fahrten mit Ersatztreibstoffen. ${ }^{506}$ Das Reichsverkehrsministerium war für das NSKK ein wichtiger Adressat, da die Zuteilung verkehrsrechtlicher Aufgaben und finanzieller Sondermittel in seinen Zuständigkeitsbereich fiel und damit auf die Machtentfaltung des NSKK Einfluss hatte.

\section{Zusammenfassung}

Die Untersuchung des Aufbaus des Nationalsozialistischen Kraftfahrkorps, der Dienstinhalte und des Selbstverständnisses zeigt, dass es sich beim NSKK nicht um einen Sportverein, Automobilclub oder um ein ehrenamtliches Speditionskorps gehandelt hat. Vielmehr war das NSKK eine straff organisierte und hierarchisch gegliederte NS-Formation, die mit SA und SS eine Art politisches Triumvirat in der NSDAP bildete. Seit der Unabhängigkeit von der SA im August 1934 war das NSKK infolge des Mitgliederzuwachses und der Ausdehnung auf alle Teile Deutschlands fortwährend im Aufbau begriffen. Von der SA unterschied sich das NSKK vor allem durch die Ausbildungsschwerpunkte Motorsport und technische Schulung. Gerade diese Aktivitäten förderten seine Anziehungskraft und motivierten die jüngeren Mitglieder zu großem Diensteifer. ${ }^{507}$

So wie Hitler auf der Internationalen Automobil- und Motorradausstellung 1933 die Motorisierung nicht nur als politisches, sondern auch als militärisches, wirtschaftliches und verkehrsförderndes Instrument für das neue Deutschland erkannt hatte, ${ }^{508}$ spiegelte das NSKK in seinem Selbstverständnis die gesamten Ausdrucksformen, Möglichkeiten und Ziele der Motorisierung im „Dritten Reich“ wider. Das NSKK beschränkte sich nicht auf eine oder wenige Identitäten, sondern definierte sich als politische, sportliche und paramilitärische Schulungs- und Erziehungsstätte. Im Kern war und blieb das NSKK, wie der Korpsführer in seinen Ansprachen mit Nachdruck betonte, eine politische Gliederung, die bestrebt war, dem angekündigten Kampf um die Motorisierung Deutschlands eine nationalsozialistische Prägung zu geben.

Programmatische Aussagen darüber, welchen Anteil das NSKK an der Motorisierung Deutschlands übernehmen sollte, fehlten jedoch in den Verlautbarungen des NSKK unmittelbar nach der Machtübernahme. Um die angestrebte Führung in der deutschen Kraftfahrt zu erringen und die Verkehrsentwicklung in allen wesentlichen Punkten mitzugestalten, bedurfte es ausgedehnter Machtbefugnisse und eines fest umrissenen Aufgabenfeldes. Doch mangelte es nicht nur an klaren

\footnotetext{
506 Vgl. zu dem Auftrag der Fahrlehrerüberprüfung S. 366 und zur Versuchsfahrt 1935 S. 423 dieser Arbeit.

507 Vgl. 1. Halbjahresbericht 1936 der Motorbrigade Kurpfalz-Saar an die Motorobergruppe Süd, LA Speyer, T 65 Nr. 66.

508 Vgl. Oppermann: Unter den Sturmstandern, S. 87.
} 
Bevollmächtigungen seitens des „Führers“, sondern auch an einem machtpolitischen Instrumentarium, um direkten Einfluss auf Verkehr, Sport und Vereine ausüben zu können. Es blieb dem Engagement der Korpsführung vorbehalten, die Worthülse vom „Willensträger der Motorisierung“ in den Jahren 1933 bis 1939 mit Inhalt zu füllen. Das Ziel stand jedoch bereits nach der NS-Machtübernahme fest: die Umformung der deutschen Gesellschaft in eine "motorisierte Volksgemeinschaft".

Die gesetzliche Oberhoheit des Reichsverkehrsministeriums, die Partei und die Vierjahresplan-Behörde setzten den Einflussmöglichkeiten des NSKK innerhalb des zivilen Verkehrswesens von Anfang an Grenzen. Führer des Korps wurden in Beiräte berufen, sie hatten Vorschlagsrechte im Reichsverkehrsrat, doch waren sie immer von Sondermandaten abhängig. Dies ließ eine freie Entfaltung des weltanschaulichen Führungsanspruchs und "Gleichschaltungsdrangs" im Kraftfahrwesen nicht zu.

Fasst man die Ergebnisse der Untersuchung der Mitglieder- und Führerstruktur im NSKK zusammen, kann festgestellt werden: Das Image des NSKK als motorisierte Gliederung der NSDAP und als Vereinigung von nationalsozialistischen Kraftfahrern stimmte weder im Hinblick auf die verfügbaren Dienstfahrzeuge noch im Hinblick auf die vorhandenen Privatfahrzeuge mit der Wirklichkeit überein. Beim NSKK sind soziale Nivellierungsprozesse geringer zu veranschlagen als bei anderen Gliederungen. Zwar spielten Herkunft, Beruf und Alter im Dienstalltag und in Bezug auf den politischen Aufstieg nicht die entscheidende Rolle, jedoch spaltete der Besitz bzw. Nichtbesitz von Fahrzeugen und Führerscheinen die Mitglieder auf. Eine aktive Teilnahme im NSKK und der Aufstieg in Führungspositionen war an den Besitz eines Fahrzeugs gebunden. ${ }^{509}$ Dies war jedoch nur bei einem Drittel der Mitglieder vorhanden. Die Mehrheit der Mitglieder kompensierte - teils mit größerer, teils mit geringerer Leidenschaft - das Defizit an fahrerischen Möglichkeiten mit handwerklichen Übungen, Verkehrsunterricht und allgemeinem Geländesport.

An der gezielten Anwerbung von Führerschein- und Fahrzeugbesitzern handwerklich und technisch ausgerichteter Berufsgruppen sowie von Berufsangehörigen des Kraftfahrwesens lässt sich erkennen, dass Hühnlein Abstriche an der von ihm gepriesenen freiwilligen Dienstleistung machen musste. Die Vergrößerung der Mitgliederzahl und die Einflussnahme auf die Belange der Automobil- und Motorradindustrie erhielten zunehmend Priorität vor dem „politischen Kämpfertum“. Durch den Status des „Korpsangehörigen“ war es den in der Automobilindustrie Tätigen ihrerseits möglich, Loyalität gegenüber dem Nationalsozialismus zu demonstrieren, ohne aktive Leistungen für das NSKK erbringen zu müssen oder sich durch eine Parteimitgliedschaft enger an die NSDAP zu binden. Berufliche Gründe waren - neben der Sport- und Technikbegeisterung und dem Eintritt aus politischer Überzeugung oder Anpassung - ein wichtiges Beitrittsmotiv.

509 Aus den Personalakten von Scharführern der Standarte Saar geht hervor, dass sie bis auf wenige Ausnahmen über einen Führerschein und ein eigenes Fahrzeug verfügten; vgl. Personalakten der Motorstandarte Saar, LA Speyer, T 65 Nr. 37. 
Das höhere Führerkorps setzte sich aus Männern zusammen, die militärische Erfahrungen, politisches Engagement in der Motor-SA und technische Fähigkeiten aufwiesen. Der Korpsführer bevorzugte bei der Aufstellung seines Stabes Männer, die die Kompetenz des NSKK in den Bereichen paramilitärische Ausrichtung, Kraftfahrtechnik und Verkehr vergrößerten. Der unumstrittene Führer des NSKK Adolf Hühnlein drückte der erst 1934 selbständig gewordenen NSGliederung bis zu seinem Tode 1942 den Stempel auf und war bestrebt, das NSKK nach Haltung, Struktur, Personal und Dienstgestaltung in eine nationalsozialistische Mustergliederung zu verwandeln. 